\title{
Bruno Castaldi
}

\section{SPATIAL AND TEMPORAL VARIABILITY OF THE VOLUME TRANSPORT ACROSS THE INDONESIAN STRAITS AND CONNECTIONS WITH THE INDIAN OCEAN CIRCULATION}

(CorRected Version)

Thesis submitted to the Oceanographic Institute of the University of São Paulo in partial fulfillment of the requirements for the degree of Doctor of Science, program of Oceanography, Physical Oceanography area

Adviser: Prof. Dr. Edmo José Dias Campos

São Paulo 
Universidade de SÃo Paulo

INSTITUTO OCEANOGRÁFICO

Bruno Castaldi

\section{SPATIAL AND TEMPORAL VARIABILITY OF THE VOLUME TRANSPORT ACROSS THE INDONESIAN STRAITS AND ConNections With the INDIAN OCEAN CiRCULATION}

A thesis submitted to the Instituto Oceanográfico of the Universidade de Sao Paulo, in partial fulfillment of the requirements for the degree of Doctor of Science, program of Oceanography, Physical Oceanography area

Evaluated in l

GRADE

Prof. Dr.

GRADE

Prof. Dr.

GRADE

Prof. Dr.

Prof. Dr.

GRADE

Prof. Dr. 


\section{CONTENTS}

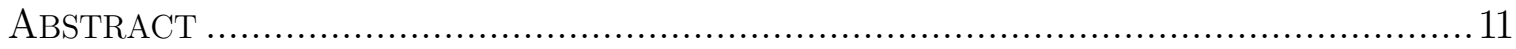

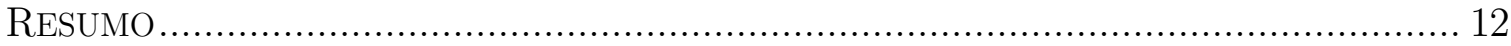

1 | INTRODUCTION 13

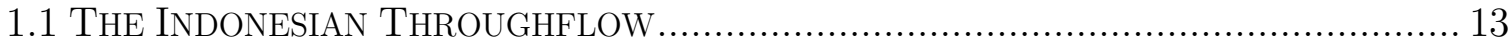

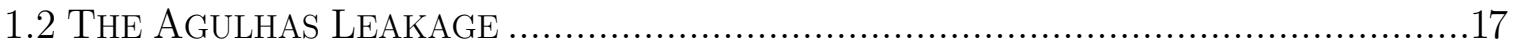

1.3 The Global Warming Hiatus ................................................................. 20

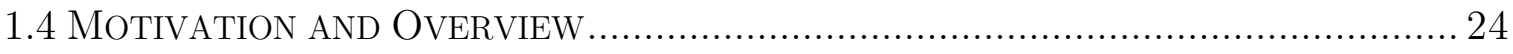

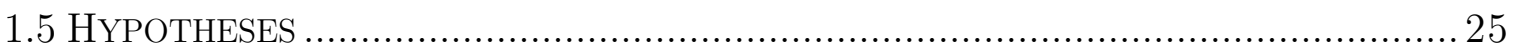

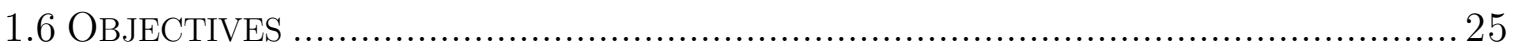

2 | NUMERICAL TOOLS 27

2.1 The Ocean Circulation Model ........................................................... 27

2.1.1 Expt. 18.1 - Climatological Run................................... 30

2.1.2 Expt. 18.3 - Forced with Interannual variability ......................31

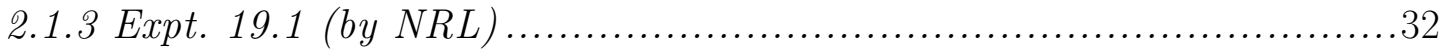

2.2 The Connectivity Modeling SySTEM .................................................. 34

2.2.1 The CMS Algorithm ............................................... 34

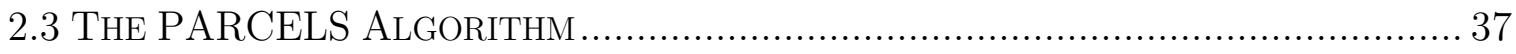

3 | EULERIAN ANALYSIS OF THE INDONESIAN THROUGHFLOW 41

3.1 Average Flow AND PATHWAYS - Climatological Run .............................. 42 
3.2 Vertical Profiles: Cross-Section Currents and Stratification - ExPt.

18.1

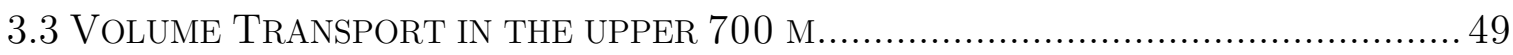

3.3.1 Methodology ...................................................... 49

3.3.2 Expt. 18.1 - Climatological Run.....................................50

3.3.3 Expt. 18.3 - Interannual Forcing Run ..............................53

3.3.4 Expt. 19.1 - HYCOM GLBu0.08 by NRL ....................... 58

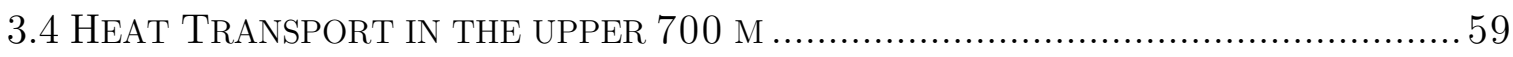

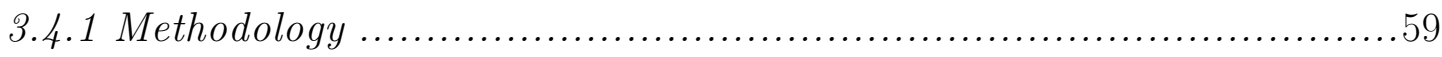

3.4.2 Expt. 18.3 - Interannual Forcing Run ...............................60

4 | LAGRANGIAN ANALYSIS 63

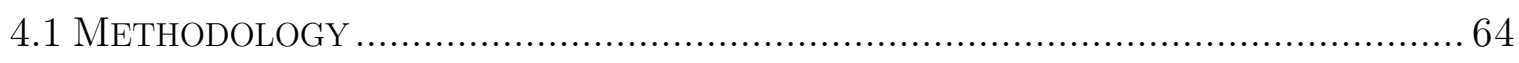

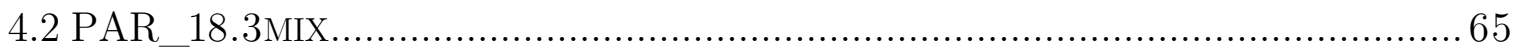

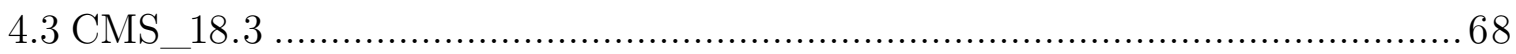

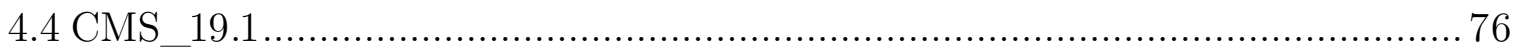

5 | CONCLUSION

5.1 SugGeStions for Future Work ….................................................. 84

$\begin{array}{ll}\text { APPENDIX A } & 85\end{array}$

GEOGRAPHIC COORDINATE SYSTEMS …............................................. 85

$\begin{array}{ll}\text { APPENDIX B } & 88\end{array}$

EULERIAN AND LAGRANGIAN REPRESENTATIONS OF THE

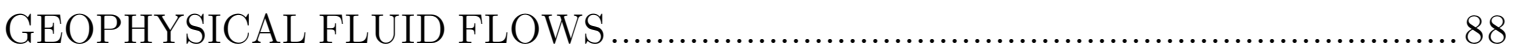




\section{ACKNOWLEDGEMENTS}

To my parents, Matheus and Margarete, for the exceptional education whose I am so proud to have received;

To my adviser, Prof. Edmo Campos, for the beautiful friendship;

To my H2B Tom Frisby, for providing me the energy and a concrete reason to move forward in the last months;

To FAPESP for the financial support under grants number:

$\rightarrow$ 2014/02225-2 that supported me as a doctorate student;

$\rightarrow$ 2016/16959-3 that supported my internship abroad in the University of Miami, where I could learn about the CMS and HYCOM with their creators;

$\rightarrow$ 2011/50552-4 the thematic project SAMOC-BR, that actually motivated me to apply for this graduate course and is linked to my scholarship;

$\rightarrow$ 2017/09659-6 the thematic project that allowed LABMON to renew the storage discs system of its computers and is in fact finally supporting the execution of this work.

I would love to say...

...thank you so much. 


\section{LIST OF FIGURES}

FIGURE 1.1 | ITF domain in the globe (left) and water masses route flowing through different straits (right). Following the surface flow, North Pacific waters (blue) come into the system crossing the Makassar strait, transporting about $80 \%$ of all ITF volume. Intermediate waters, below the thermocline, carry South Pacific waters (red) into the archipelago's circulation crossing the Lifamatola Passage. Waters flowing through Timor, Ombai and Lombok straits represent almost all the volume exported from the ITF system into the Indian Ocean. Values indicate the annual mean volume transport, in Sverdrups $\left(1 \mathrm{~Sv}=10^{6} \mathrm{~m}^{3} / \mathrm{s}\right)$, across the main straits for the inflow and the outflow (adapted from Gordon and Fine, 1996).

FIGURE 1.2 | Stratification in the Indonesian Seas: samples of waters from different positions labeled as "i, ii, iii, ... , x", are shown in the graph and are associated to their own local T-S diagram, representing the temperature in the vertical axis and salinity in the horizontal one. Colors are the depth in meters of each sample providing a T-S value at that position. (adapted from Sprintall et al., 2014).

FIGURE 1.3 | Schematic representation of the wind-driven circulation in the South Atlantic and Indian Ocean, pointing out subtropical gyres and the Agulhas Leakage. On the right, graphs show the zonal mean of the wind stress for two periods: from 1965 to 1974 (blue) and from 1995 to 2004 (red). It reveals the Westerlies intensification and the displacement of the latitude lines where these winds are maximum to the south, between $45^{\circ} \mathrm{S}$ and $60^{\circ} \mathrm{S}$. (adapted from Beal et al., 2011)

FIGURE 1.4 | GMST evolution from 1950 to 2014, for three independent data sets and the CMIP-5 averageresult of 124 simulations from 41 different climate models. The big hiatus of the mid $20^{\text {th }}$ century is showed to be finished by 1972, and the most recent hiatus should be considered from 2001, to avoid influences due to the 1997/98 El Niño and the 1999/2000 La Niña events. The last volcanic eruptions of El Chichón (1982) and Pinatubo (1991) are highlighted to show their short-term influence on the surface temperature drop. (adapted from Fyfe et al., 2016)

FIGURE 2.1 | Schematic representation of the HYCOM's hybrid coordinate system: for stratified regions of the ocean interior, the model is described by surfaces of constant density (isopycnals) as the vertical coordinate; in the surface mixed layer, the isopycnals automatically transform to Euclidean z-coordinates; in shallow regions over the continental shelf, the layers become terrain-following $\sigma$-coordinates; and come back to z-coordinates for very shallow areas.

FIGURE 2.2 | PanAm grid: a combination of a Mercator projection south of $47^{\circ} \mathrm{N}$ then a dipole patch for the Arctic

FIGURE 2.3 | Snapshot of the surface circulation of an arbitrary day after 27 years of simulation in the Expt. 18.1 Experiment. Warmer colors represent higher speeds.....

FIGURE 2.4 | Sea Surface Hight (SSH) for a snapshot on December 31th, 1972, according to the forecast of the Expt. 18.3 .

FIGURE 2.5 | Sea Surface Temperature (SST) on December 1², 2012 as represented by Expt 19.1 (NRL) . 32

FIGURE 2.6 | Flowchart of CMS, showing the Input process and interpolation grid needs, the Lagrangian Code and its modules, and the Output possibilities (adapted from Paris et al., 2013).....

FIGURE 2.7 | PARCELS algorithm flowchart. The code was conceived in a high abstraction level, requesting from the user the strictly necessary input information. (Adapted from Lange \& van Sebille, 2017)..... 
FIGURE 3.1 | Location of the ITF's region on the globe (top) and Mean Sea Surface Height (SSH) on the ITF colored by SSH, using output data of Expt. 18.1 (see Section 2.1.1). The graphic shows the names of sections used to estimate the transports. Karimata, Makassar and Moluccas correspond to the inflow pathway; and Timor, Ombai, Flores and Lombok to the outflow one.

FIGURE 3.2 | Horizontal Map of the flow in the mixed layer considering the average velocity field for the ten last years of the Climatological Run. Makassar Passage is shown as the major inflow passageway for superficial flows. In this layer, water coming from Pacific are transported within Flores Sea toward Banda Sea, exiting from Indonesian archipelago to Indian Ocean basin by travelling throughout Lombok, Flores, Ombai and Timor straits. A smaller intense flow can be observed entering the Indonesian seas by inflowing through Karimata strait. ..... 43

FIGURE 3.3 | Horizontal Map of flow at $1000 \mathrm{~m}$ depth considering the average velocity field in the last ten years of the Climatological Run. The Lifamatola passage is the only pathway for the inflow of deep water from Pacific Ocean into the Indonesian seas. A southward deep flow is formed in Banda Sea and its trajectory follows is affected by topographic boundaries which exist in the sea due to presence of small islands. Lastly, these deep waters exit from the Indonesian archipelago toward the Indian Ocean by outflowing through Ombai strait and Timor passage. The graph also marks the $200 \mathrm{~m}$ (wider light blue line) and $1000 \mathrm{~m}$ (white) bathymetries. The grey area is shallower than $1000 \mathrm{~m}$.

FIGURE 3.4 | Vertical Structure of major inflow passageway of ITF: Makassar strait (left) and Lifamatola passage (right). Current speed across the strait (meridional component) are showed in the graphs on top and Salinity and Potential Temperature stratification on bottom. Blue color intensities indicate a southward flow, while red ones denote a northward flow. In Makassar there is a continuous flux with two cores (above and below the thermocline) and it is not deeper than $800 \mathrm{~m}$. In Lifamatola, HYCOM is representing an alternating direct flux, where the deep flux presents a core $\approx 1100 \mathrm{~m}$ depth. The stratification patterns show Lifamatola subthermocline waters slightly more saline than ones in Makassar. This suggests origins in North Pacific for waters within Makassar and South Pacific for Lifamatola deep flow.

FIGURE 3.5 | Vertical structure of Ombai strait (left) and Timor passage (right) showing the flow across the straits (top) and the stratification profile (bottom). Blue intensities denote westward velocities and red ones means eastward velocities crossing the section. In both straits, the flow presents two cores, one above and other below thermocline, transporting waters which previously passed through Makassar and Lifamatola, respectively.

FIGURE 3.6 | Maps of the upper $700 \mathrm{~m}$ depth-integrated transport. Values are shown for each single grid point, where blue colors denote lower values of transport and red higher. Units are given in $10^{-9} \mathrm{~Sv} / \mathrm{m}^{2}$ (in a $0.08^{\circ}$ horizontal grid). Arrows represent the wind field. Name of the months are abbreviated in the bottom right corner of each map. The change in wind direction along the year is due to a monsoon pattern that drives winds in the ITF region. As it can be seen in the Figure, this drives seasonal variability of the ITF transports, and consequently in the amount of waters exchange from Pacific to the Indian Ocean. .51

FIGURE 3.7 Inflow (red) and outflow (black) volume transport in the upper $700 \mathrm{~m}$ depth for the Climatological Run. The envelopes represent standard errors based on the definition of each curve as being the sum of transports in individual straits. Negative values indicate transports southward or westward. Dashed lines are the mean annual value for inflow (red) and outflow (black). Superficial ITF transports presents a high seasonal variability that is driven mostly by the monsoon winds pattern, in a reverse mode increase/decrease for inflow/outflow along the year. 
FIGURE 3.8 | The ITF's outflow volume transport in the upper $700 \mathrm{~m}$ from 1970 to 2015. Individual time series is shown for transport across Lombok+Flores straits (top-left), Ombai (top-middle) and Timor (top-right), and for total transport (bottom). Plot data were smoothed every four months. Blue dashed lines indicate the mean transport in each region and the red lines is the linear fit. 3 periods: the base historical period (1970-1990); the "accelerated warming" (1991-2000) where, between 1991 and 1995 there was a systematic increase in the transport with trend $1.4 \mathrm{~Sv} /$ year; and the "slowdown warming" (1991-2000) where ITF also presented an increasing transport of volume...

FIGURE 3.9 | Monthly mean volume transport in the upper $700 \mathrm{~m}$ across the major three inflow straits, considering five different El Niño (green) and La Niña (blue) events, in comparison with the mean values for all years (black line). Largest values are obtained during La Niña events and smallest during El Niño. The envelopes represent the standard error......

FIGURE 3.10 | Monthly mean volume transport in the upper $700 \mathrm{~m}$ across the major four outflow straits, considering five different El Niño (green) and La Niña (blue) events, in comparison with the mean values for all years (black line). Largest values are obtained during La Niña events and smallest during El Niño. The envelopes represent the standard error......

FIGURE 3.11 | Transport of Volume vertically integrated in the upper $700 \mathrm{~m}$ for the ITF outflow straits, considering the last three years of the output data of the Expt. 19.1. the line in red is the linear adjustment of the curve and the grey dashed line is the mean value $16.01 \pm 8 \mathrm{~Sv}$, close to the results showed in previous sections.

FIGURE 3.12 | ITF heat transport in the upper $700 \mathrm{~m}$ estimated across the outflow straits from 1970 to 2015 , smoothed every four months. The envelopes denote the standard error. Blue dash line is the mean value and the red line is the linear fit of the curve. As for the volume transport, the ITF's heat transport also presents a strong interannual and seasonal variability. MEAN total $=-1.20 \mathrm{PW} \mid$ mean1 $=-1.14 \mathrm{PW} \mid$ trend1 $=+0.004 \mathrm{PW} /$ year $\mid$ mean $2=-1.32 \pm 0.5 \mathrm{PW} \mid$ trend $2=-0.01 \mathrm{PW} /$ year $\mid$ trend_green $=-0.10 \mathrm{PW} /$ year.

FIGURE 3.13 | ITF's heat transport anomaly from 2002 to 2012, bi-monthly smoothed. The anomaly was calculated considering the mean value for the entire time series, and the transports are estimated across the outflow straits. Envelopes are the standard errors. Red line is the fit linear of the points plotted. A large linear increasing trend of the ITF's heat transport was observed at this period. 61

FIGURE 3.14 | ITF's heat transport anomaly from 2013 to 2015 (brown line) and Nino3.4 Index anomaly (colored blue-red line). Unlike the previous period, the last two years of time series show a strong decrease in the heat transport, following the increase of Nino3.4 index, in accordance to what is expected from the ITF along ENSO event years.

FIGURE 4.1 | Conjunct of all trajectories of simulation PAR_18.3mix, between 1990 and 2015. Colors indicate the temperature at each trajectory position, in ${ }^{\circ} \mathrm{C}$.

FIGURE 4.2 $\mid$ Probability to observe a particle in a $1^{\circ} \times 1^{\circ}$ horizontal binned grid at the sea surface, considering the simulation time for all trajectories, according to the analysis PAR_18.3mix. The white line shows the SAMBA line, the initial position on which particles were released.

FIGURE 4.3 | Conjunct of trajectories connecting ITF and AL, according to simulation PAR_18.3mix, corresponding to only 3 trajectories (or $0.05 \%$ ) of the whole 5912 initial conditions computed.

FIGURE 4.4 | Conjuct of all trajectories computed by simulation CMS_18.3 (1994 - 2015). Blue colors represent different depths (in meters). The red dots show the region of initial condition on the SAMBA line... 70

FIGURE $4.5 \mid$ Probability to observe a particle in a $1^{\circ} \times 1^{\circ}$ horizontally spaced grid expanded from the surface to the bottom, considering the analysis CMS_18.3, for the complete time of simulation and all trajectories..... 70 
FIGURE 4.6 | Conjunct of trajectories connecting ITF and AL (6.45\% of the whole ensemble), considering the simulation CMS_18.3 (1994-2015).

FIGURE 4.7 | Probability to observe a particle in a $1^{\circ} \times 1^{\circ}$ horizontally spaced grid expanded from the surface to the bottom, considering only the trajectories the connect the Pacific and Atlantic Oceans, for the complete time of simulation of the analysis CMS_18.3.

FIGURE 4.8 | Evolution of the mean depth of the conjunct of trajectories connecting ITF and AL, over the time of simulation of CMS_18.3. 73

FIGURE 4.9 | Probability to observe a particle at different depths, over the simulation time of CMS_18.3, considering the complete conjunct of trajectories (grey) and the conjunct of trajectories connecting ITF and AL (red).

FIGURE 4.10 | Conjunct of trajectories that have kept themselves in the upper $100 \mathrm{~m}$ of depth during the entire time of simulation .74

FIGURE 4.11 | Average behavior of the conjunct of trajectories connecting ITF and AL: colors represent the mean depth of the whole ensemble, being closer to the surface when traveling over in the Indian Ocean basin, considering the simulation CMS_18.3.

FIGURE 4.12 | Probability of transient time observed for the pathway between the SAMBA line and the ITF System, considering the conjunct of trajectories that connect both regions in the simulation CMS 18.3 76

FIGURE 4.13 | Conjunct of all trajectories computed by simulation CMS_19.1 (1997 - 2012). Green colors represent different depths (in meters). Red dots in red show the region of initial condition on the SAMBA line.

FIGURE 4.14 | Probability to find a particle in a $1^{\circ} \times 1^{\circ}$ spaced horizontal grid cell, expanded from surface to $1000 \mathrm{~m}$ of depth, considering the analysis CMS_19.1, for the whole time of simulation and all trajectories...... 78

FIGURE 4.15 | Conjunct of trajectories connecting ITF and AL (5.22\% of the whole ensemble), considering the simulation CMS_19.1 (1997-2012)

FIGURE 4.16 $\mid$ Probability to find a particle in a $1^{\circ} \times 1^{\circ}$ spaced horizontal grid cell, expanded from surface to $1000 \mathrm{~m}$ of depth, considering the analysis CMS_19.1, for the trajectories connecting the Pacific Ocean and the South Atlantic Ocean for the whole time of the simulation CMS_19.1.

FIGURE 4.17 | Probability to observe a particle at different depths, over the time of simulation for the experiment CMS_19.1, considering all trajectories (green) and the trajectories connecting ITF and AL (blue).. 81 


\section{LIST OF SYMBOLS AND ABBREVIATIONS}

$\mathrm{AC}$

AMOC

$\mathrm{AL}$

CFSR

CMS

CMS_18.3

CMS_19.1

CPTEC

ECS

ENSO

Expt. 18.1

Expt. 18.3

Expt. 19.1

GLBa0.08

GLBa0.08

GMST

SA

SAMBA

SAMOC

$\mathrm{SSH}$

SST

HYCOM

ITF
Agulhas Current

Atlantic Meridional Overturning Circulation

Agulhas Leakage

Climate Forecast System Reanalysis

Connectivity Modeling System

Lagrangian Analysis with CMS, using fields data from Expt. 18.3

Lagrangian Analysis with CMS, using fields data from Expt. 19.1

Center for Weather Forecasting and Climate Studies

Earth's Climate System

El Niño-Southern Oscillation

Climatological Run using eddy resolving $1 / 12^{\circ}$ Global HYCOM (GLBa0.08), performed by LABMON

Climatological Run using eddy resolving $1 / 12^{\circ}$ Global HYCOM (GLBa0.08), performed by LABMON

HYCOM+NCODA $1 / 12^{\circ}$ Global Ocean Reanalysis (GLBu0.08), performed by NRL

Implementation of $\mathrm{HYCOM}$ for the global ocean, with $0.08^{\circ}$ zonal resolution in the equator

Interpolation of GLBa0.08 for the global ocean, with $0.08^{\circ}$ horizontal resolution in a regular Mercator grid

Global Mean Surface Temperature

South Atlantic

South Atlantic Meridional Overturning Circulation Basin-wide Array

South Atlantic Meridional Overturning Circulation

Sea Surface Height

Sea Surface Temperature

HYbrid Coordinate Ocean Model

Indonesian Throughflow 
IOD

Indian Ocean Dipole

IOUSP

Oceanographic Institute of the University of Sao Paulo

LABMON Laboratory for Modeling and Observations of the Ocean

MOC Meridional Overturning Circulation

NCAR National Center for Atmospheric Research

NCEP National Centers for Environmental Prediction

NCODA Navy Coupled Ocean Data Assimilation

NRL Naval Research Laboratory

OGCM Ocean General Circulation Model

PARCELS Probably A Really Computationally Efficient Lagrangian Simulator

PAR_18.3mix Lagrangian Analysis with PARCELS, using mixed layer fields data from Expt. 18.3

PDO Pacific Decadal Oscillation (PDO)

PO Pacific Ocean 


\section{ABstRact}

The global Meridional Overturning Circulation (MOC) plays a significant role in the Earth's climate system by redistributing all over the world the excess heat gained by Earth in low latitudes. In its superficial branch, warm waters are exchanged throughout the world's ocean basins. The Indonesian Throughflow (ITF) and the Agulhas Leakage (AL) are the main processes responsible, respectively, for importing Pacific Ocean waters into the Indian Ocean, and for exporting Indian Ocean waters into the Atlantic Ocean. Recently, changes in both systems have been reported and can be related to global warming consequences, processes of air-sea interactions and variabilities in the ocean circulation and wind patterns. In the present work, output of a high-resolution, global implementation of HYCOM (Hybrid Coordinate Ocean Model) from different runs were used, aiming at a study of the structure and variability of the ITF, and to evaluate the use of a numerical tool for tracking virtual Lagrangian particles to correlate circulation patterns of the ITF and the AL. For the ITF, analysis of the models' output provided a mean volume transport in the upper $700 \mathrm{~m}$ depth of about $13 \mathrm{~Sv}$, what is in the range of values reported by observations and other numerical simulations in the region. The seasonal variability was found to be related to the monsoons wind regimes, and the ITF's response to the El Niño-Southern Oscillation (ENSO) was evaluated. During five La Niña events, the mean volume transport was of approximately $16 \mathrm{~Sv}$, and for also five El Niño events, of approximately 12 Sv. Results show an abrupt increase in the heat transport between 2002 and 2012, what could be related to changes in the heat content within the Indian Ocean for the same period. Heat transport anomalies were analyzed in the last years of the time series and present a clear correlation with Nino3.4 index, denoting a strong response of the ITF to the 2014/16 El Niño. Numerical test-experiments simulating Lagrangian particles have been performed, to identify and quantify water masses' origins compounding the ITF and to correlate variabilities signals of ITF in the Indian Ocean's basin circulation and in the Agulhas Leakage.

Keywords: Indonesian Throughflow; Agulhas Leakage; ENSO; Lagrangian tracers 


\section{Resumo}

A Circulação de Revolvimento Meridional do oceano desempenha um papel importante no sistema climático da Terra, através da redistribuição do excesso de calor ganho pelo planeta em baixas latitudes. No seu ramo superficial, massas de águas quentes são carregadas entre as diferentes bacias oceânicas no mundo. O fluxo que ocorre através dos estreitos dos mares da Indonésia (ITF, Indonesian Throughflow), e o Vazamento das Agulhas (VA) são dois importantes processos responsáveis, respectivamente, por importar águas do Pacífico para o Oceano Índico, e por exportar águas do Índico para o Oceano Atlântico. Recentemente, mudanças em ambos sistemas têm sido reportados e podem estar relacionados a consequências do aquecimento global, a processos de interação ar-mar e a variabilidades da circulação oceânica e de padrões de vento. No presente trabalho foram usadas saídas de diferentes rodadas usando uma implementação global em alta resolução do HYCOM (Hybrid Coordinate Ocean Model), com o objetivo de estudar a estrutura e variabilidade do ITF e avaliar o uso de uma ferramenta numérica para rastrear virtualmente a trajetória de partículas Lagrangianas e correlacionar padrões de circulação do ITF e do VA. Para o ITF, análises dos resultados dos modelos forneceram um valor de transporte de volume de $\approx 13 \mathrm{~Sv}$ para os primeiros $700 \mathrm{~m}$ de profundidade, o qual está em acordo com valores obtidos por observações e outras simulações numéricas. A variabilidade sazonal foi demonstrada estar relacionada aos regimes de vento de monções, e a resposta do ITF para o El Niño-Oscilação Sul (ENOS) foi avaliada. Durante cinco eventos de La Niña o transporte de volume médio foi de $\approx 16 \mathrm{~Sv}$, e para cinco eventos de El Niño, em $\approx 12 \mathrm{~Sv}$. Os resultados mostram um aumento abrupto no transporte de calor entre 2002 e 2012, o qual pode estar relacionado a mudanças na quantidade de calor dentro do Oceano Índico para o mesmo período. Anomalias no transporte de calor foram analisadas para os últimos anos da mesma série temporal e também apresentou clara correlação com o índice Nino3.4, configurando uma forte resposta do ITF para o El Niño de 2014/16. Experimentos numéricos simulando partículas Lagrangianas foram implementados, com o objetivo de identificar origens de massas de águas que compõem o ITF e correlacionar sinais de variabilidade do ITF na bacia de circulação do Índico e do Vazamento das Agulhas.

Palavras-chave: Indonesian Throughflow; Vazamento das Agulhas; ENOS; traçadores Lagrangianos 


\section{1 | INTRODUCTION}

\subsection{THE INDONESIAN THROUGHFLOW}

The flux of waters at tropical latitudes from the Pacific Ocean (PO) toward the Indian Ocean (IO) basin, traveling through different straits and seas around the Indonesian islands, corresponds to the so called Indonesian Throughflow (ITF), which is also part of the superficial branch of the Meridional Overturning Circulation (MOC) and, as such, integrant part of the global climate system (Sprintall et al., 2014). The ITF is the only pathway connecting large ocean basins in low latitudes, permitting the exchange of warm and fresh waters that could carry different climate signals and anomalies (Godfrey, 1996; Hirst \& Godfrey, 1993; Schneider, 1998; Wajsowicz \& Schneider, 2001).

To describe the ITF pathway, in a general way, one can say that surface waters coming from the North Pacific enter the Indonesian seas by flowing through Makassar strait (see Fig. 1.1), whose pathway corresponds to approximately $80 \%$ of total inflow transport. Because of the $680 \mathrm{~m}$ deep sill, only upper thermocline waters may flow into the Flores Sea. There, to the south of Makassar, the flux bifurcates. The western branch exits directly towards the Indian Ocean, passing through Lombok strait. The other retroflects eastward to the Banda Sea, and then exits the ITF system by flowing through the Ombai strait or the Timor passage. Deeper waters, from the South Pacific (denser than North Pacific ones), come in the system travelling through Lifamatola passage (Fig. 1.1), with 1940 m depth sill. The flux follows toward Banda sea, where these water masses are modified by different processes, and eventually goes out also flowing through both sides of Timor island (Gordon, 1995; Gordon and Fine, 1996; Gordon et al, 1999; Gordon, 2005; Mayer et al., 2010; Tillinger and Gordon, 2010; Sprintall et al., 2009). 


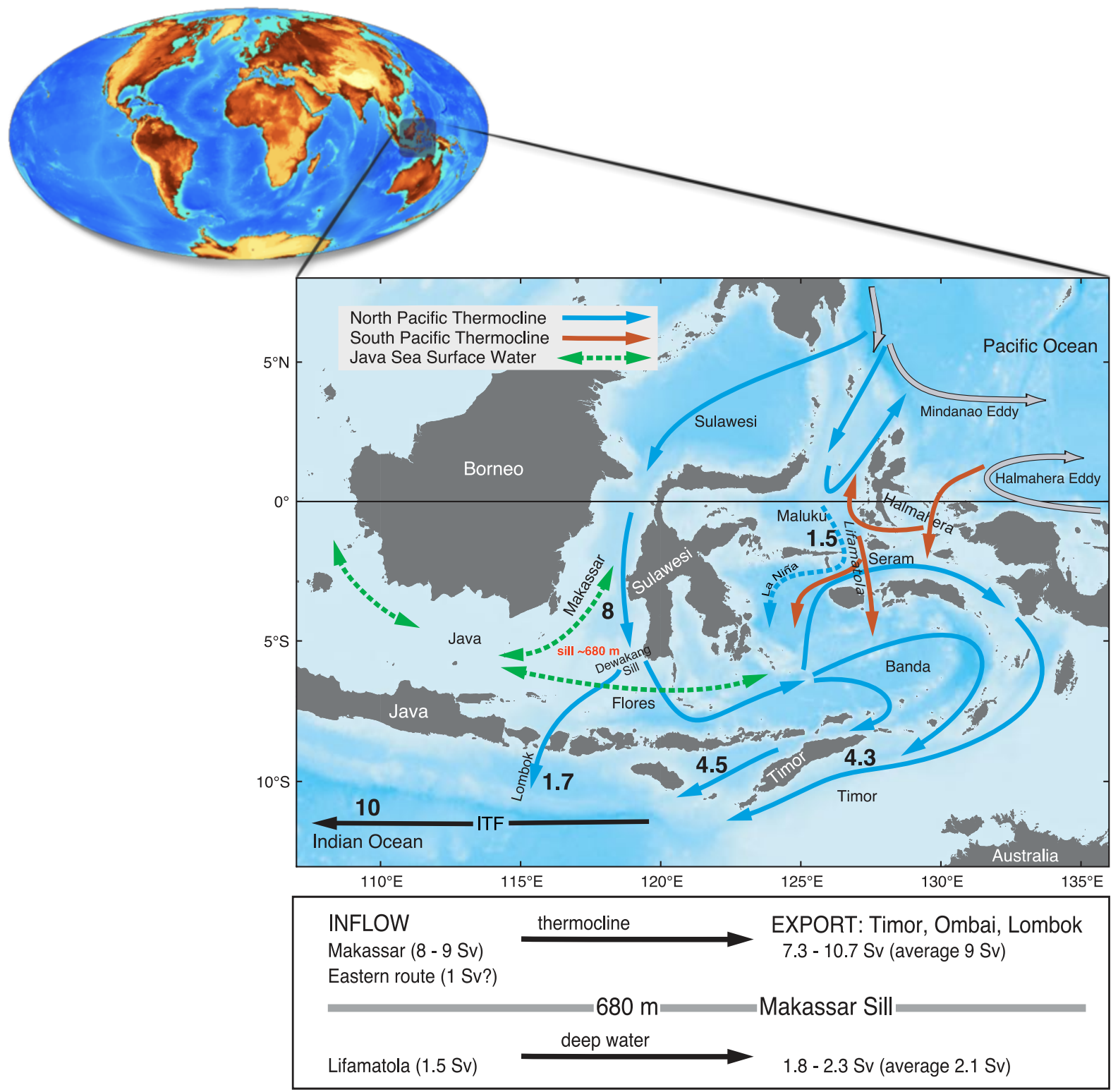

FIGURE 1.1 | ITF domain in the globe (left) and water masses route flowing through different straits (right). Following the surface flow, North Pacific waters (blue) come into the system crossing the Makassar strait, transporting about $80 \%$ of all ITF volume. Intermediate waters, below the thermocline, carry South Pacific waters (red) into the archipelago's circulation crossing the Lifamatola Passage. Waters flowing through Timor, Ombai and Lombok straits represent almost all the volume exported from the ITF system into the Indian Ocean. Values indicate the annual mean volume transport, in Sverdrups $\left(1 \mathrm{~Sv}=10^{6} \mathrm{~m}^{3} / \mathrm{s}\right)$, across the main straits for the inflow and the outflow (adapted from Gordon and Fine, 1996).

Previous works (Gordon et al., 1999; Susanto and Gordon, 2005; van Aken et al., 1988) estimated a total ITF volume transport of approximately 10 Sv. However, recently, the International Nusantara Stratification and Transport (INSTANT) program has made direct measurements (Sprintall et al., 2004; see also: www.marine.csiro.au/ $\sim$ cow $074 /$ index.htm) of the ITF in all major inflow and outflow passages, providing observational data for more accurate estimates of transports along the flow. The analysis 
of data between 2004 and 2006 (Sprintall et al., 2009; Gordon et al., 2010) suggests a total transport considerably larger: average transport through Makassar of $\approx 12 \mathrm{~Sv}$; Lifamatola $\approx 2.5 \mathrm{~Sv}$; Lombok $\approx 2.6 \mathrm{~Sv}$; Ombai $\approx 4.9 \mathrm{~Sv}$ and Timor: $\approx 7.5 \mathrm{~Sv}$. A mean total inflow transport was estimated in $\approx 12.7 \mathrm{~Sv}$ and outflow $\approx 15 \mathrm{~Sv}$.

Not just being a very intricate ocean flow, and besides promoting an exchange pathway, ITF also plays a key role in the ocean circulation, modifying the original Pacific's waters characteristics within the Indonesian seas before depositing them into the Indian Ocean, creating a very particular stratification profile in that region. As shown in Fig. 1.2, waters poured into the Indian Ocean from ITF (locations "ix" and "x") reveal vertical profiles of salinity and temperature quite different of those ones flowing into the archipelago seas from the Pacific Ocean (locations "i", "iv", and "v", for example). With a shallow topography, most of the colder Pacific waters that manage to flow through

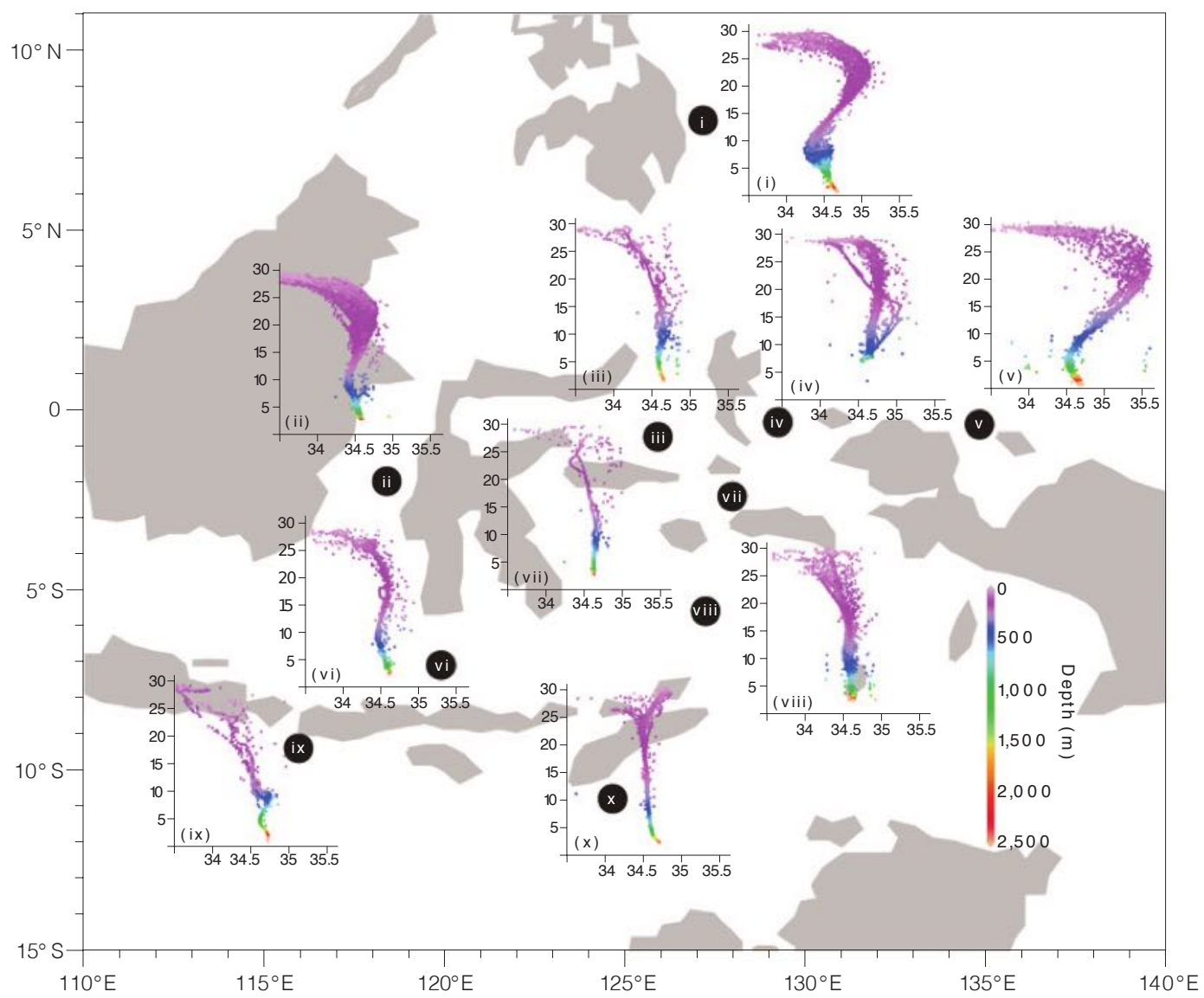

FIGURE 1.2 | Stratification in the Indonesian Seas: samples of waters from different positions labeled as "i, ii, iii, ... x", are shown in the graph and are associated to their own local T-S diagram, representing the temperature in the vertical axis and salinity in the horizontal one. Colors are the depth in meters of each sample providing a T-S value at that position. (adapted from Sprintall et al., 2014). 
the Lifamatala passage (location "iii", "iv" and "vii") are vertically advected in an upwelling flow in the Banda Sea (location "viii"), cooling the waters coming from the Java Sea - in the east, (location "vi"). This last one, is also fresher and cooler than the ones placed at its inflow pathway in Makassar strait (position "ii") because, as revealed by the profile of position "ix", this waters flowing out of the ITF, crossing the Lombok strait, have been also modified in Java Sea (position "vi").

Once incorporated in the Indian Ocean, the waters transported by ITF can be now advected toward the African continent, flowing westward with the South Equatorial Current and eventually exit out the Indian Ocean basin, carried mostly by the Agulhas Current, and leaks into the South Atlantic (SA) Ocean (Le Bars et al., 2013).

Thus, the states of the Indian and Atlantic oceans are directly affected by the heat and volume transported by ITF (Lee et al., 2002), modulating the regional climate while regional patterns of precipitation and air-sea interaction vary (Wajsowicz, 2002).

The ITF is also reported as being strongly influenced by climate conditions and presents itself high seasonal and interannual variabilities (Murtugudde et al., 1998; Schiller et al, 2010), part related to air-sea interaction, for instance, to the typical monsoonal winds of the region, and also due to ocean circulation variability, as revealed by notable responses of ITF to the El Niño-Southern Oscillation (ENSO), to the Pacific Decadal Oscillation (PDO) and to the Indian Ocean Dipole (IOD) (England \& Huang, 2005; Gordon et al., 2010; van Sebille et al., 2014; Wilson et al., 2013; Wunsch, 2010; Zhou et al., 2015; Li et al., 2018).

The imbalance $\sim 2 \mathrm{~Sv}$ was reported by these authors, and it is compatible with the uncertainty of the data and the standard deviation. There are also some issues concerning the INSTANT mooring array, leading to poor extrapolations for side-walls and incomplete measurements in inflow passages. At Lifamatola passage, there is a reversing direction of the flux (to north in surface, and to south below $1250 \mathrm{~m}$ ). Also, 
the Karimata strait ${ }^{1}$ (50 $\mathrm{m}$ sill), is not considered in the moorings, and it is known that flows crossing it allows introducing South China Sea water into the Java Sea (Susanto et al., 2013).

\subsection{The Agulhas Leakage}

The Pacific waters, processed and modified by ITF, once merged into the Indian Ocean, can now be carried away by the South Equatorial Current to the west side of the IO basin to be incorporated into the IO subtropical gyre. Flowing southward within the Agulhas Current (AC), eventually, these fully modified waters, that now hold the local IO properties, can leak into the South Atlantic, through a strongly non-linear flow, bounded by the South Africa's coastline, known as the Agulhas Leakage (AL). The whole pathway, from the tropical Pacific to the South Atlantic Ocean, constitutes part of the global MOC "warm route", that is fundamental in modulating the state of the Earth's Climate System (ECS). Studies with climate models showed, for example, changes in the MOC can be correlated, in genesis and intensity, to precipitation patterns and decadal variabilities of extreme atmospheric events (Hu et al., 2008; Liu et al., 2017).

The AC is the western boundary current that, similarly to the Brazil Current, flows along the western portion of the wind driven subtropical gyre in the Indian Ocean (Lutjeharms, 2006). As in the South Atlantic, the subtropical gyre is bounded to the south by the Subtropical Front, associated to the zone of zero wind stress curl, located at approximately $45^{\circ} \mathrm{S}$, and corresponds to the region where the Westerlies are maximum.

Differently from South America, though, the African continent is delimited to the north of this latitude. In the absence of any forcing, the AC would tend to flow into the Atlantic, advected to the west by planetary waves, forming a "super gyre" that would

\footnotetext{
${ }^{1}$ Karimata strait is located to the southwest of Borneo island, and it is out of the bounds of all maps showed in this chapter, which have been extracted or adapted from their original referenced sources. Please, see Figs. 3.1 and 3.3, in Chapter 3, to visualize the ITF straits considered in this work.
} 
connect both basins (de Ruijter, 1982; de Ruijter et al., 1999). However, forced inertially southward, the current accumulates anticyclonic relative vorticity due to changes in the local planetary vorticity (" $\beta$ effect"), and once the current approaches the latitude where the African continent's margin ends, the bathymetry change enhances this effect, eventually making the movement to deflect to the east, flowing back into the Indian Ocean. This process has been referred as the Agulhas Current retroflection (Lutjeharms, 2006; Beal et al., 2011).

But the retroflection is not a stationary phenomenon. The inertial state of the $\mathrm{AC}$ and the location of the line of zero wind stress curl depend on the general distribution of the wind over the Indian Ocean. Mesoscale (baroclinic and/or barotropic) instabilities transfer energy from the main flow, producing the increase of the retroflection loop predominantly to the west, before the current could flow back toward the IO basin. Eventually, the loop can close and release itself from the current, forming the Agulhas rings: anticyclonic eddies propagating westward and transporting with them a relevant volume of IO waters into the SA Ocean (Speich et al., 2006; Zarkhov \& Nof, 2008).

In addition to the current's inertia and instability processes, the latitude of zero wind stress curl, together with the bottom topography and the coastline geometry also influence the rings' generation, playing an important role in controlling the retroflection. For instance, supposing this latitude line was too close to the African continent border, the AC would be simply deflected to the east along this latitude, resulting in a reduced or even in an absence of the IO waters leaking into the Atlantic. Paleoclimate indicators suggest this "inertial shock" situation already happened in the past and could be associated with climate changes (Peeters et al., 2004).

On the other hand, simulations with wind driven ocean models show that changes in the atmosphere circulation, in response to global warming, have been produced an increase in the AL and, also, a possible weaker MOC (Biastoch et al., 2008). Fig. 1.3 illustrates the process. It shows the pathway connecting different basins: the 


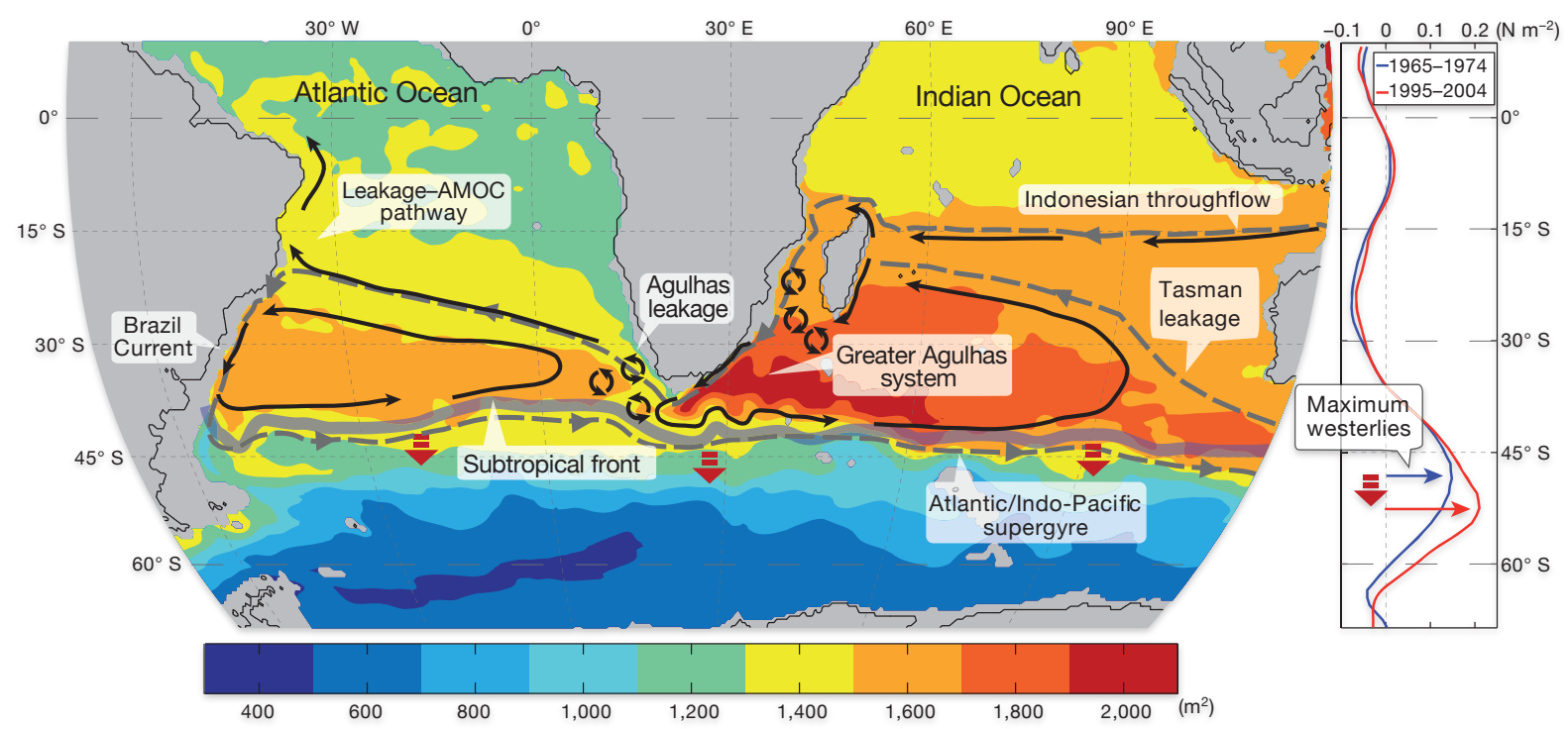

FIGURE 1.3 | Schematic representation of the wind-driven circulation in the South Atlantic and Indian Ocean, pointing out subtropical gyres and the Agulhas Leakage. On the right, graphs show the zonal mean of the wind stress for two periods: from 1965 to 1974 (blue) and from 1995 to 2004 (red). It reveals the Westerlies intensification and the displacement of the latitude lines where these winds are maximum to the south, between $45^{\circ} \mathrm{S}$ and $60^{\circ} \mathrm{S}$. (adapted from Beal et al., 2011)

Indian Ocean, fed with Pacific Ocean waters coming from ITF and the Tasman leakage (south of Australia), is connected to the South Atlantic Ocean through the Agulhas System. In the west side of the Atlantic basin, part of the flow is incorporated to the subtropical gyre, and the other flows northward to form the Atlantic Meridional Overturning Circulation (AMOC). The line defined by the latitudes in which the Westerlies are maximum delimits both SA and IO subtropical gyres (black curves), the Subtropical Front (grey wide line) and a "super gyre" (dashed grey line): an inter-basin circulation pattern, exchanging waters from the South Atlantic to the Pacific, that eventually flows back into the Indian Ocean. The graph on the right shows the meridional profile for the westerly wind stress during two different periods. The blue and red arrows highlight the latitudes for the maximum shear stress and suggests it can be changing over recent years, as that position was pushed to the south and the values of wind stress are higher for the last period (1995-2004) if compared to the first one (1964-1974).

This phenomenon is known as the southward expansion of the Southern Hemisphere mid-latitude westerly wind (Biastoch et al., 2009), and has been associated to the anthropogenic global climate change (Biastoch \& Böning, 2013). Its direct 
consequence would be the southward shift of the Subtropical Front, represented by the wider dashed red arrows in the graphs of Fig. 1.3. This could cause an increase in the leakage of waters from the Indian to the Atlantic Ocean, because the Subtropical Front delimits the retroflection and the rings' formation. Thus, once it is shifting southward, a longer distance between the south border of Africa and that delimiter line could make the loops of the retroflection and the rings of the leakage become also larger, resulting in an increased inter-basin volume transport (Beal et al., 2011).

Although it is still not a consensus, a possible consequence for the Atlantic would be related to the fact that the IO waters are hotter and more saline than the SA ones. An increased AL could propagate this anomaly northward in the Atlantic, interfering with the North Atlantic Deep Water formation that could lead to a weaker MOC (Biastoch et al., 2008; Delworth \& Zeng, 2008). In addition, numerical experiments using low resolution coupled ocean-atmosphere models show anomalies in the region of the $\mathrm{AC}$ retroflection propagate far away the atmosphere, inside the thermocline, and resurge to surface in equatorial regions (e.g.: Haarsma et al., 2009), where these anomalies would be able to change properties of the ocean mixed layer, acting on the airsea interaction processes.

\subsection{The Global Warming Hiatus}

Such as the Agulhas Leakage, apart from simple correlations with the ECS variability modes, the ITF - as the main pathway to connect the great Indo-Pacific System - has a fundamental hole on the heat distribution all over the globe, transporting significant energy and transferring anomalies from the tropical upper ocean into the global conveyor belt (Tillinger \& Gordon, 2010).

Lee et al. (2015), for example, simulated the abrupt increase of the Indian Ocean heat content in the upper $700 \mathrm{~m}$, as observed in past years, and could establish its origin in heat budget anomalies of the Pacific Ocean, which was tagged to be abruptly cooling 
for the same period. The heat sent to the Indian Ocean, must have traveled from a basin to the other by flowing westward through the Indonesian islands. In addition, authors pointed out this dynamic could be causally related to the so-called global warming hiatus, that hereafter will be referred as the hiatus.

The hiatus was a phenomenon marked by the slowdown of the Earth surface warming observed over the first decade of the $21^{\text {st }}$ century, when the increase rate of the Global Mean Surface Temperature (GMST) was less intense than observed in earlier decades, and up to 4 times smaller than the one that had been represented by most climate models for that period. This ended to misguide popular and some scientific-like beliefs about an apparent "pause" in the global human-induced warmth (Easterling \& Wehner, 2009). However, empiric observations of the ECS, such as measurements of the top of atmosphere, heat budgets, snow and ice covers, sea level, among others, aligned with record levels of carbon emissions, used to keep pointing out a warming planet (Fyfe et al., 2013; Trenberth \& Fasullo, 2013; Xie et al, 2016; Seneviratne et al., 2014).

In fact, "hiatuses" are climate change natural fluctuations that happen due to nonlinear behaviors of the ECS and have been observed for long- and near-term scales of climate estimation in the past (Lovejoy, 2014; Lewandowsky et al., 2015). The most recent one, would have begun just after the 1997/98 El Niño event, classified as "very strong" and once referred as "the climate event of the $20^{\text {th }}$ century" (Changnon \& Bell, 2000; Slingo \& Annamalai, 2000), and no longer observed as the effects of the successive La Niña events spanning 2010/2012 have been completely gone.

Although the causes and abrupt origins of the recent hiatus are not completely clarified, they have been associated to distinct natural factors, to name a few: internal climate variabilities (Watanabe et al., 2014; Trenberth, 2015; Dai et al., 2015), water vapor (Solomon et al., 2010), volcanic activity (Haywood, et al., 2014; Maher et al., 2014; Ridley et al., 2014; Santer et al., 2014), reduction in the solar radiation forcing (Folland et al., 2018), and even biases associated to the data utilized in warming 
estimates (Karl, 2015). It has been claimed, for example, the fast warming of the Arctic could have been underestimated (Cowtan \&. Way, 2014), what would cause the hiatus to be statistically insignificant (Huang et al., 2017).

However, Fyfe et al. (2016) suggested that, to make sense of the early-2000's surface warming slowdown, a different historical base-period comprising the 2000/2001 La Niña event should be employed to compare increase rates of the GMST rather than the usual 1971-1998 one, what would clearly reveal different scenarios for the first decade of the $21^{\text {st }}$ century and the last years of the $20^{\text {th }}$ century.

Fig. 1.4 illustrates this overview. The big hiatus that happened between 1945 and 1970 is likely related to aerosols effect, that reduced the solar insolation. The Clear Air acts of the 1970's ended that era. Two recent volcanic activities (natural aerosols) in Mexico (El Chichón) and Philippines (Pinatubo) are highlighted in the graph and would have impacted globally the climate on the Earth, dropping the GMST over short-term periods, that lasted less than 3 year. The mid-period (1971 to 2000) shows a robust constant warming, perturbed by the volcanic activities. The final period represents the recent hiatus, taken after the strong ENSO events that were observed from 1997 to 2000,

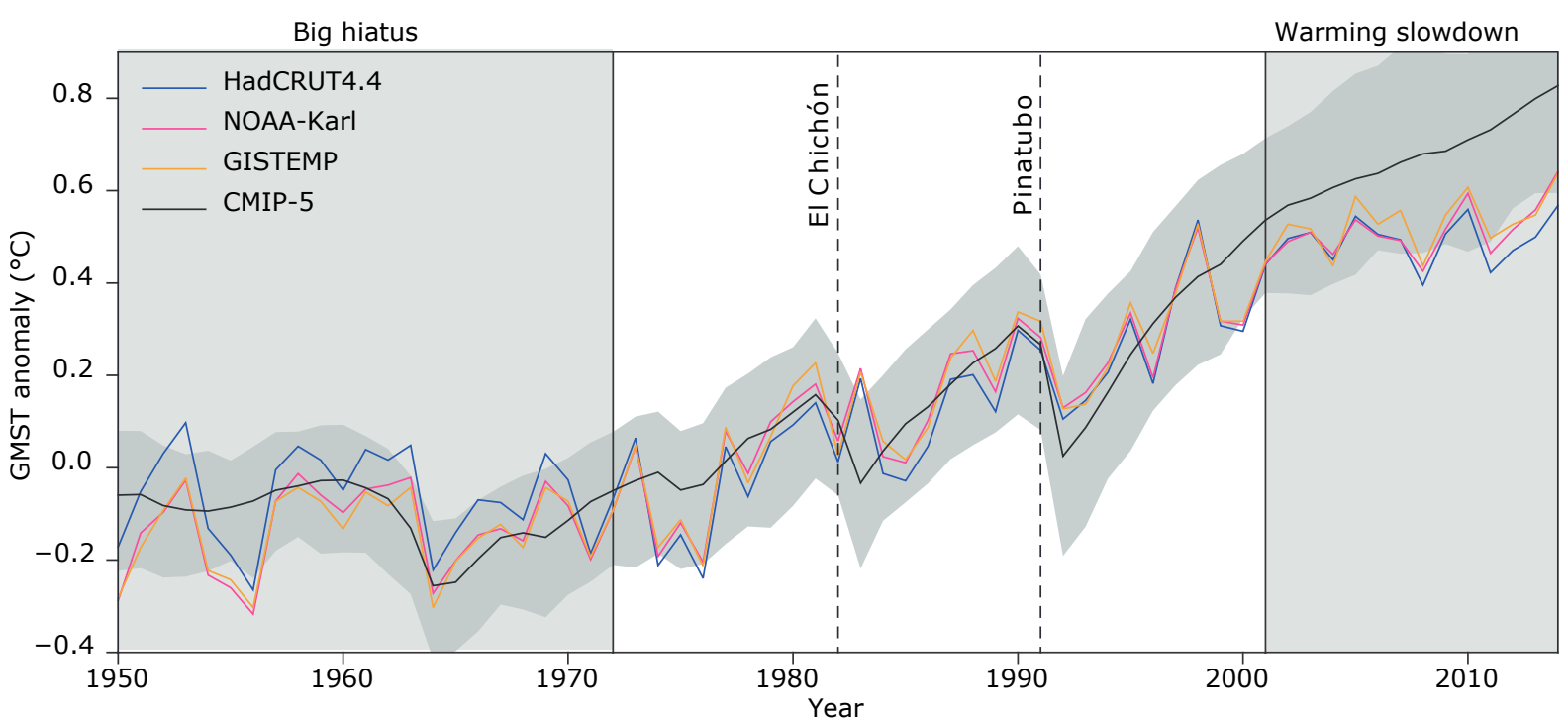

FIGURE 1.4 | GMST evolution from 1950 to 2014, for three independent data sets and the CMIP-5 averageresult of 124 simulations from 41 different climate models. The big hiatus of the mid $20^{\text {th }}$ century is showed to be finished by 1972, and the most recent hiatus should be considered from 2001, to avoid influences due to the 1997/98 El Niño and the 1999/2000 La Niña events. The last volcanic eruptions of El Chichón (1982) and Pinatubo (1991) are highlighted to show their short-term influence on the surface temperature drop. (adapted from Fyfe et al., 2016) 
and where the climate models' forecasts, represented by the CMIP-5 average (dark black curve), differed from the observed GMST, represented in the data sets, and reveals the slowdown in the GMST increase between 2001 and 2012.

The existence of a hiatus in recent years propitiated an encouraging environment of scientific discussion, noticed in the substantial number of reports, that eventually communicated with the wider public as a hot topic and an opportunity to provide a better understanding of the ECS and climate change (Hawkins et al., 2014).

Studies were made to elucidate possible general origins of that phenomenon (Allan, 2017; Hedemann et al., 2017) and the contemporaneous climate events that could have contributed to it (England et al., 2014; Yan et al. 2016; Hu \& Fedorov, 2017). In most cases, however, the Ocean has been the particular component of the ECS to be explored as a fundamental key to analyze the surface warming slowdown for longer than a decade in a human-induced warming planet, as part of a natural variability along the warmth process that did not cease (Katsman \& van Oldenborgh, 2011; Loeb et al., 2012; Meehl et al., 2011; Kosaka \& Xie, 2013; Aschmann et al., 2014; Cheng et al., 2015; Liu et al., 2016; Song et al., 2016; Wang et al., 2017).

Part of the oceanic contribution for the slowdown is, therefore, likely to be related with the thermal capacity of sea water, that makes the ocean a "natural sink" for the atmosphere, acting on the inter-basin heat uptake that plays a fundamental hole on the global vertical distribution of heat (Drijfhout et al., 2014), associated to internal dynamics of the ocean circulation that presents themselves decadal and multidecadal variabilities.

Despite the fact most of the referenced studies do not agree with which ocean basin or variability mode can be associated to the surface warming slowdown, it seems like each great basin holds its own time scale of contribution. Although not conclusive, the Atlantic Ocean is thought to drive longer scales, being tide to multidecadal variabilities of the ECS internal variability, mostly correlated to the AMOC and to the 
Atlantic Multidecadal Oscillation (AMO) - whose period vary between 60 to 80 years. The Pacific Ocean is more likely to contribute to interannual variability especially due to ENSO, but also to multidecadal variability, linked with PDO in two distinct signals, one almost bidecadal - period varying 16 to 20 years - and other multidecadal that is somehow connected to AMO (Steinman et al., 2015).

For all the cases, AMO, ENSO and PDO present themselves chaotic phases, making it difficult to establish a linear causal relation with them and the hiatus. The Indian Ocean also presents an interannual variability, but it is still not clear if the IOD is a global mode of variability, although it interacts strongly with ENSO.

\subsection{Motivation AND OVERVIEW}

The present work is motivated based on the following evaluations:

- the Atlantic Ocean is the basin that has absorbed the biggest amount of heat since 1970 , with a rate of $\sim 2 \times 10^{22} \mathrm{~J}$ per decade, what is almost the rate of the Pacific $\left(\sim 1.5 \times 10^{22} \mathrm{~J}\right.$ per decade $)$ and the Indian Ocean $\left(\sim 0.5 \times 10^{22} \mathrm{~J}\right.$ per decade $)$ combined, and it would be likely related to an enhanced Agulhas Leakage over the last years (Lee et al., 2011). During the recent warming slowdown, however, the deep $(700-1500 \mathrm{~m})$ heat uptake was observed, and it would be rather related with the anthropogenic warming than to the hiatus (Liu et al., 2015);

- Shallow La Niña-like conditions in the Pacific Ocean during the hiatus are associated with increasing Ocean Heat Content (OHC) in subsurface in the Indian Ocean (Lee et al., 2015);

- The Western Indian Ocean has been warmed for more than a century, and the Indian Ocean is becoming more active, making its strong connection with the Pacific Ocean to be gradually weaker in the last years (Roxy et al., 2014). 
That makes the Indonesian Throughflow - that connects the tropical Pacific Ocean to the Indian Ocean -, and the Agulhas Leakage - that connects the Indo-Pacific to the Atlantic - constitute main oceanic systems to explore correlations of the recent slowdown of the GMST warming with the upper ocean circulation.

\subsection{HYPOTHESES}

i) Changes in the upper Indian Ocean's heat content during the surface warming slowdown hold correlations with ITF trends.

ii) The enhanced leakage of waters from the Indian Ocean to the South Atlantic Ocean, which is increasing in response to global warming, can cause the SA Ocean circulation to be directly affected by variabilities and changes of ITF and in the Agulhas system.

\subsection{OBJECTIVES}

The main objectives of the present work are:

1) to investigate the structure and variability of the Indonesian Throughflow as represented in output data of a global implementation of an eddyresolving model of the ocean circulation, considering the global warming scenario and its recent slowdown;

2) to implement a fully operational Lagrangian Analysis that can establish the study of direct connections of the South Atlantic Ocean with the Agulhas Leakage and the Indonesian Throughflow, using open-source algorithms of virtual particles' tracking, in a comparison set of numerical experiments employing output data of the high-resolution ocean circulation model.

Some specific objectives can be pointed out:

- analyze results of a global implementation of the ocean circulation model considering climatological and interannual forcings;

○ evaluate general aspects related to circulation pattern, temperature and salinity profiles of ITF; 
- Study ITF variability in the intraseasonal, interannual, decadal and multidecadal timescales;

- Evaluate volume and heat transports related to ITF and their variabilities;

o Identify and explore possible long-term trends in the time series obtained;

○ Design and implement numerical experiments using virtual particle tracking that permits interocean exchange Lagrangian analysis;

The remaining of this document is structured in the following way. In Chapter 2 it is presented a brief description of HYCOM, general aspects of the numerical experiments conducted and an overview of the Lagrangian models. The results of the experiments with HYCOM are described in Chapter 3, together with a comparison with available observational data. In Chapter 4 the status of the effort to develop the Lagrangian tool is presented and discussed, with indications of the additional work needed to reach a fully reliable and operational system. Finally, in Chapter 5, a summary with main results and conclusions are presented, ending with suggestions for future work and recent scientific production overview. 


\section{2 | NUMERICAL TOOLS}

\subsection{The OCean Circulation Model}

HYCOM is an Ocean General Circulation Model (OGCM) designed with different vertical coordinate schemes to better represent the ocean circulation according to local characteristics (Bleck \& Benjamin, 1993; Bleck, 2002). In its "hybrid" approach, the vertical coordinates remain isopycnic in the stratified regions of the open ocean, below the surface mixed-layer and far from the boundaries. In the weakly stratified upper-ocean mixed-layer, the isopycnic vertical coordinates smoothly transition to z-coordinates and in shallow water regions the coordinates are dynamically converted to terrain-following sigma coordinates. In very shallow waters, along the coastal regions, the coordinates are turned back to z-levels (Fig. 2.1).

The Laboratory for Modeling and Observations of the Ocean (LABMON) of the Oceanographic Institute of the University of Sao Paulo (IOUSP), in collaboration with the Center for Weather Forecasting and Climate Studies (CPTEC), utilized a setup of version 2.1 of HYCOM, hereafter referred as GLBa0.08, to perform two numerical simulations on the global ocean circulation: Expt. 18.1 - the Climatological Run -, and Expt. 18.3 - the Interannual Forcing Run.

For the GLBa0.08 setup, the spatial domain used by HYCOM is discretized. The horizonal coordinates are represented in terms of elements $\left(\lambda_{i j}, \theta_{i j}\right)$ sorted in a PanAm mesh: a hybrid projection combining Mercator for latitudes between $79^{\circ} \mathrm{S}$ and $47^{\circ} \mathrm{N}$ and bipolar to the north of $47^{\circ} \mathrm{N}$, resulting in a tripole global grid (Murray, 1996), where $\lambda$ is the longitude and $\theta$ the latitude, $i \in[1,4500]$ and $j \in[1,3298]$ are the indices associated to the horizontal grid nodes in eastward and northward directions, 
respectively. Thus, the spacing between two consecutive grid points in the zonal direction is:

$$
\delta \lambda^{(j)}=\left|\lambda_{i}-\lambda_{i-1}\right|^{(j)}=1 / 12^{\circ}=0.08^{\circ}
$$

and in the meridional direction:

$$
\delta \theta^{(i)}=\left|\theta_{j}-\theta_{j-1}\right|^{(i)}=1 / 12^{\circ} \cdot \cos \theta_{i j}
$$

The result is a horizontal spacing (see Appendix A) given by:

$$
\delta x^{(j)} \approx \delta y^{(i)} \approx R_{E} \frac{1 / 12^{\circ}}{180^{\circ}} \pi \cos \theta_{i j}
$$

where $R_{E}$ is the mean radius of the Earth, resulting in $\delta x \sim 6.5 \mathrm{~km}$ for mid-latitudes and $\delta x \sim 3.5 \mathrm{~km}$ in the Arctic.

Finally, the components of the vector fields are staggered on an Arakawa C-grid (Arakawa, 1972; Arakawa \& Lamb, 1977) to be evaluated on time.

Although the model's equations are described by the hybrid system of vertical coordinates (Arakawa \& Suarez, 1983; Bleck \& Benjamin, 1993; Bleck, 2002), the vertical structure of the spatial domain is represented by 32 layers of constant $\sigma_{2}=\sigma_{2}\left(\sigma_{2}\right)$ surfaces, where:

$$
\begin{aligned}
& \sigma_{2_{K}}=\{28.1,28.9,29.7,30.5,30.95,31.5,32.05,32.6,33.15, \\
& 33.7,34.25,34.75,35.15,35.5,35.8,36.04,36.2,36.38,36.52, \\
& 36.62,36.7,36.77,36.83,36.89,36.97,37.02,37.06,37.1, \\
& 37.17,37.3,37.42,37.48\} \quad(\mathrm{kg} \cdot \mathrm{m}-3) ; K \in[1,32]
\end{aligned}
$$

denotes values of potential density anomalies with respect to the reference pressure of 2000 dbar. Those layers are eventually smooth-interpolated for each $\left(\lambda_{i j}, \theta_{i j}\right)$ to be written in terms of 33 vertical depth levels, $z=z\left(z_{k}\right)$ :

$$
\begin{aligned}
& z_{k}=\{0,5,10,25,50,75,100,125,150,200,250,300,400, \\
& 500,600,700,800,900,1000,1100,1200,1300,1400,1500, \\
& 1750,2000,2500,3000,3500,4000,4500,5000,5500\}(\mathrm{m}) \\
& k \in[1,33]
\end{aligned}
$$


The ocean bathymetry was based on the 1-minute resolution version of the Smith \& Sandwell (1997) bottom topography. The final setup provides a global horizontal and vertical resolution suitable for resolving eddies and an adequate representation of mesoscale processes.

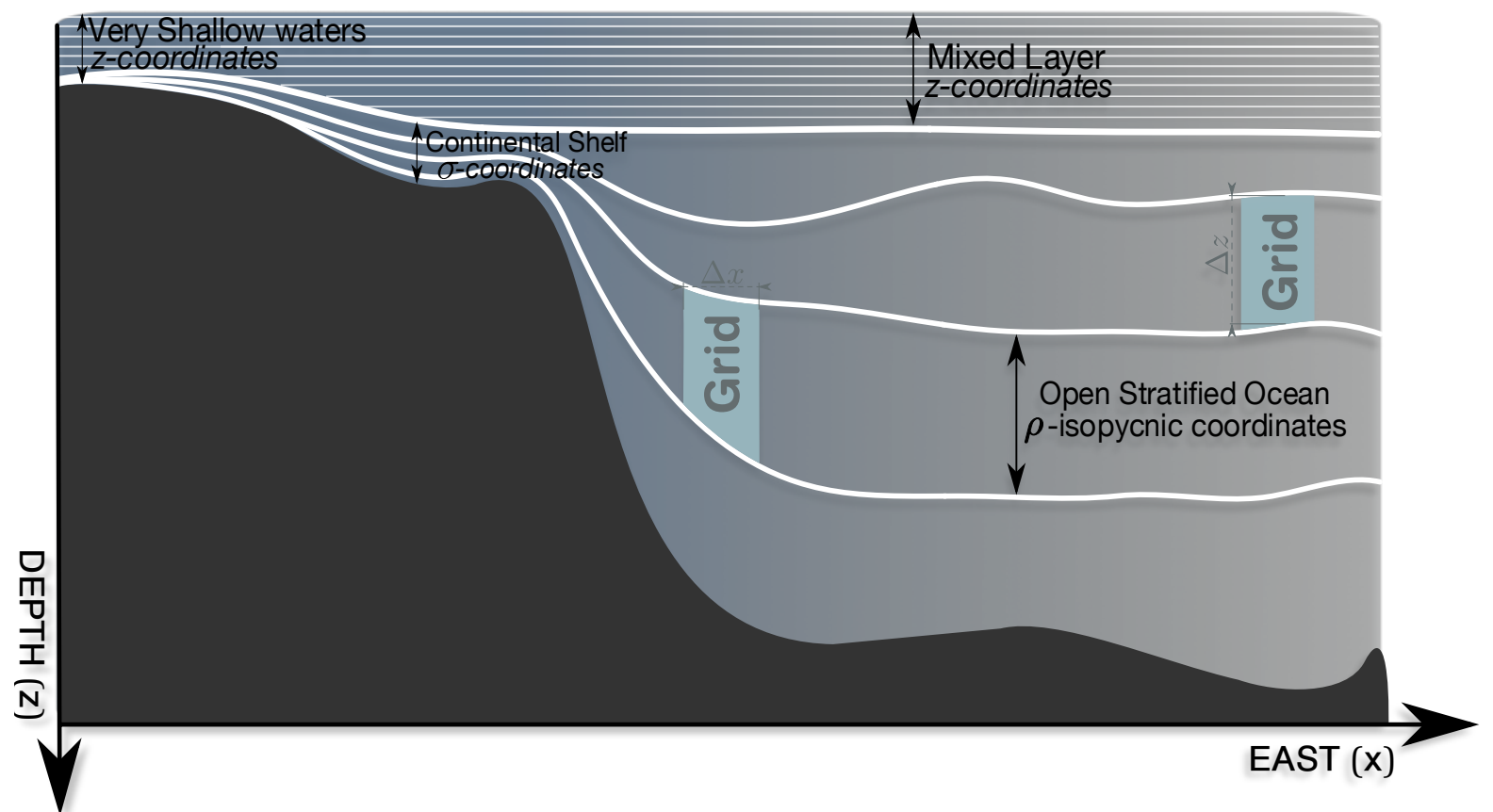

FIGURE 2.1 | Schematic representation of the HYCOM's hybrid coordinate system: for stratified regions of the ocean interior, the model is described by surfaces of constant density (isopycnals) as the vertical coordinate; in the surface mixed layer, the isopycnals automatically transform to Euclidean z-coordinates; in shallow regions over the continental shelf, the layers become terrainfollowing $\sigma$-coordinates; and come back to z-coordinates for very shallow areas.

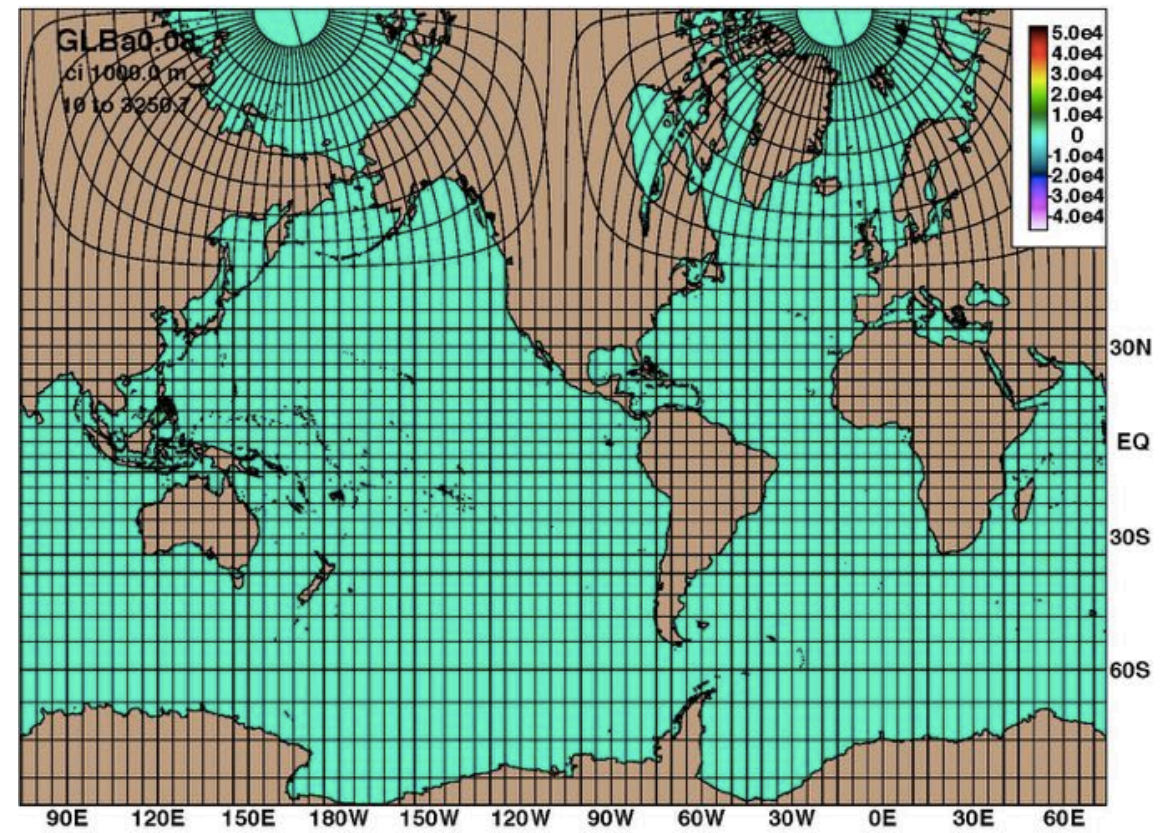

FIGURE 2.2 | PanAm grid: a combination of a Mercator projection south of $47^{\circ} \mathrm{N}$ then a dipole patch for the Arctic 
Among the Eulerian fields (see Appendix B) represented in the experiments' outputs, the present work used the: eastward, northward and downward components of velocity; sea surface height, potential temperature, density and salinity. Each one of these fields are evaluated in the grid points as:

$$
\phi(i, j, k)=\phi_{i, j, k}
$$

where $\phi$ represents any of the Eulerian fields given by the model and $i, j, k$ are the indices of the spatial grid.

In addition, to these experiments, output of other one performed by the U.S Naval Research Laboratory (NRL), using a similar configuration of the same model (GLBa0.08), and labeled as Expt. 19.1, was considered for comparison and validation, and it is detailed in Section 2.1.3.

\subsubsection{Expt. 18.1 - Climatological Run}

Data products of the Reanalysis 1 by National Center for Environmental Prediction (NCEP) National Center for Atmospheric Research (NCAR) (Kalnay et al., 1996) were used to force the model with atmospheric fields containing wind velocity and shear stress, heat and radiation fluxes, and precipitation data. In this experiment (18.1), monthly averaged data of the climatological year (mean state obtained by averaging the whole time series) were used to force the model for 27 years. The ocean's initial state was an arbitrary realization of a global run available at the HYCOM Consortium (see: www.hycom.org).

That is to say, the model was started from a "warm" initial condition. Output of the runs were written every six days, considering the mean values of all output variables along the previous six days. Because, despite the "warm" initialization, the model would take a time to stabilize, the first 10 years of the time series were considered as transient and were not used in the analyses performed in the present work. Fig. 2.3 illustrates the surface circulation in one arbitrary day of the $27^{\text {th }}$ year of the simulation. 


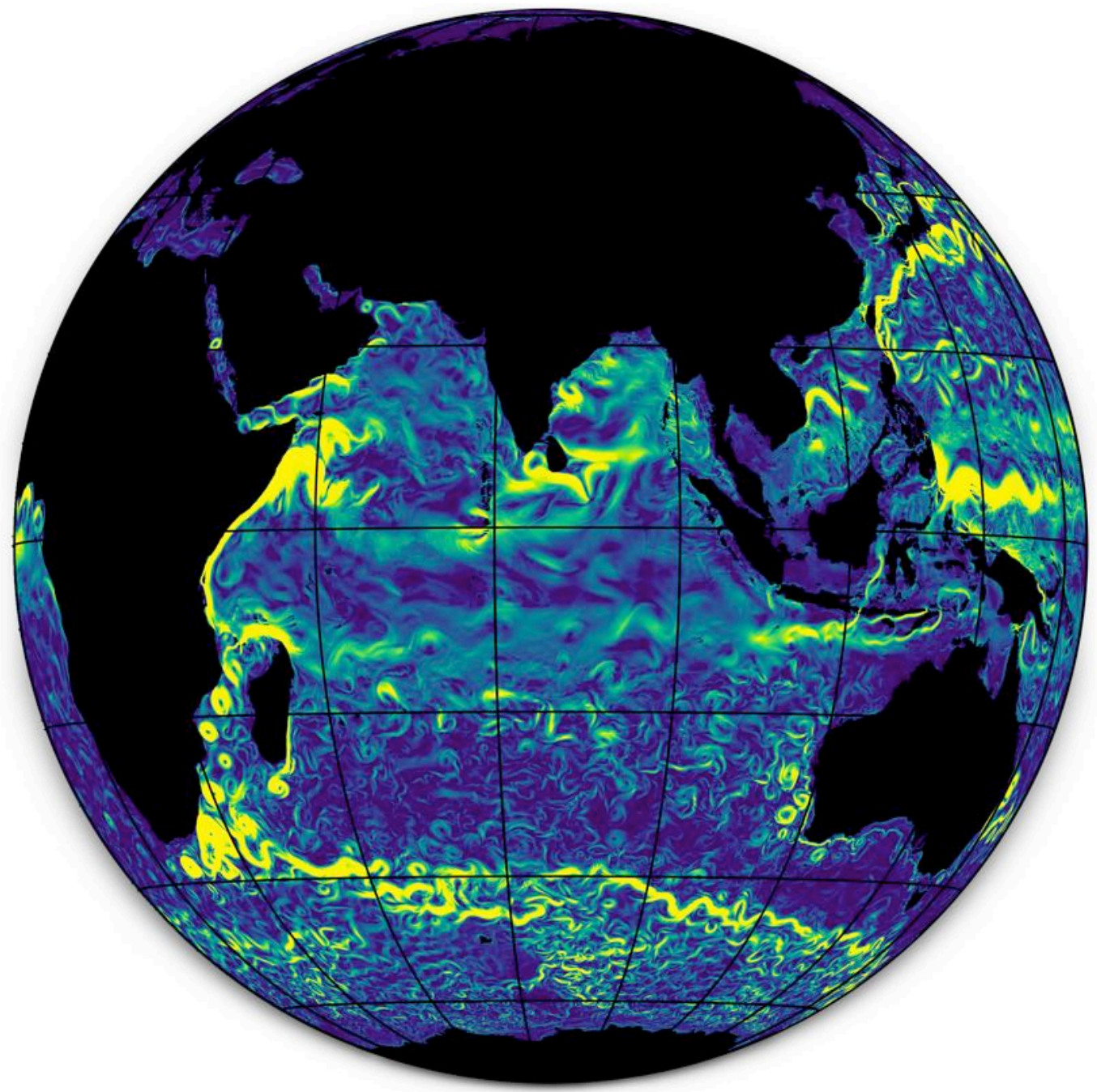

FIGURE 2.3 | Snapshot of the surface circulation of an arbitrary day after 27 years of simulation in the Expt. 18.1 Experiment. Warmer colors represent higher speeds

The motivation for running this experiment was to evaluate how much the longterm variability in the model when forced with interannual variability was due to the forcing variability or to any model's intrinsic internal variability.

\subsubsection{Expt. 18.3 - Forced with Interannual variability}

For this experiment, also NCEP/NCAR Reanalysis-1 data product was used. The monthly averaged data containing the inherent interannual variability are used to force the model from 1949 to 2015. The model's state in the end of the $20^{\text {th }}$ year of the Climatological Run was used as initial condition for this experiment. As in the previous run, the mean outputs were saved each six days. The time series here analyzed comprises the period from 1970 to 2015. 


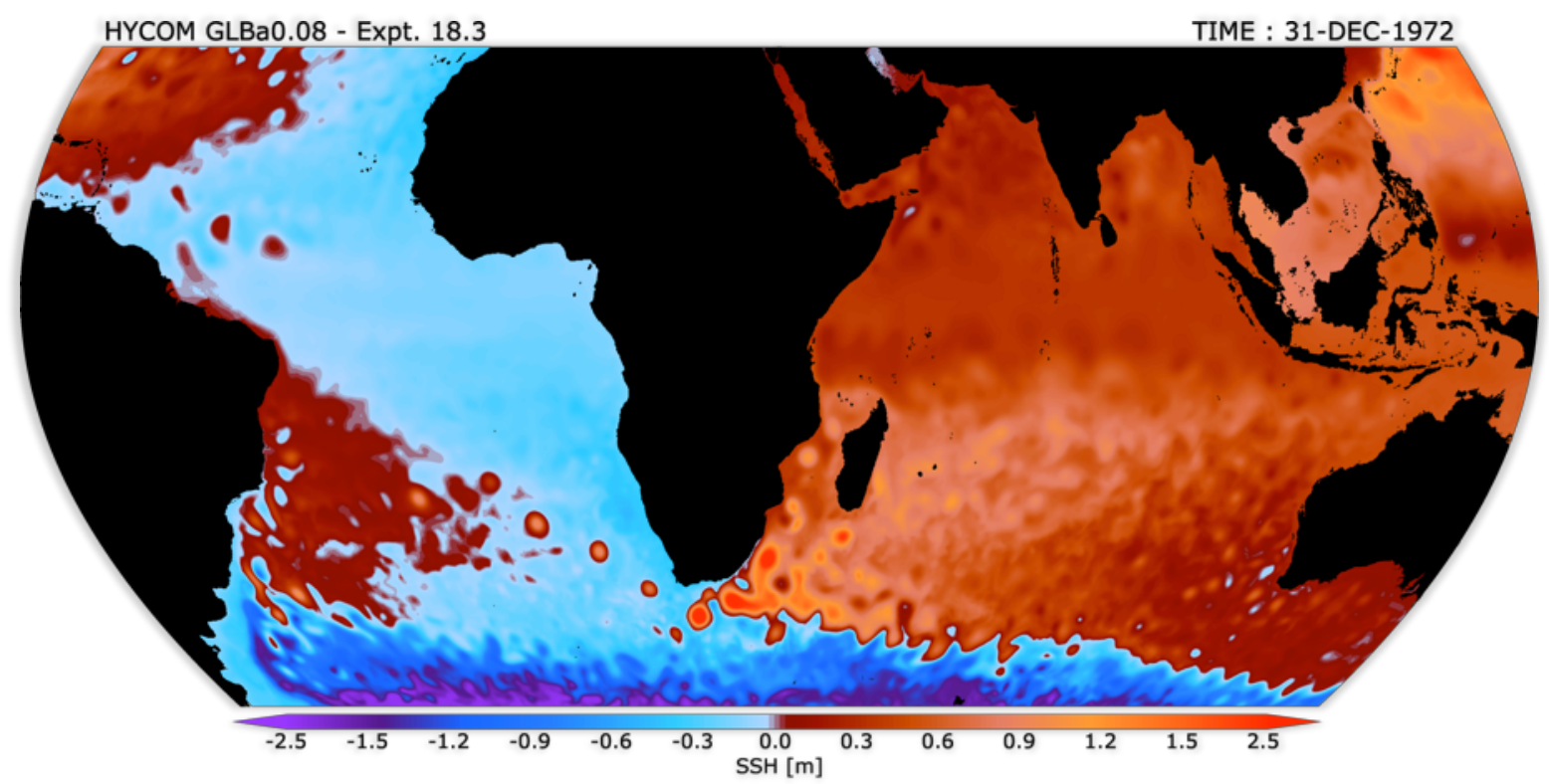

FIGURE 2.4 | Sea Surface Hight (SSH) for a snapshot on December 31th, 1972, according to the forecast of the Expt. 18.3

\subsubsection{Expt. 19.1 (by NRL)}

HYCOM is an OGCM used worldwide by different research groups and performed in many experiments using different configurations. The Consortium for Data Assimilative Modeling has performed some experiments with HYCOM involving the use of data assimilation, which adjusts the model with real empiric data provided by a certain reanalysis. Because the HYCOM runs performed by LABMON have no data assimilation, some tests were done using results of HYCOM with data assimilation by NRL.

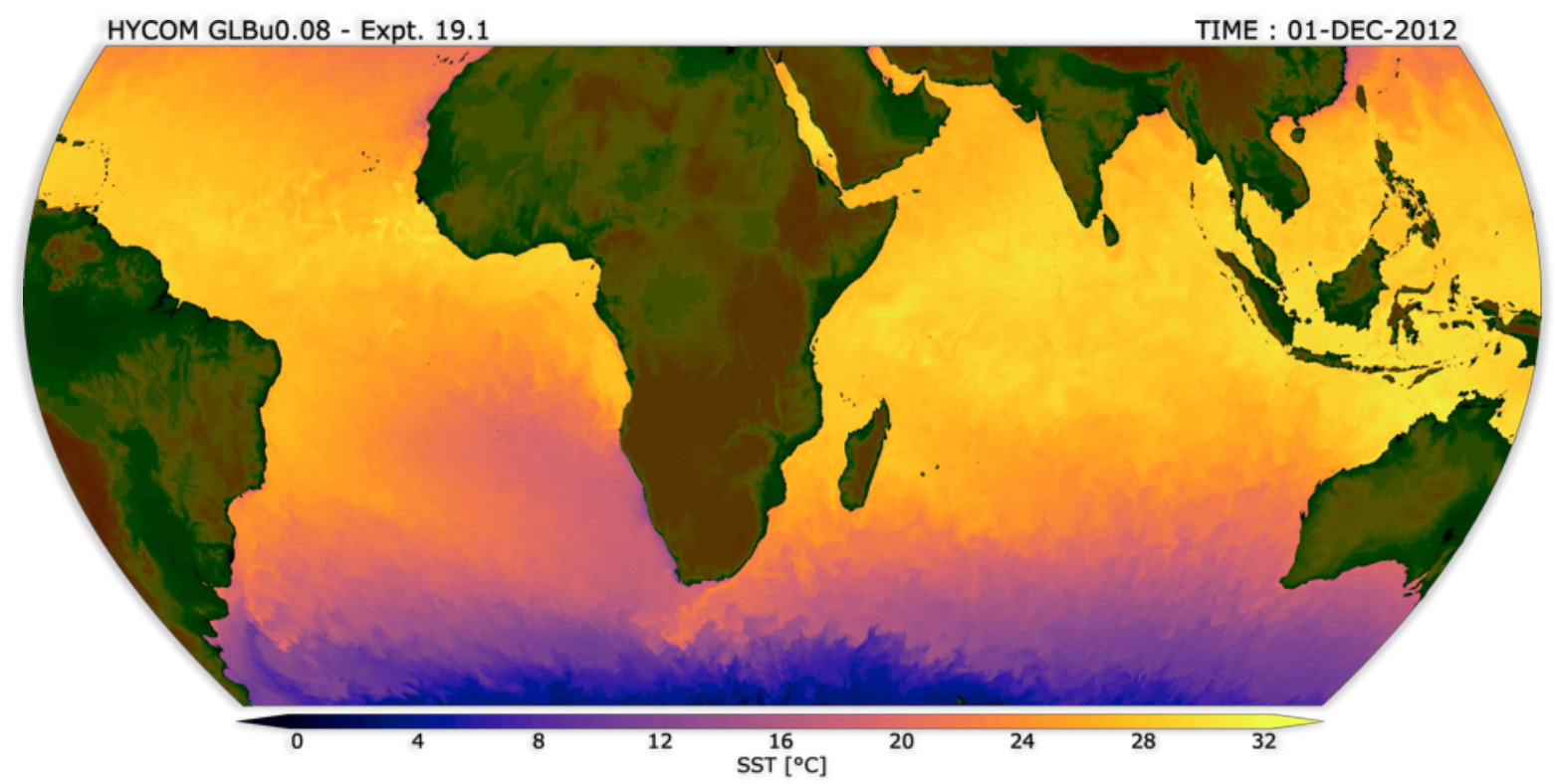

FIGURE 2.5 | Sea Surface Temperature (SST) on December $1^{\text {st }}$, 2012 as represented by Expt 19.1 (NRL) 
At www.hycom.org is possible to find a description of a few experiments achieved using HYCOM and the Navy Coupled Ocean Data Assimilation (NCODA) system (Cummings, 2005, Cummings \& Smedstad, 2013). NCODA considers the model forecast in a three-dimensional variational scheme and assimilates available satellite, and in situ data of Sea Surface Temperature (SST), in situ vertical temperature and salinity profiles from XBTs, ARGO floats and moored buoys, and satellite altimeter observations.

Expt. 19.1 was forced with NCEP Climate Forecast System Reanalysis (CFSR) data (Saha et al., 2006) and fulfill a date range from Aug. 1995 to Dec. 2012. Outputs are available in a 3-hourly frequency. This one is openly distributed via OPeNADP ((Open-source Project for a Network Data Access Protocol) at: http://tds.hycom.org /thredds/dodsC/GLBu0.08/expt_19.1.html, where a GLBu0.08 setting output is distributed, and it denotes an interpolation of the original GLBa0.08 setup to an uniform cartesian horizontal grid, equally spaced by $0.08^{\circ}$ between $80.48^{\circ} \mathrm{S}$ and $80.48^{\circ} \mathrm{N}$, and 40 vertical depth levels given by:

$$
\begin{aligned}
& z_{k}=\{0,2,4,6,8,10,12,15,20,25,30,35,40,45,50,60,70, \\
& 80,90,100,125,150,200,250,300,350,400,500,600,700,800, \\
& 900,1000,1250,1500,2000,2500,3000,4000,5000\} \quad(\mathrm{m}) ; \\
& k \in[1,40]
\end{aligned}
$$

The Eulerian fields provided by Expt. 19.1 and used in this work were: eastward and downward velocity components; temperature and salinity. Data for downward velocity, potential temperature and water density were not available at the official web page referenced above.

A setup that uses data assimilation, as this Expt 19.1, is supposed to provide more realistic results than a free run, as the Expt 18.1 and 18.3 performed by LABMON. Also, outputs are saved in a higher frequency, which allows for more accurate spatial advection of virtual particles, part of the tasks proposed in the Lagrangian section of this work. 


\subsection{The Connectivity Modeling System}

The Connectivity Modeling System (CMS) is a free open source software written in Fortran 90 and can be downloaded from: https:/github.com/beatrixparis/ connectivity-modeling-system. It is a multiscale stochastic Lagrangian framework developed at the Rosenstiel School of Marine \& Atmospheric Science (RSMAS), at the University of Miami, to study complex migrations and provide probability estimates of dispersion, connectivity, fate of pollutants, and other Lagrangian phenomena (Paris et al., 2013). The tool is inherently multiscale, allowing for the seamless moving of particles between grids at different resolutions, for the multi-scale tracking of biotic and abiotic particles in the ocean.

As a modular software, CMS permits adding or removing behaviors of the particles being simulated as such as of the software by itself. Pre-built modules include the Parallel, the Multiscale, the Landmask Boundary, the Vertical Movement, the Connectivity Matrix and the Flexible Input and Output ones. Other Modules also present in CMS are related to biological studies, such as the Individual Based Model - which allows giving particles specific behaviors - the Buoyancy Module - applied, for example, to simulate buoyancy of larval eggs - and the Seascape Module - that can be used to simulate different marine habitats and their connectivity.

\subsubsection{The CMS Algorithm}

Basically, CMS works "offline" by reading locally stored data that provide fields of the Eulerian velocity components along the time of simulation and spatial domain desired. Additional information can be considered, as temperature, salinity, and density, as such as individual behaviors for each passive or active particle, that can also be associated to a specific habitat. In this last case, CMS is able to provide outputs with information connecting initial and final position to the corresponding habitats and their particles when released and killed: the outstanding feature of CMS, more frequently 
applied for biological purposes.

Usually, the velocity field is provided by OGCMs output data, that can present three components: $u$ (eastward velocity), $v$ (northward velocity), and $w$ (vertical velocity); or only two: $u$ and $v$. The user needs to detail every single particle that must be considered for the numerical experiment with CMS, informing, at least, position and date of releasing for each single particle, with the condition the offline data must provide the velocity fields and other additional variable needed to compute individual behaviors (as water density and water temperature) at the exact location where the particle is being released for advection. The. multi-scale module permits to utilize data from different runs and different OGCMs for different spatial domain, by coupling them with a smooth transition.

Then, the user settles details for the advection method, that can be either deterministic, following the velocity field in data, or also stochastic, where random small kicks are given on the particle's velocity components at every time step desired to simulate any dynamic process not solved by the OGCM. For evaluating particle advection, CMS uses a $4^{\text {th }}$ order Runge-Kutta scheme, and it is applied both in time and space (Paris et al., 2013).

For position, CMS uses a tricubic interpolation method, where 64 neighboring grid nodes are used for each dimension of the OGCM output, by using a third-degree (cubic) polynomial fitted to the data in every 4 points of each dimension $(4 \times 4 \times 4=$ 64). For the case in which a two dimensional only Eulerian velocity field is given, then CMS will compute a simpler bicubic method. That is aimed to set the position of the particle in the grid points of the model grid and then compute variables' values. A simple linear interpolation over time is also performed to adjust the instantaneous velocity fields between consecutive snapshots of the integration method and input data, as necessary.

The particle located at the new numerically integrated position, one time step ahead, is now susceptible to the Eulerian fields interpolated at this new position and 
time, as provided by the OGCM data. Thus, a new integration process begins, and the trajectory of each particle released in the ensemble is saved in an CMS output file. A basic flow chart of the complete code is shown in Fig 2.4, adapted from Paris et al., 2013.

CMS is previously prepared to run in multiprocessors computers, through its parallel module, that uses the Message Passage Interface (MPI) library, so a proper compiler that supports MPI is also necessary if parallel computing is intended to be applied. CMS supports access to on-the-fly ocean circulation data via OPeNADP, and it is also able to read local files of OGCM data in NetCDF, and write output files (with the CMS results) in both NetCDF or ASCII formats.

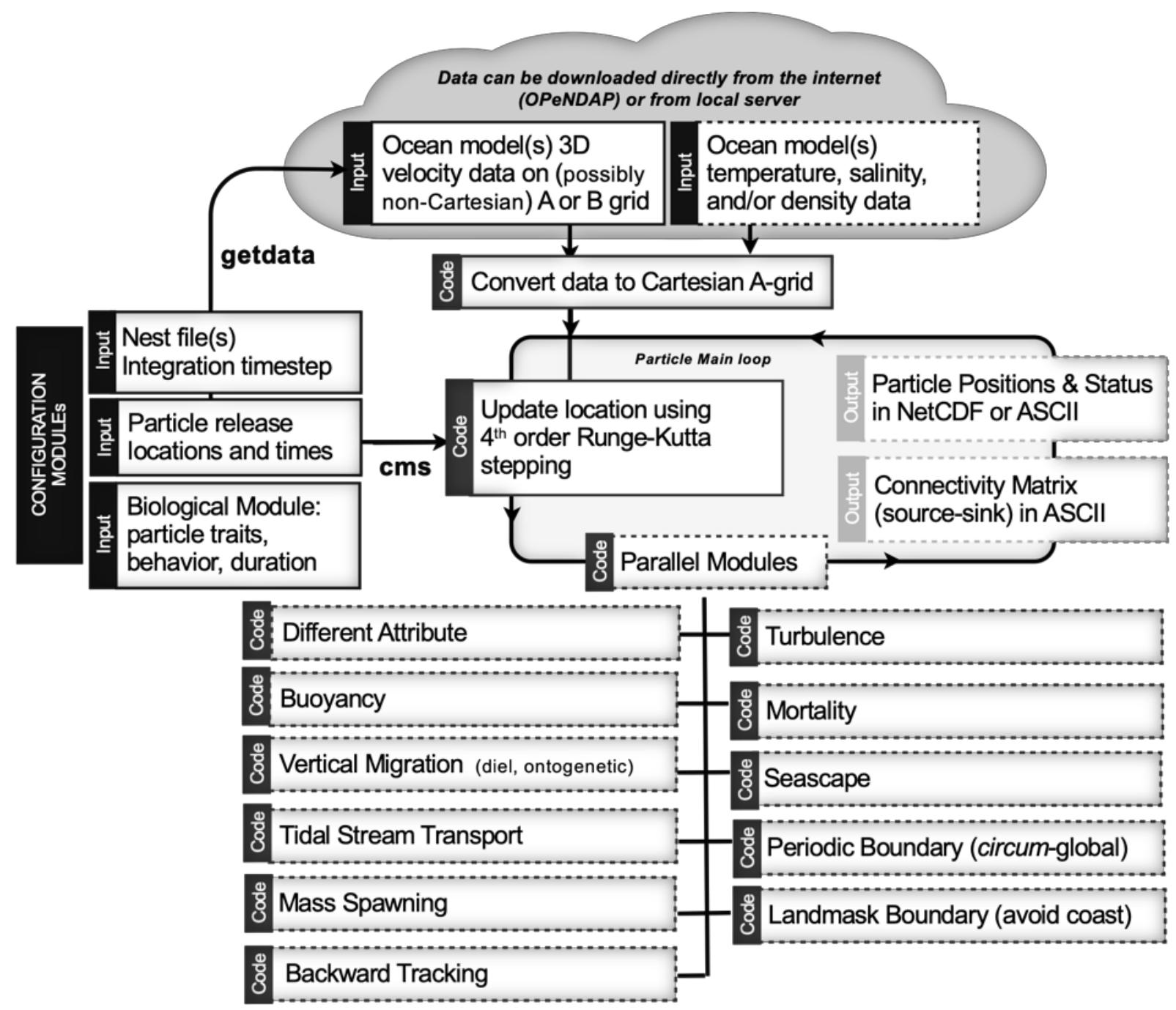

FIGURE 2.6 | Flowchart of CMS, showing the Input process and interpolation grid needs, the Lagrangian Code and its modules, and the Output possibilities (adapted from Paris et al., 2013). 


\subsection{THE PARCELS ALGORITHM}

\section{Probably, A Really Computationally Efficient Lagrangian Simulator} (PARCELS) is a set of Python classes and methods developed in the OceanParcels Project to create customized simulations of particles' trajectories based on output data of OGCMs. PARCELS can be used to track passive and active particulates, such as water, plankton, plastic and fish (Lange \& van Sebille, 2017). It is open source, under an MIT license, and can be downloaded at https://github.com/OceanParcels/parcels. The project also keeps a dedicate webpage at www.oceanparcels.org, where a number of tutorials on the numerical simulator is available to provide an overview of how to use the algorithm and customize experiments.

This code is designed to match computing needs over the "petaescale era": the current time of human civilization whose technological development allows for multiprocessor systems that are capable of achieving computer performances that exceed 1 petaflop $=1,000,000,000,000,000$ logical operations per second.

Following computing evolution, the OGCMs and Climate Models have also begun to be implemented in experiments that request an increasingly higher spatial and temporal grid resolutions. Higher resolution models usually mean higher fidelity of the results obtained from these models and the real life, but with that is brought a significant increase in storage and physical memory demand, once amounts of data reaching more than hundreds of terabytes represent outputs of a single experiment.

Thus, beyond the models themselves, the methods and tools concepted to process and analyze all that resulting information should also follow the same computing development timescale. However, numerical algorithms of Lagrangian Ocean Analysis currently available are not, at the same time, customizable or computationally efficient enough to match the increasing complexity requests of numerical experiments, the volume of data produced by the high resolution OGCMs, and the individual needs of each simulation proposal, whose may present diversified objectives, spatial domain or 
timescales of interest, and formats of the OGCMs' output files.

Developed from the ground up, PARCELS tries to fulfill these requirements with a code supposedly prepared for an efficient data communication (API) at the same time it was designed to operate optimally in high computational performance. Actually, the most intriguing aspect of the PARCELS code is the base language chosen by its designers to accomplish all that: Python.

Popular among computing enthusiasts and in many fields of Math and Science, Python gained popularity recently thanks to its more user-friendly interaction when compared to more traditional programming languages, such as Pascal, Cobol, Assembly, C, and Fortran. Nowadays, there are several Python-based tools, freely distributed on internet, intended for innumerous tasks, such as bi and three-dimensional graph plotting, time series analysis, scientific data processing, web browser and data base servers communicating, etc. But, despite of that, Python also got famous for its reputation of being considerably slower, especially if compared to $\mathrm{C}$ or Fortran - the preferred languages when it comes to efficiency and performance.

To satisfy this request PARCELS makes use of the CPython library, which combines a Python interface with a C-based processing algorithm. Thus, it can generate a low-level $\mathrm{C}$ code for routines that demand higher performance, through a run-time compilating CPython code (Just-in-time compilation), making it suitable for critical performing computation.

The code, in a general way, presents a deep level of abstraction that hides from the user details about inherent aspects of the algorithm work, as grid changing, interpolation, units of measurement, etc. The algorithm is able to read data saved in most common formats for big datasets (such as NetCDF, ASCII, etc.) and easily scale the velocity fields and any other variable, which can be written in almost any spatial grid, including the generalized vertical ones (like the $\sigma_{2}$ one adopted by HYCOM or the one from curvilinear grids, or even any other Cartesian orthogonal ones). The algorithm 
can handle missing data and data is used as is, then only the interpolations that are required to evaluate the Eulerian field at a specific particle's position and instant of time are performed during the execution of the simulation. The Eulerian fields data may be provided by different sources, from different models and grids, the code is also able to perform a loop over the data boundaries and evaluate the initial particles' positioning on a line, or an external file, and the same ensemble can be released every customizable interval, and they are advected until some specific date and time or until a maximum simulation time. These aspects may save a valuable time when it comes to the tuning and implementation of experiments, and reveal a great advantage over other Lagrangian simulators, as the CMS, for example.

Figure 3.1 shows a schematic diagram of the functional abstraction with which the model was conceived: The user should define: the variables of the system; the ensemble of particles to be simulated and the customizable routines to be computed besides the time advection (the so-called kernels). The algorithm is responsible for performing the time integration loop and updating the state of the particle ensemble, adapting the OGCMs Eulerian fields data as needed and writing the output files. It is still possible to visualize, in real time, the simulated movement of the ensemble of particles, and the temporal variation of the velocity field or any other property.

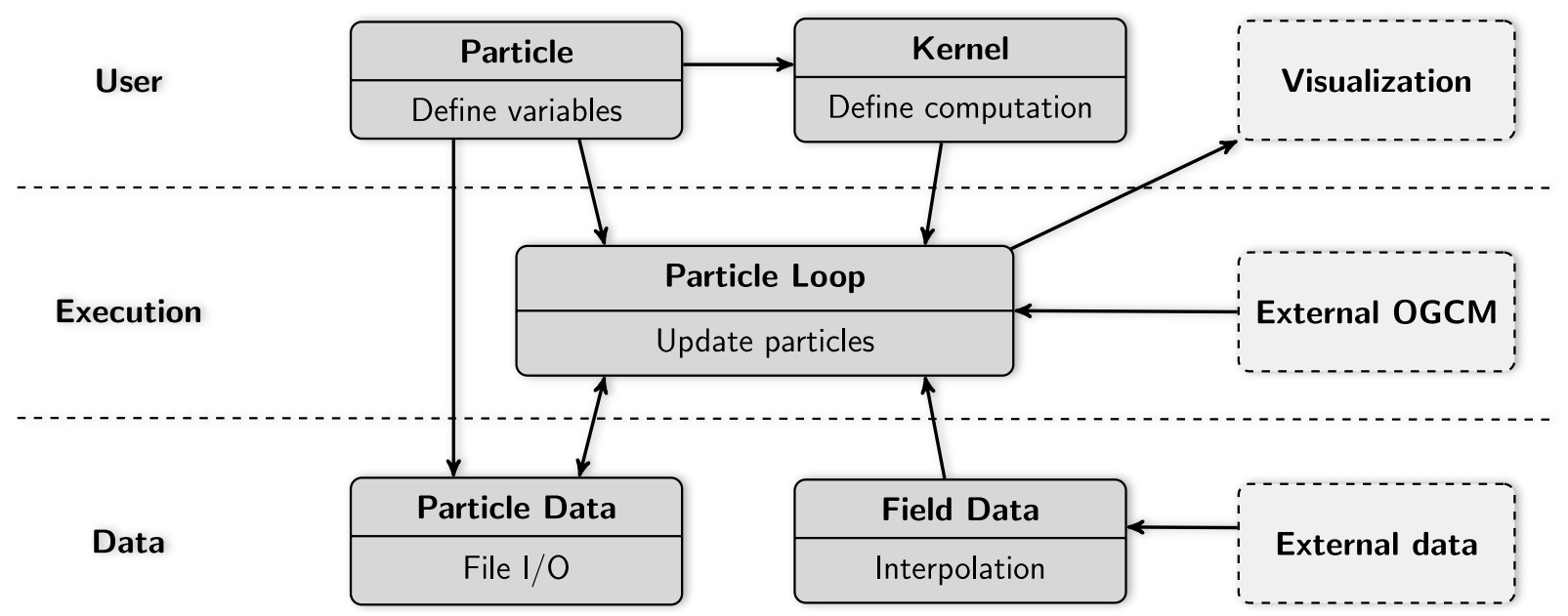

FIGURE 2.7 | PARCELS algorithm flowchart. The code was conceived in a high abstraction level, requesting from the user the strictly necessary input information. (Adapted from Lange \& van Sebille, 2017) 
Finally, the user can create as many custom kernels as he wants or needs. A kernel is the outstanding feature of PARCELS, defined as a customizable and versatile routine algorithm, write by the user, that will be evaluated along the simulation, and can be a function of any field or variable, allowing the user to assign a special or individualized behavior to the particles. That may represent, for example: boundaries of integration for each particle in terms of their life time, mortality rate, or habitat; a discretized model for biotic or abiotic tracer; an along trajectory sampling of the fluid's properties - such as temperature, salinity, nutrients, etc.; any specific actions matching conditional clauses, useful in cases which the particle may be placed at certain nonrealistic or killing depth, or if it approaches the coast; etc.

In a matter of fact, PARCELS and CMS employ the same numerical method for advection, the $4^{\text {th }}$ order Runge-Kutta, two- or three-dimensional; but the PARCELS's user can also choose between the Runge-Kutta45 (a varying timestep method) or the simpler Euler forward, instead. A stochastic method to simulate horizontal diffusion is implemented in the code, described by a simple Brownian motion.

For post-processing analysis, PARCELS brings a number of scripts and methods for graphical visualization of the simulated results, whose output can be written in an adjustable chunk size NetCDF format, that can be adapted to reduce the final volume of data saved in disk. In addition, a vast library of Python tools is freely distributed by diverse sources, and they can be used with PARCELS's output files. An extensive documentation and a set of tutorials for PARCELS is supplied by the OceanParcels webpage, making the installing process and the initial familiarization with the algorithm and its features, for any user that holds a minimum knowledge of computer programing, even if new to Python specifically, to become easy and clear.

However, PARCELS is not yet fully prepared for large simulations that considers long time series, and high resolution OGCM, once the implementation of parallel processing is a functionality still in development stage and promised for its next versions. 


\section{3 | EULERIAN ANALYSIS OF THE INDONESIAN THROUGHFLOW}

This chapter discusses the ITF based on the HYCOM experiments performed at LABMON (here referred as Expt 18.1 and Expt. 18.3) and a short analysis for the Expt. 19.1 with HYCOM+NCODA performed by NRL.

The output of the climatological run (Expt. 18.1) was analyzed to identify the average patterns concerning the ITF circulation and of the vertical profiles of speed, temperature and salinity along the straits that compounds the inflow and outflow pathways, considering a Eulerian framework.

The volume transport was estimated in the upper $700 \mathrm{~m}$ depth. The time series of this run, once there is no interannual variability forcing, was also used to determine the seasonal variability of ITF. On the other hand, the run forced with inter-annually varying data was studied to analyze interannual ITF variabilities, the expected responses to ENSO and long-term trends, considering the volume and heat transports in each strait, also in the upper $700 \mathrm{~m}$.

To obtain a more accurate result, in addition to the estimations of the transports across Makassar, Lombok, Ombai and Timor straits, two more regions were also considered: the Karimata Strait, located to southeast of Borneo island; and another small strait to the south of Flores Sea.

Furthermore, instead of computing the transports along Lifamatola passage, an alternative section crossing small islands to south of Maluku Sea was been chosen. Thus, the inflow pathway comprehends the Karimata, Makassar and Moluccas sections; and the outflow, Lombok, Flores, Ombai and Timor sections. This methodology allows to 
acquire values in more grid points and leads to a closer ITF domain. Fig. 3.1 illustrates the names and location of all straits considered for calculations. Lifamatola passage is highlighter in Fig. 3.3.

\subsection{Average flow and pathWays - Climatological Run}

Fig. 3.1 illustrates the spatial domain of ITF on the globe (top) and the contouring of the average Sea Surface Height (SSH), colored by SSH variance, for the whole ten last years of the Expt. 18.1 time series. As it has been previously shown (Mayer et al., 2010), the ITF is mostly driven as part of the strong Tropical Pacific Ocean circulation, where the western boundary is not completely closed when it reaches the Indonesian archipelago, allowing the flux to go through ITF straits. Thus, it is possible to note on northeastern corner of the region plotted, the pathway of input of superficial waters from North Pacific into the Indonesian seas, where higher values of SSH around this poorlyclosed boundary indicate an accumulation of volume that cannot easily enter the Indonesian seas, generating local anomalies on the elevation of surface. Also, high values of SSH and SSH variance to northwestern of Australia indicate the mean surface flux around the outflow region.

The average horizontal velocity field in ITF has been plotted using data of the climatological run, considering the mean field in the last ten years of the time series. The horizontal map obtained for the mixed layer are shown in Fig. 3.2. For the superficial flow, as expected, waters coming from North Pacific enters the Indonesian seas mostly through Makassar strait, where one could observe a stronger southward flow, that reaches Flores Sea and bifurcates. The western branch goes straightly southward in direction of the Lombok strait, where it is then injected into the Indian Ocean basin. The other branch, in its turn, seems to retroflects to east toward the Banda Sea. A small flux exits Indonesian archipelago still in Flores sea through a small strait. The major flow keeps in route within Banda Sea and goes out toward the Indian Ocean passing through both 


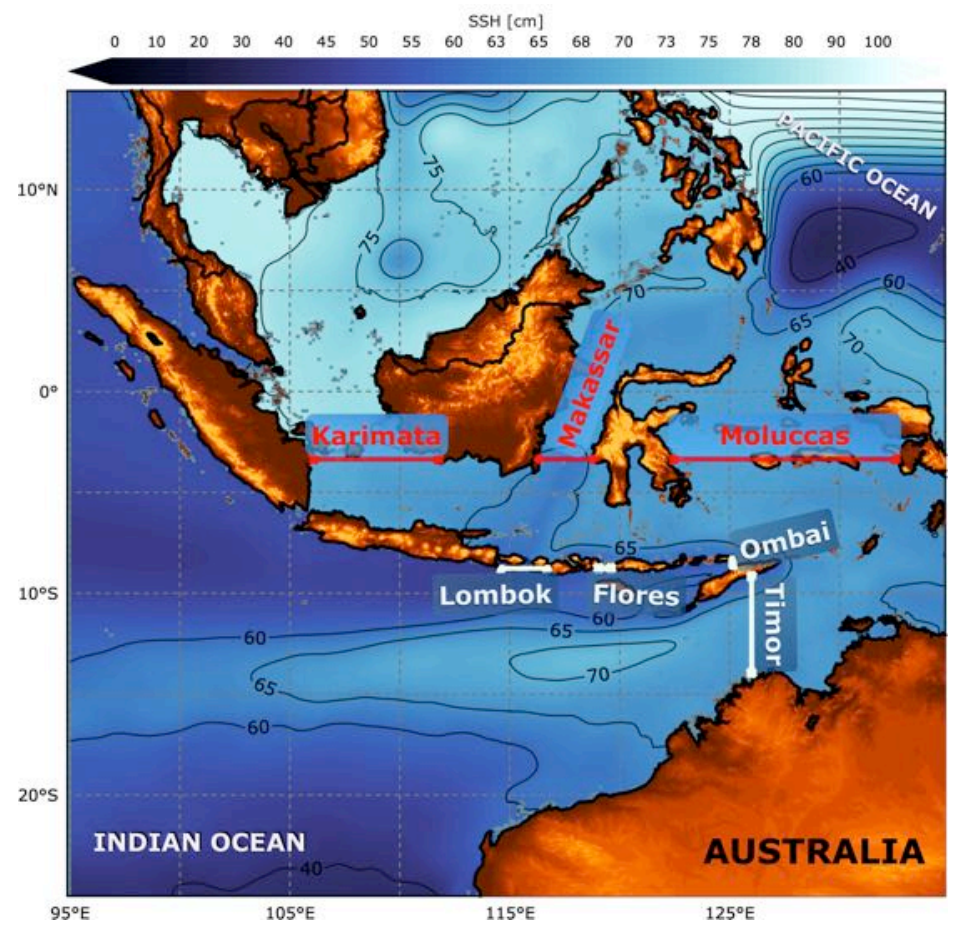

FIGURE 3.1 | Location of the ITF's region on the globe (top) and Mean Sea Surface Height (SSH) on the ITF colored by SSH, using output data of Expt. 18.1 (see Section 2.1.1). The graphic shows the names of sections used to estimate the transports. Karimata, Makassar and Moluccas correspond to the inflow pathway; and Timor, Ombai, Flores and Lombok to the outflow one.

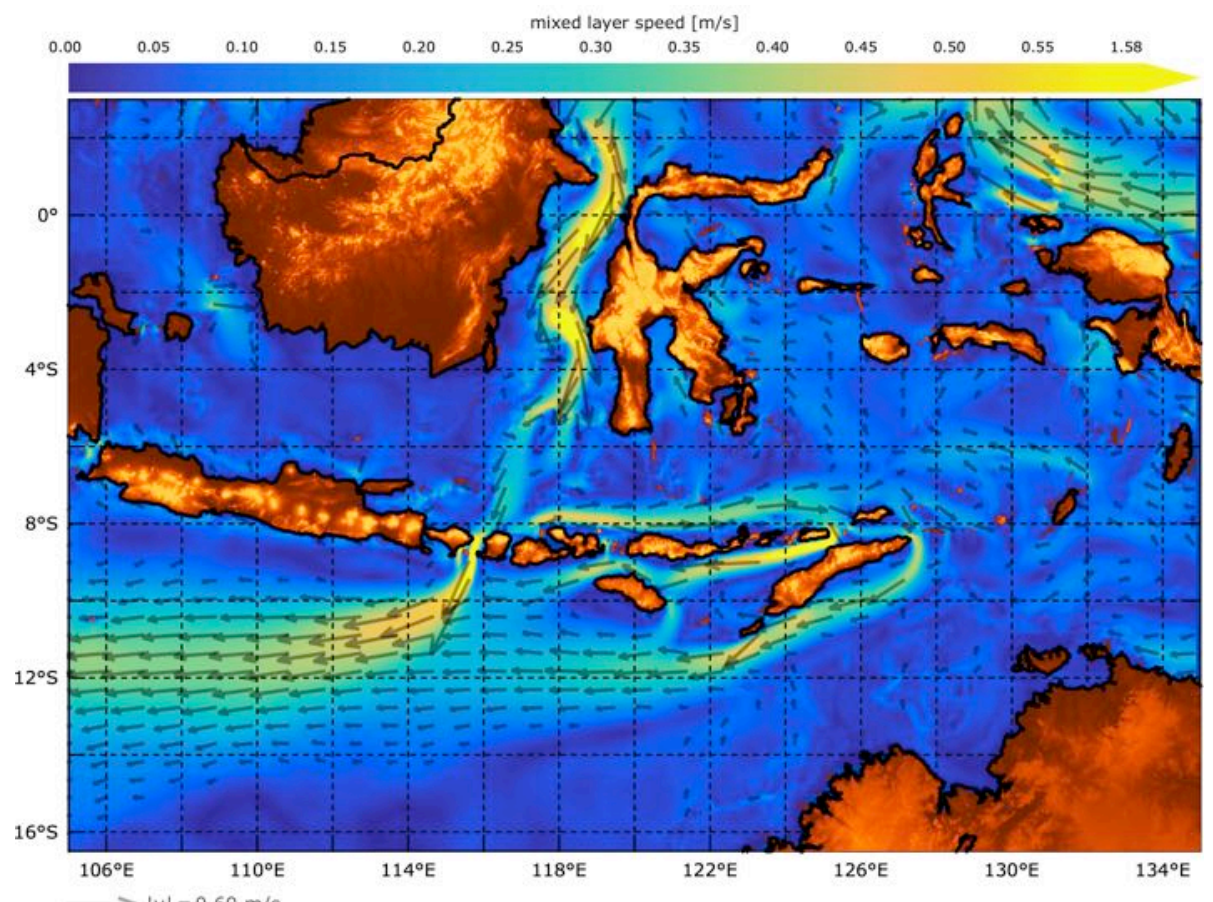

FIGURE 3.2 | Horizontal Map of the flow in the mixed layer considering the average velocity field for the ten last years of the Climatological Run. Makassar Passage is shown as the major inflow passageway for superficial flows. In this layer, water coming from Pacific are transported within Flores Sea toward Banda Sea, exiting from Indonesian archipelago to Indian Ocean basin by travelling throughout Lombok, Flores, Ombai and Timor straits. A smaller intense flow can be observed entering the Indonesian seas by inflowing through Karimata strait. 
sides of Timor island, crossing the Ombai strait and the Timor island's southern passage. All the outflows converge in the Indian Ocean in a westward superficial flux with core around $11^{\circ} \mathrm{S}$. Another relatively smaller inflow can be distinguished in the figures crossing the Karimata strait southward, entering the Java Sea, which is shallower than Flores and Banda Seas (as it is represented in bathymetry of Fig. 3.3). Another weak flow, north of Australia, seems also to go into the Banda Sea. But the average field shows this superficial flux mixing with other superficial Banda's water forming a flow northward, exiting the Indonesian seas through Lifamatola passage.

Fig. 3.3 depicts the mean velocity field at $1000 \mathrm{~m}$ depth. At this depth, the Lifamatola passage acts as a single inflow pathway with subthermocline waters entering the Banda Sea through Lifamatola. The southward flow follows the topographic boundaries of different islands of the sea and eventually enters the Indian Ocean basin by outflowing through Ombai and Timor straits. In Fig. 3.3 it is also represented the

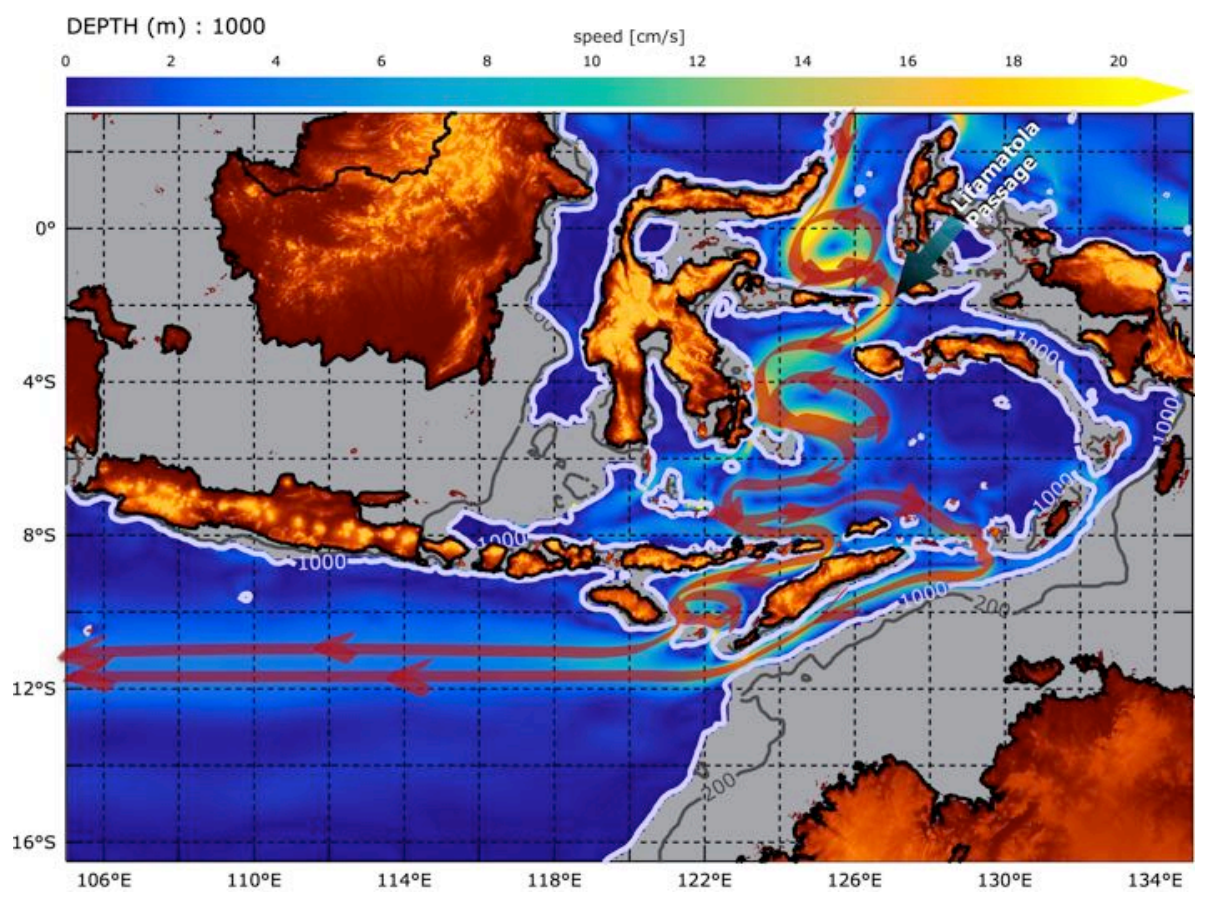

FIGURE 3.3 | Horizontal Map of flow at $1000 \mathrm{~m}$ depth considering the average velocity field in the last ten years of the Climatological Run. The Lifamatola passage is the only pathway for the inflow of deep water from Pacific Ocean into the Indonesian seas. A southward deep flow is formed in Banda Sea and its trajectory follows is affected by topographic boundaries which exist in the sea due to presence of small islands. Lastly, these deep waters exit from the Indonesian archipelago toward the Indian Ocean by outflowing through Ombai strait and Timor passage. The graph also marks the $200 \mathrm{~m}$ (wider light blue line) and $1000 \mathrm{~m}$ (white) bathymetries. The grey area is shallower than $1000 \mathrm{~m}$. 
$200 \mathrm{~m}$ and $1000 \mathrm{~m}$ isobaths. Since the southern Banda Sea is shallower than the Lifamatola sill (van Aken et al., 2009), this passageway controls the deep flow from the Pacific to the Indian Ocean.

\subsection{Vertical Profiles: Cross-Section Currents and Stratification - ExPT. 18.1}

The output of the climatological run was also analyzed to study the vertical structure of flows and waters physical properties represented by HYCOM. For that purpose, major sections have been analyzed: Makassar strait and the Lifamatola passage for their importance on inflow pathways and the Ombai strait and Timor passage for carrying both shallow and deep ITF outflow.

Fig. 3.4 shows vertical sections across two inflow passageways. In this figure, the mean vertical profiles, for the last ten years of the climatological run, the cross-section velocity, the potential temperature and the salinity are plotted for Makassar strait and Lifamatola passage. Across Makassar, as it was expected, the flow is southward in the whole strait and occurs in the upper $800 \mathrm{~m}$ depth. Two cores appear to be distinguished: the first one closer to surface, at $\sim 100 \mathrm{~m}$ depth, with mean along-section speed greater than 1.0 $\mathrm{m} / \mathrm{s}$; and the other, below the thermocline, at approximately $500 \mathrm{~m}$, showing a slower maximum speeds $\sim 0.2 \mathrm{~m} / \mathrm{s}$.

The vertical distribution of velocity in Lifamatola, however, is quite different. The graphic in Fig. 3.4 shows two different regimes: one in the upper $450 \mathrm{~m}$ depth and other between 450 and $2000 \mathrm{~m}$ below the surface. In the shallower part, it shows, for the western portion of the strait, an average surface northward flow, that reverses to southward, at $\approx 100 \mathrm{~m}$ depth, and turns back to the north between $\approx 200 \mathrm{~m}$ and $\approx 450 \mathrm{~m}$ 

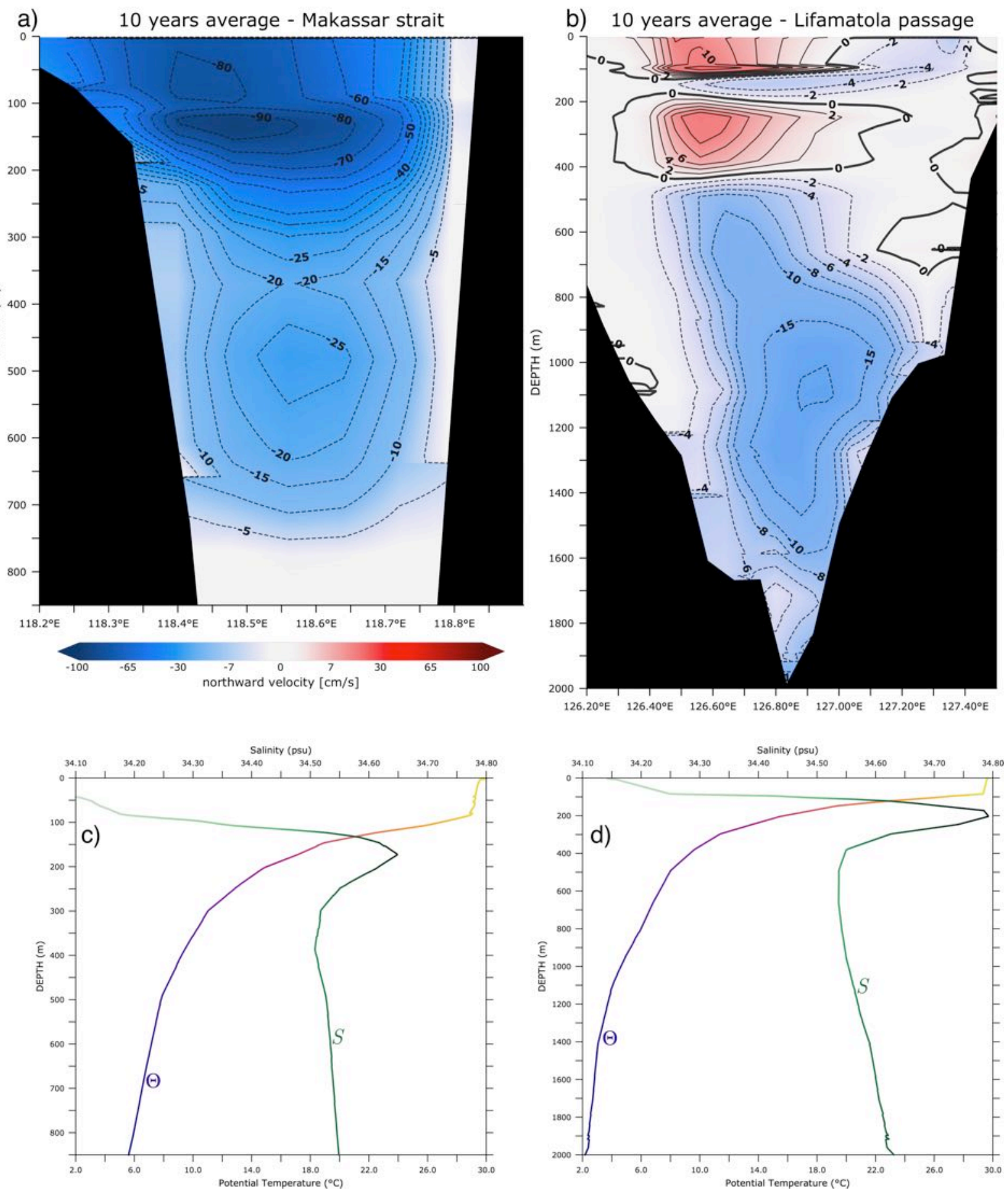

FIGURE 3.4 | Vertical Structure of major inflow passageway of ITF: Makassar strait (left) and Lifamatola passage (right). Current speed across the strait (meridional component) are showed in the graphs on top and Salinity and Potential Temperature stratification on bottom. Blue color intensities indicate a southward flow, while red ones denote a northward flow. In Makassar there is a continuous flux with two cores (above and below the thermocline) and it is not deeper than $800 \mathrm{~m}$. In Lifamatola, HYCOM is representing an alternating direct flux, where the deep flux presents a core $\approx 1100 \mathrm{~m}$ depth. The stratification patterns show Lifamatola subthermocline waters slightly more saline than ones in Makassar. This suggests origins in North Pacific for waters within Makassar and South Pacific for Lifamatola deep flow.

depth; but for the eastern portion, only a slower southward flow exists in the upper 200 $\mathrm{m}$ depth. Below $450 \mathrm{~m}$ depth, the flux is more intense, directed southward and extending 
to the bottom, with the core at $\approx 1100 \mathrm{~m}$.

These results concerning the circulation in Lifamatola appear to disagree to analyses obtained with INSTANT data. van Aken et al. (2009) observed a northward flow in the upper $1250 \mathrm{~m}$ depth, and the core of the deep southeastward current would be closer to the bottom, at $\approx 1900 \mathrm{~m}$ depth. However, there are two different approaches: here, in order to represent the Lifamatola passage, a zonal section at $1.78^{\circ} \mathrm{S}$ has been chosen, and the vertical profile of the cross-section current is just the meridional component of velocity; in (van Aken et al., 2009), authors used a different analysis, considering the effect of internal tides on the dynamic, thus, the vertical profile of the along-section flow assumes a more realistic current's component.

On the other hand, this representation of HYCOM for the throughflow structure along the Lifamatola seems to be closer to results achieved by Luick \& Cresswell (2001). As in INSTANT analyses, authors also used data of a single mooring located in Maluku Sea, and assuming a horizontally homogenous flow they found an average southward current between $740 \mathrm{~m}$ and $1500 \mathrm{~m}$ below the surface along the whole Lifamatola passage, estimating a total transport of $7 \mathrm{~Sv}$, very larger than the $2.5 \mathrm{~Sv}$ estimated by van Aken et al. (2009).

Nevertheless, the temperature and salinity stratification agree to the previous work for both inflow straits. In Lifamatola, a relatively more salinity water below the thermocline is observed, which corresponds to South Pacific subthermocline waters carried into Indonesian Seas by the South Equatorial current (van Aken et al, 2009; Mayer et al., 2010). Makassar inflow is mostly formed by North Pacific waters, coming from the North Equatorial current.

The same representation for Ombai strait and Timor passage is shown in Fig. 3.5. These are the outflow pathways where the deep waters from Lifamatola exit to the Indian Ocean. For both straits, a westward mean flow is observed, with two distinct cores along the water column. The shallower transports waters inflowing through 
a)
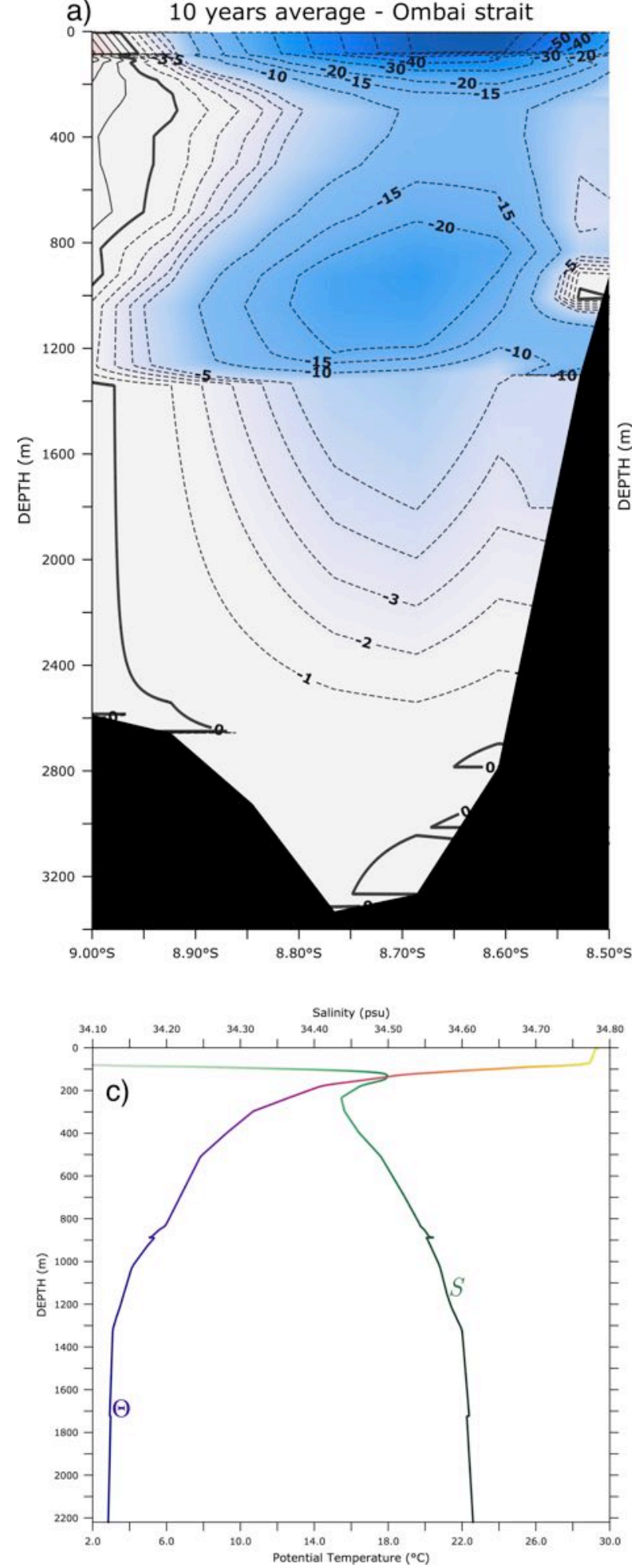

b) 10 years average - Timor passage
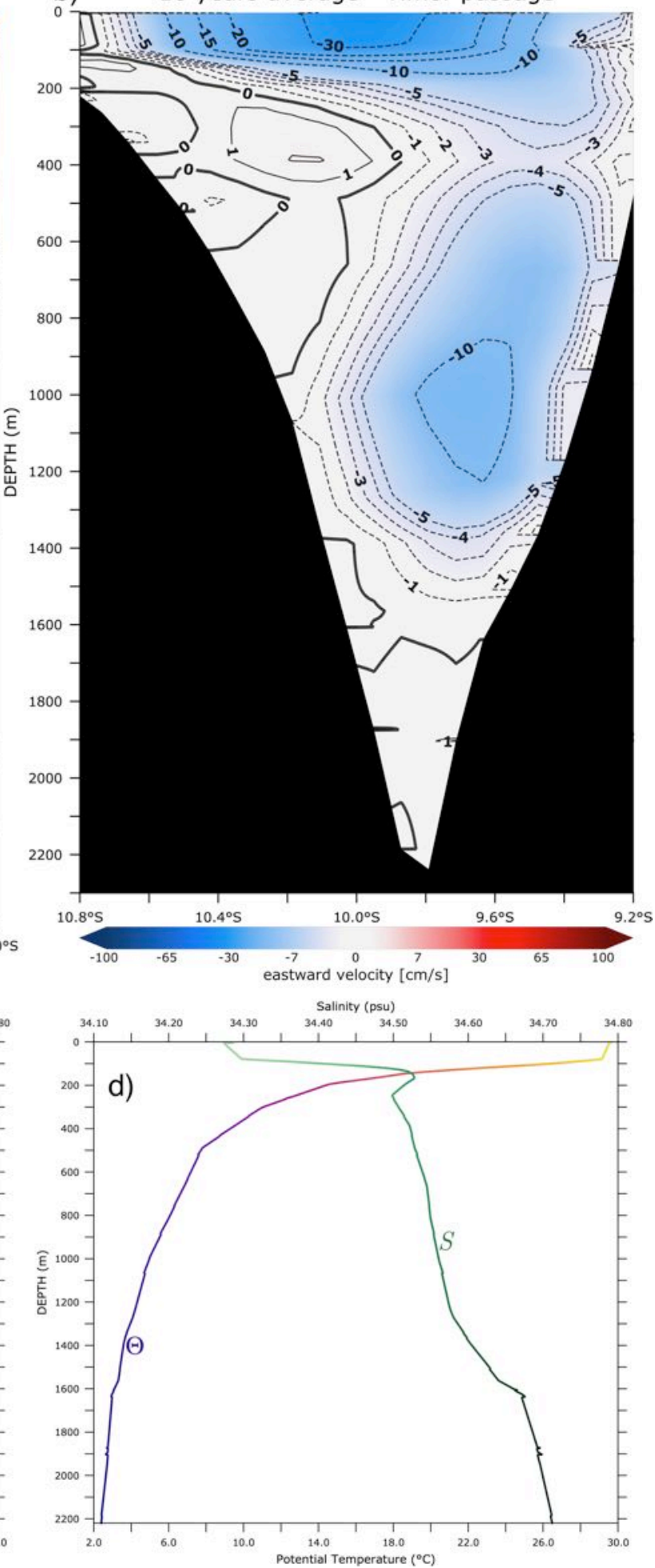

FIGURE 3.5 | Vertical structure of Ombai strait (left) and Timor passage (right) showing the flow across the straits (top) and the stratification profile (bottom). Blue intensities denote westward velocities and red ones means eastward velocities crossing the section. In both straits, the flow presents two cores, one above and other below thermocline, transporting waters which previously passed through Makassar and Lifamatola, respectively.

Makassar, at $\sim 50 \mathrm{~m}$ depth (above thermocline). The other, at approximately $1000 \mathrm{~m}$ depth in Ombai and $1100 \mathrm{~m}$ in Timor (below thermocline). In Timor, the deeper flow 
occurs between $400 \mathrm{~m}$ and $1600 \mathrm{~m}$ depths. In Ombai strait the flow seems to extend from $400 \mathrm{~m}$ below the surface down to the bottom in the middle of strait's width. These deeper cores are related to the deep water coming from Lifamatola. This agrees to direct estimates using INSTANT data (Sprintall et al., 2009). The stratification profiles show a relatively lesser saline waters passing through both straits if compared to those within Lifamatola. This is a good representation of the model concerning the role of ITF on changing the Pacific inflow waters before putting them into the Indian basin.

\subsection{VOLUME TRANSPORT IN THE UPPER $700 \mathrm{M}$}

To quantify the volume transported by ITF in Expt. 18.1, the upper $700 \mathrm{~m}$ data were considered. This depth allows to study variabilities related to air-sea interaction and anomalies that can be propagated under the thermocline.

\subsubsection{Methodology}

The volume transported by a geophysical flow crossing a vertical section, here also referred as vertically (or depth-) integrated volume transport, is:

$$
V_{T}=\iint_{A} \mathbf{v} \cdot \hat{\mathbf{n}}_{S} \mathrm{~d} A
$$

where $\mathbf{v}$ is the velocity vector; $u$ and $v$ are, respectively, the eastward and northward components of the velocity field; $A$ is the surface delimited by the section; $\hat{\mathbf{n}}_{\boldsymbol{S}}$ is the pointing vector normal to the surface $A ; x$ and $y$ are the eastward and the northward position components, respectively; and $z$ is the depth (see Appendix A).

For the meridional transport of volume across a vertical section along a fixed latitude $\theta_{s}$ (as for Karimata, Makassar, Moluccas, Lombok and Flores straits), from the free surface down to $700 \mathrm{~m}$ depth, using the grid discretization of the HYCOM GLBa0.08 and GLBu0.08, given by Eq. (2), (5), (6) and (7), the Eq. (8) can be written as (for latitudes to the south of $\left.47^{\circ} \mathrm{N}\right)$ : 


$$
\begin{aligned}
V_{T m}\left(i, j\left(\theta_{s}\right), k\right) & =\int_{z=0}^{z=700} \int_{x=x_{W}}^{x=x_{E}} v \mathrm{~d} x \mathrm{~d} z \approx \\
& \approx\left|i\left(x_{E}\right)-i\left(x_{W}\right)\right|(1 / 12)^{\circ} \cdot \frac{\pi R_{E}}{180^{\circ}} \cos \theta_{s} \sum_{k(z=0)}^{k(z=700)} \sum_{i\left(x_{W}\right)}^{i\left(x_{E}\right)} \frac{\delta v_{i, j\left(\theta_{s}\right), k}}{2} \delta z_{k}
\end{aligned}
$$

where $x_{E}$ and $x_{W}$ are the east and west limit of the section; $R_{E}$ is the mean radius of the Earth;

$$
\delta z_{k}=z_{k}-z_{k-1}
$$

is the vertical thickness of the grid element; and

$$
\frac{\delta v_{i, j, k}}{2}=\frac{1}{2}\left(v_{i, j, k}-v_{i, j, k-1}\right)
$$

is the mean northward velocity along the vertical direction of the grid element. The transport $V_{T m}$ is a scalar value, and it is positive for a northward flow and negative for a southward flow.

The zonal transport of volume across a vertical section along a fixed longitude $\lambda_{s}$ (as considered for Ombai and Timor straits), from the surface down to $700 \mathrm{~m}$ depth, using the grid discretization of HYCOM GLBa0.08 and GLBu0.08, given by Eq. (3), (5), (6) and (7), the Eq. (8) can be written as (for latitudes to the south of $47^{\circ} \mathrm{N}$ ):

$$
\begin{aligned}
V_{T z}\left(i\left(\lambda_{s}\right), j, k\right) & =\int_{z=0}^{z=700} \int_{y=y_{S}}^{y=y_{N}} u \mathrm{~d} y \mathrm{~d} z \approx \\
& \approx\left|j\left(y_{N}\right)-j\left(y_{S}\right)\right|(1 / 12)^{\circ} \cdot \frac{\pi R_{E}}{180^{\circ}} \sum_{k(z=0)}^{k(z=700)} \sum_{j\left(y_{s}\right)}^{j\left(y_{N}\right)} \frac{\delta u_{i\left(\lambda_{s}\right), j, k}}{2} \cos \theta_{i\left(\lambda_{s}\right), j} \delta z_{k}
\end{aligned}
$$

where $y_{N}$ and $y_{S}$ are the north and south limits of the section, respectively, and

$$
\frac{\delta u_{i, j, k}}{2}=\frac{1}{2}\left(u_{i, j, k}-u_{i, j, k-1}\right)
$$

is the mean eastward velocity along the vertical direction of the grid element. $V_{T z}$ is positive for an eastward flow, but negative for a westward flow.

\subsubsection{Expt. 18.1 - Climatological Run}

In the ITF region winds are strongly driven by a monsoon system, which forces seasonal variability of ITF. To illustrate the wind pattern along the climatological year 
and the seasonal variability in the volume transport of the ITF, using data of the climatological run and the wind field from NCEP data used as forcing, Fig. 3.6 shows maps for each typical (climatologically averaged) month of the upper $700 \mathrm{~m}$ depthintegrated transport per grid element area (in $\mathrm{Sv} / \mathrm{m}^{2}$ ). That is given by:

$$
\begin{aligned}
\frac{V_{T}(i, j, k)}{A(i j k)} & =\frac{1}{A}\left(\int_{z=0}^{z=700} \iint_{x, y}(u \hat{\boldsymbol{x}}+v \hat{\boldsymbol{y}}) \cdot(\hat{\boldsymbol{x}} \mathrm{d} y+\hat{\boldsymbol{y}} \mathrm{d} x) \mathrm{d} z\right) \approx \\
& \approx \frac{1}{\delta x_{i, j} \delta y_{i, j}}\left(\sum_{k(z=0)}^{k(z=700)} \frac{\delta u_{i, j, k}}{2} \delta y_{i, j} \delta z_{k}+\sum_{k(z=0)}^{k(z=700)} \frac{\delta v_{i, j, k}}{2} \delta x_{i, j} \delta z_{k}\right)
\end{aligned}
$$
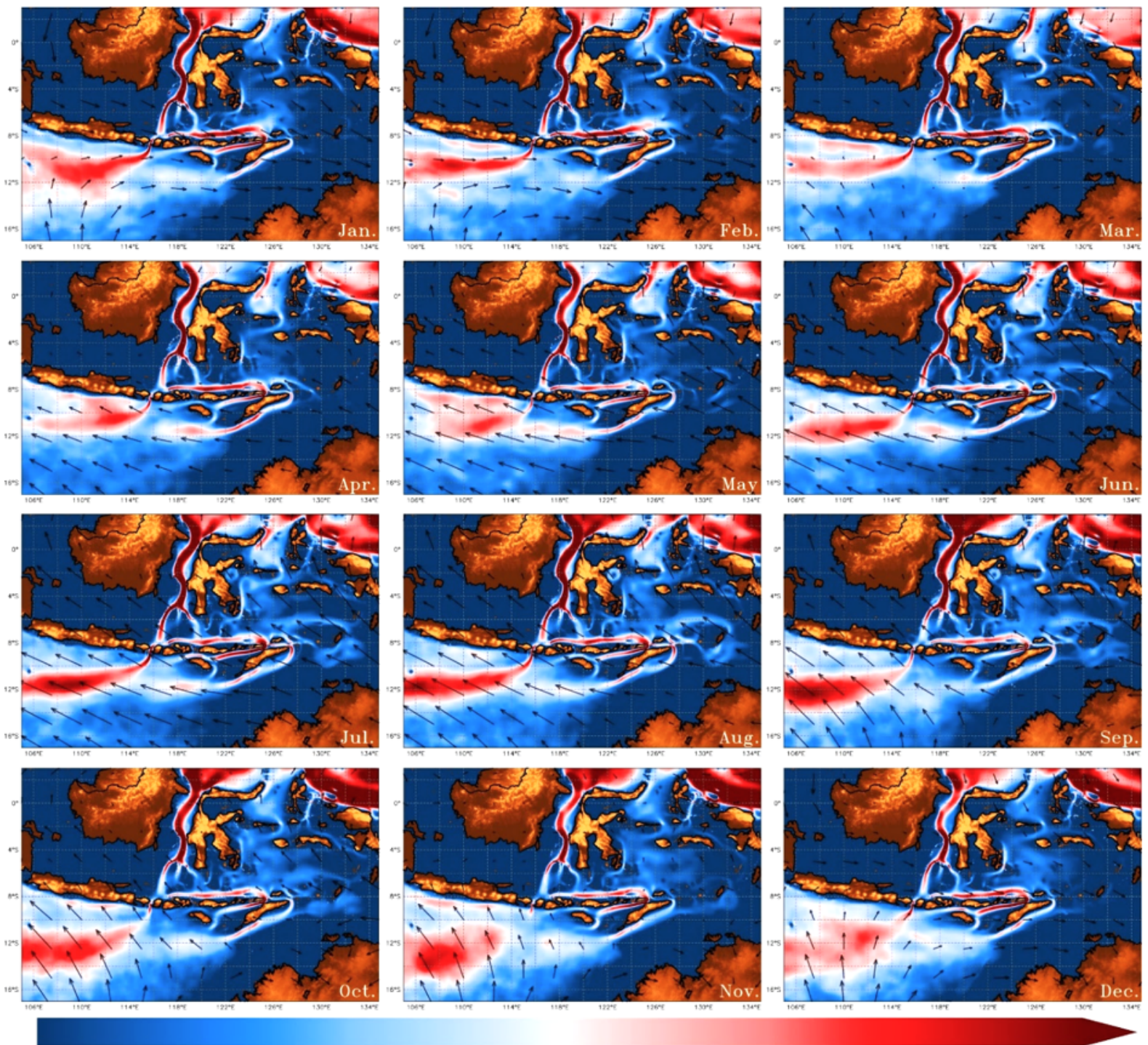

$\begin{array}{llllllllllllll}0.00 & 3.95 & 4.95 & 5.95 & 6.95 & 7.95 & 8.95 & 9.95 & 10.95 & 11.95 & 12.95 & 13.95 & 14.95 & 15.95\end{array}$

FIGURE 3.6 | Maps of the upper $700 \mathrm{~m}$ depth-integrated transport. Values are shown for each single grid point, where blue colors denote lower values of transport and red higher. Units are given in $10^{-9} \mathrm{~Sv} / \mathrm{m}^{2}$ (in a $0.08^{\circ}$ horizontal grid). Arrows represent the wind field. Name of the months are abbreviated in the bottom right corner of each map. The change in wind direction along the year is due to a monsoon pattern that drives winds in the ITF region. As it can be seen in the Figure, this drives seasonal variability of the ITF transports, and consequently in the amount of waters exchange from Pacific to the Indian Ocean. 
The graphs reveal the change of wind directions over the climatological year and the answer of the transport in the upper ocean in the spatial domain of ITF. Stronger transports occur during the southeast monsoon, from June to September, when winds blow in the same direction of the outflow and in the opposite direction of the inflow path. Otherwise, during the northwest monsoon, the surface transport relaxes, the wind over the IO blows in opposite direction of the outflow, but in the same direction of the inflow fluxes over the Indonesian seas. This strong seasonal variability has been also observed in INSTANT data (Sprintall et al., 2009).

To estimate the volume transported by ITF, cross-section fluxes in Karimata, Makassar and Moluccas straits were used to quantify the total inflow volume transported in the upper $700 \mathrm{~m}$ depth. Transports across Lombok, Flores, Ombai and Timor straits together give the total outflow. Fig. 3.7 shows the typical year (climatology-month averaged) for the Climatological Run the ITF's inflow and outflow volume transports in the upper $700 \mathrm{~m}$ depth.

It can be seen the seasonal variability of the ITF and the reverse behavior of outflow vs inflow change along the year: while February is typically the month when there is the lowest outflow transport (negative values), is also the highest mean value for

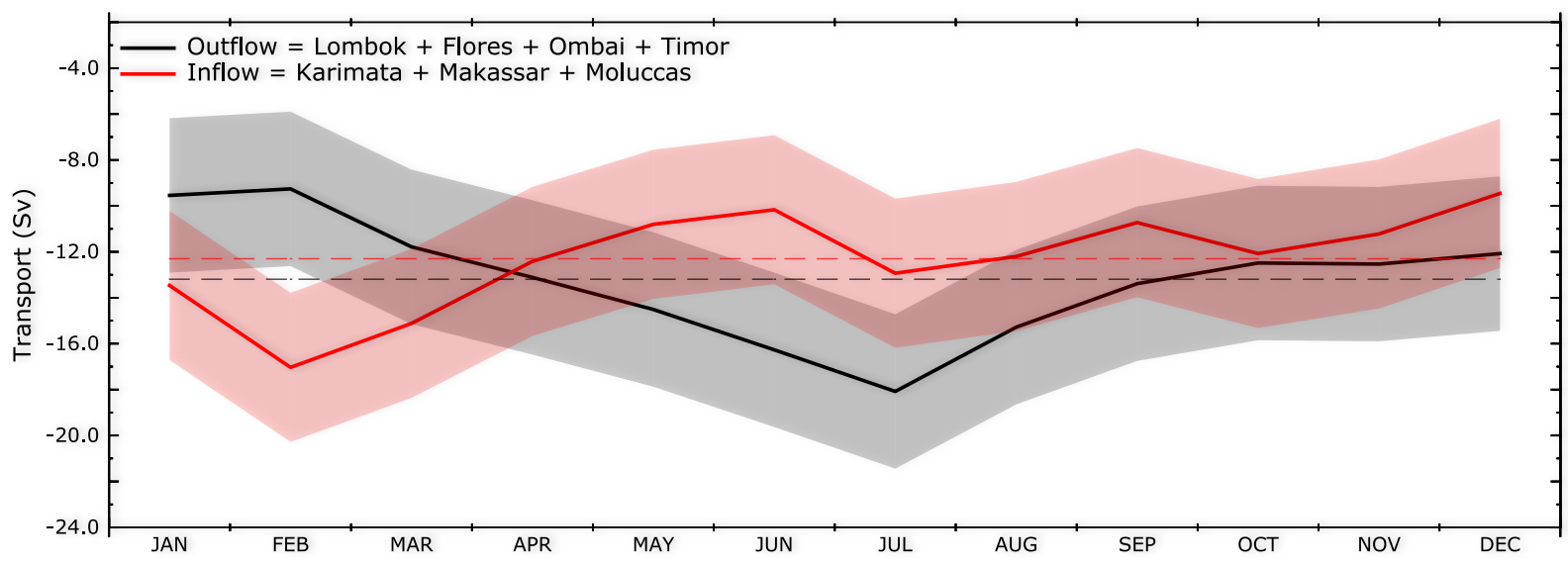

FIGURE 3.7 | Inflow (red) and outflow (black) volume transport in the upper $700 \mathrm{~m}$ depth for the Climatological Run. The envelopes represent standard errors based on the definition of each curve as being the sum of transports in individual straits. Negative values indicate transports southward or westward. Dashed lines are the mean annual value for inflow (red) and outflow (black). Superficial ITF transports presents a high seasonal variability that is driven mostly by the monsoon winds pattern, in a reverse mode increase/decrease for inflow/outflow along the year. 
the inflow transport. The mean annual value for outflow transport has been estimated in $12.3 \mathrm{~Sv}$, and for the outflow, $13.2 \mathrm{~Sv}$. The $0.9 \mathrm{~Sv}$ imbalance is proportional to the standard deviation of values.

\subsubsection{Expt. 18.3 - Interannual Forcing Run}

Outflow and inflow transports are computed as the sum of the individual transports across each strait that forms the respective pathway. Time series showing the amount of Pacific waters which transported to the Indian Ocean basin in the upper 700 m, from 1970 to 2015, smoothed every four months, are given in Fig. 3.8. The plots show the behavior of surface ITF's volume transport across Timor, Ombai, Lombok and Flores straits and the total outflow. The mean outflow for the entire period has been estimated in $14 \mathrm{~Sv}$. Also, a trend of increasing $0.04 \mathrm{~Sv} /$ year has been found.

As proposed by Fyfe et al. (2016), the present work considers the hiatus for the
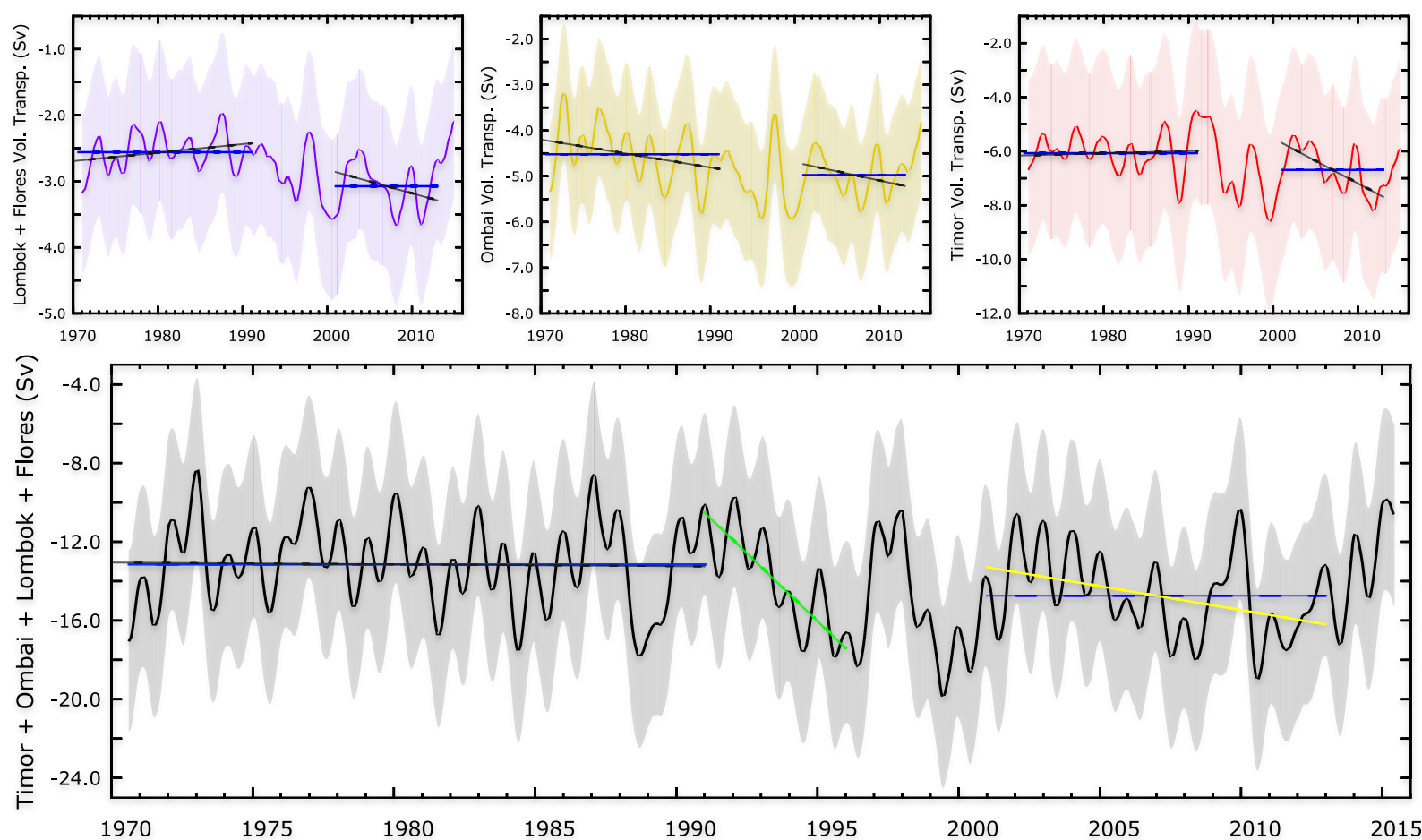

FIGURE 3.8 | The ITF's outflow volume transport in the upper $700 \mathrm{~m}$ from 1970 to 2015. Individual time series is shown for transport across Lombok+Flores straits (top-left), Ombai (top-middle) and Timor (topright), and for total transport (bottom). Plot data were smoothed every four months. Blue dashed lines indicate the mean transport in each region and the red lines is the linear fit. 3 periods: the base historical period (1970-1990); the "accelerated warming" (1991-2000) where, between 1991 and 1995 there was a systematic increase in the transport with trend 1.4 Sv/year; and the "slowdown warming" (1991-2000) where ITF also presented an increasing transport of volume 
years between 2001 and 2012. A base historical period is taken between 1970 and 1990, and an additional period between 1991 and 2000 is also considered. For this middle period, a strong term increasing the transport of volume of ITF was found, specially between 1991 and 1995. A discussion about possible effects will be given in Section 3.4.2.

As discussed in Introduction, the ITF is influenced by different modes of variability, in different timescales. The ENSO is an important global climate variability mode that affects the ITF. To measure this relation, output data of the Interannual Forcing Run was used to compute mean values of volume transport across all straits during different ENSO events.

To assess the impact of ENSO, the monthly surface ITF transport across each of the three main inflow regions (Fig. 3.9) and the four main outflow straits (Fig. 3.10). The graphics show the transports considering mean values in all years of the time series, mean values taken only during five El Niño events and five La Niña events. For El Niño, the 1972/73 (strong), 1982/83 (very strong), 1991/92 (moderate), 1997/98 (very strong) and 2014/15 (very strong) events have been considered. And for La Niña, the 1973/74 (strong), 1975/76 (strong), 1988/89 (strong), 1999/2000 (moderate), and 2010/11 (moderate) have been also considered.

Figs. 3.9 and 3.10 show, in a general line, that transports are larger during La Niña and smaller during El Niño events. For the inflow straits, Moluccas shows larger transport for both El Niño and La Niña. Previous work (van Sebille et al., 2014; Valsala et al., 2011), have obtained comparable results, but reporting a smaller transport along Moluccas section during La Niña events, in an opposite behavior with Makassar. However, in this work only the superficial transports are being considered. In Makassar strait the mean transport in all years is $12.4 \mathrm{~Sv}$, for La Niña years is $13.5 \mathrm{~Sv}$ and only 10.9 for El Niño ones.

For the outflow straits, as expected, a larger transport for La Niña events occurs in all straits. Lombok presents a mean transport value for all years of $\sim 2.5 \mathrm{~Sv}$, and it 
increases to $3.0 \mathrm{~Sv}$ for La Niña years and decrease to 2.0 for El Niño. In Timor, the values are 6.4 Sv (all years), 7.4 Sv (La Niña) and 5.5 (El Niño). In Ombai, 4.7 Sv (all years), 5.4 Sv (La Niña) and 3.9 Sv (El Niño).
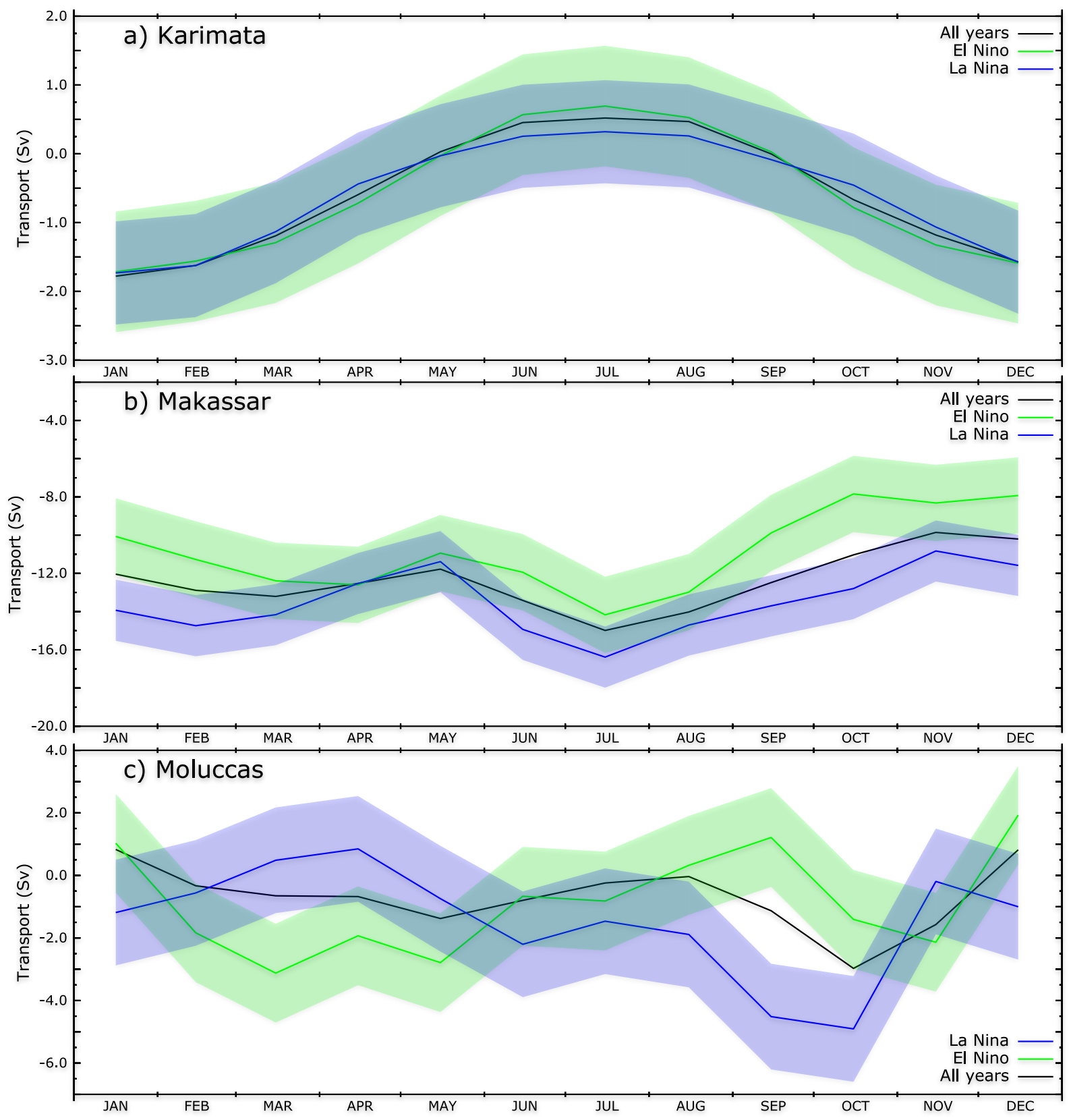

FIGURE 3.9 | Monthly mean volume transport in the upper $700 \mathrm{~m}$ across the major three inflow straits, considering five different El Niño (green) and La Niña (blue) events, in comparison with the mean values for all years (black line). Largest values are obtained during La Niña events and smallest during El Niño. The envelopes represent the standard error.

A summary of the analysis for the transport of volume across the ITF represented in both Expt. 18.1 (Climatological Run) and Expt. 18.3 (Interannual Run), performed by LABMON, in comparison to the expected values measured in observations 

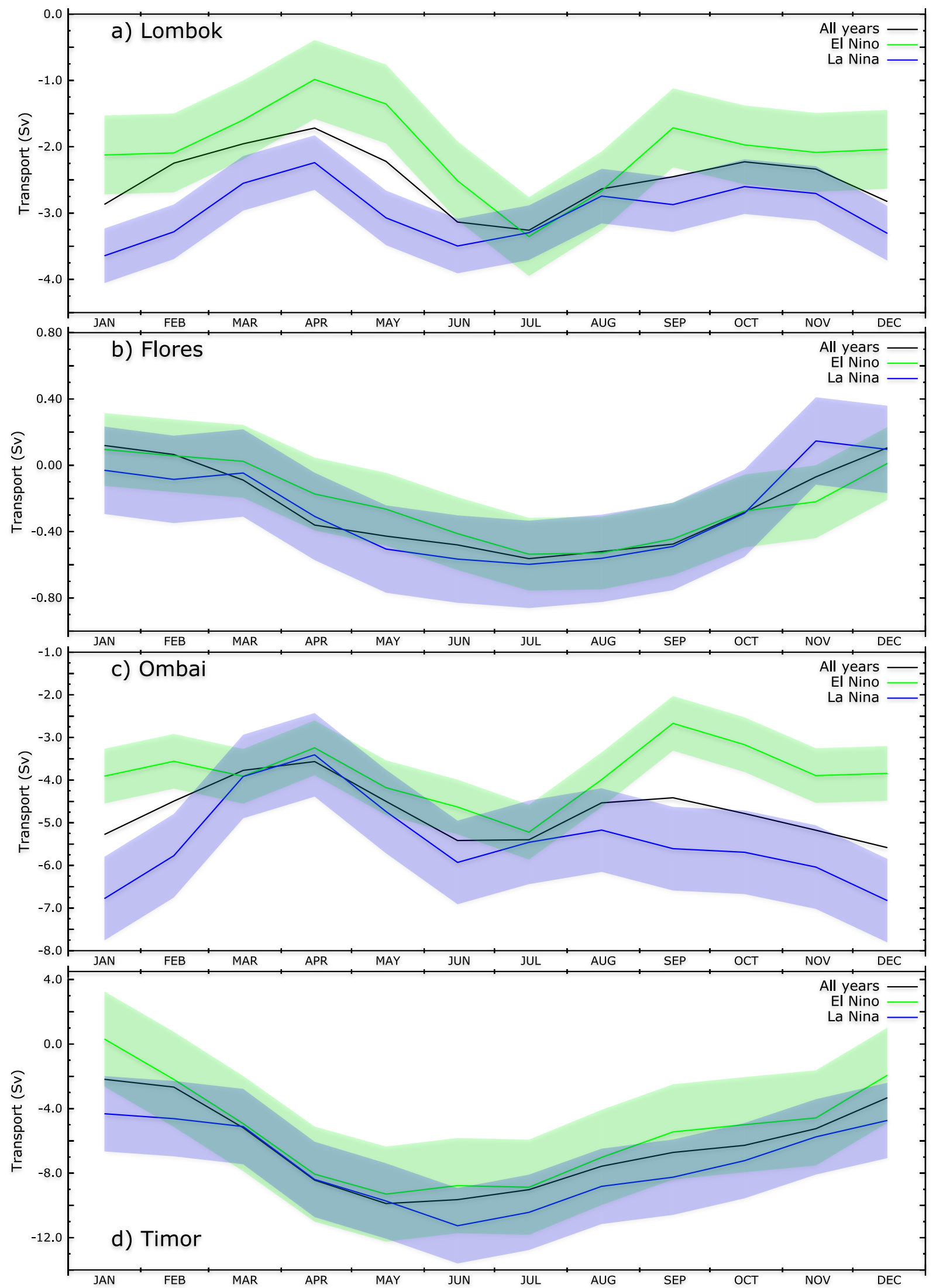

FIGURE 3.10 Monthly mean volume transport in the upper $700 \mathrm{~m}$ across the major four outflow straits, considering five different El Niño (green) and La Niña (blue) events, in comparison with the mean values for all years (black line). Largest values are obtained during La Niña events and smallest during El Niño. The envelopes represent the standard error. 
by the INSTANT expedition is shown in the Table 3.1. The table brings estimative values for the volume transport across each of the most important passages and straits that compound the inflow and outflow. Values in the two columns on the right should be compared with the behavior expected by the ITF as shown in the graphs of Figs. 3.9 and 3.10 .

TABLE 3-1 | Comparative values of volume transports evaluated across the inflow and outflow straits of the ITF, obtained via in situ measurements (Instant program) and with both HYCOM runs performed by LABMON. It also shows the mean transports evaluated only during years of El Niño and La Niña events, using the output of the Interannual forcing HYCOM run.

\begin{tabular}{|l|c|c|c|c|c|}
\hline $\begin{array}{l}\text { Values in Sv } \\
\left(\mathbf{1 S v}=1 \mathbf{m}^{\mathbf{3}} \mathbf{s}\right)\end{array}$ & $\begin{array}{c}\text { INSTANT* } \\
\text { (2004-2006) }\end{array}$ & $\begin{array}{c}\text { Climatological } \\
\text { (10 last years) }\end{array}$ & $\begin{array}{c}\text { Interannual } \\
\text { (all years) }\end{array}$ & $\begin{array}{c}\text { Interannual } \\
\text { (El Niño years) }\end{array}$ & $\begin{array}{c}\text { Interannual } \\
\text { (La Niña years) }\end{array}$ \\
\hline Karimata & ----- & $-0.6 \pm 0.8$ & $-0.6 \pm 0.9$ & $-0.6 \pm 0.2$ & $-0.6 \pm 0.2$ \\
\hline Makassar & -11.6 & $-12.3 \pm 3$ & $-12.4 \pm 3$ & $-10.9 \pm 2$ & $-13.5 \pm 2$ \\
\hline Moluccas & -1.1 & $+0.5 \pm 2$ & $-0.7 \pm 3$ & $-0.8 \pm 2$ & $-1.4 \pm 2$ \\
\hline Total Inflow & -12.7 & $-12.3 \pm 3$ & $-13.6 \pm 4$ & $-12.3 \pm 3$ & $-15.5 \pm 2$ \\
\hline Lombok & -2.6 & $-2.9 \pm 0.8$ & $-2.5 \pm 1$ & $-2.0 \pm 0.4$ & $-3.0 \pm 0.6$ \\
\hline Flores & ------ & $-0.2 \pm 0.3$ & $-0.2 \pm 0.3$ & $-0.2 \pm 0.2$ & $-0.3 \pm 0.3$ \\
\hline Ombai & -4.9 & $-4.5 \pm 1$ & $-4.7 \pm 1$ & $-3.8 \pm 0.6$ & $-5.4 \pm 1$ \\
\hline Timor & -7.5 & $-5.6 \pm 2$ & $-6.4 \pm 3$ & $-5.5 \pm 3$ & $-7.4 \pm 2$ \\
\hline Total Outflow & -15.0 & $-13.2 \pm 3$ & $-13.9 \pm 5$ & $-11.6 \pm 4$ & $-16.1 \pm 3$ \\
\hline
\end{tabular}

* INSTANT estimated ITF's transport full-depth integrated (Gordon et al., 2010)

Despite the fact we considered here only the transport in the first $700 \mathrm{~m}$ while INSTANT estimated it full-depth, the comparison is still valid once the flows are mainly concentrated close to the surface. Thus, it can be seen the HYCOM runs satisfactorily represent the ITF flows. In addition, Table 3-1 also shows mean values of volume transport across the same passages evaluated only during years when significant ENSO events occurred; and, as expected, the volume of water changed from the Pacific Ocean to the Indian Ocean are in average smaller during an El Niño and expressively larger for a year when a La Niña phase is being experienced. 


\subsubsection{Expt. 19.1 - HYCOM GLBu0.08 by NRL}

To validate the output of the Expt. 19.1 with HYCOM, by NRL, in the interest area of this work, the map in the Fig. 3.14 shows the surface speed for a snapshot considering this run.

The transport of volume in the ITF outflow were also evaluated for the three last years of the timeseries, and a mean value of $16 \mathrm{~Sv}$ for the vertically integrated transport in the upper $700 \mathrm{~m}$ was found, in accordance with the results discussed in Sections 3.4 and 3.5.

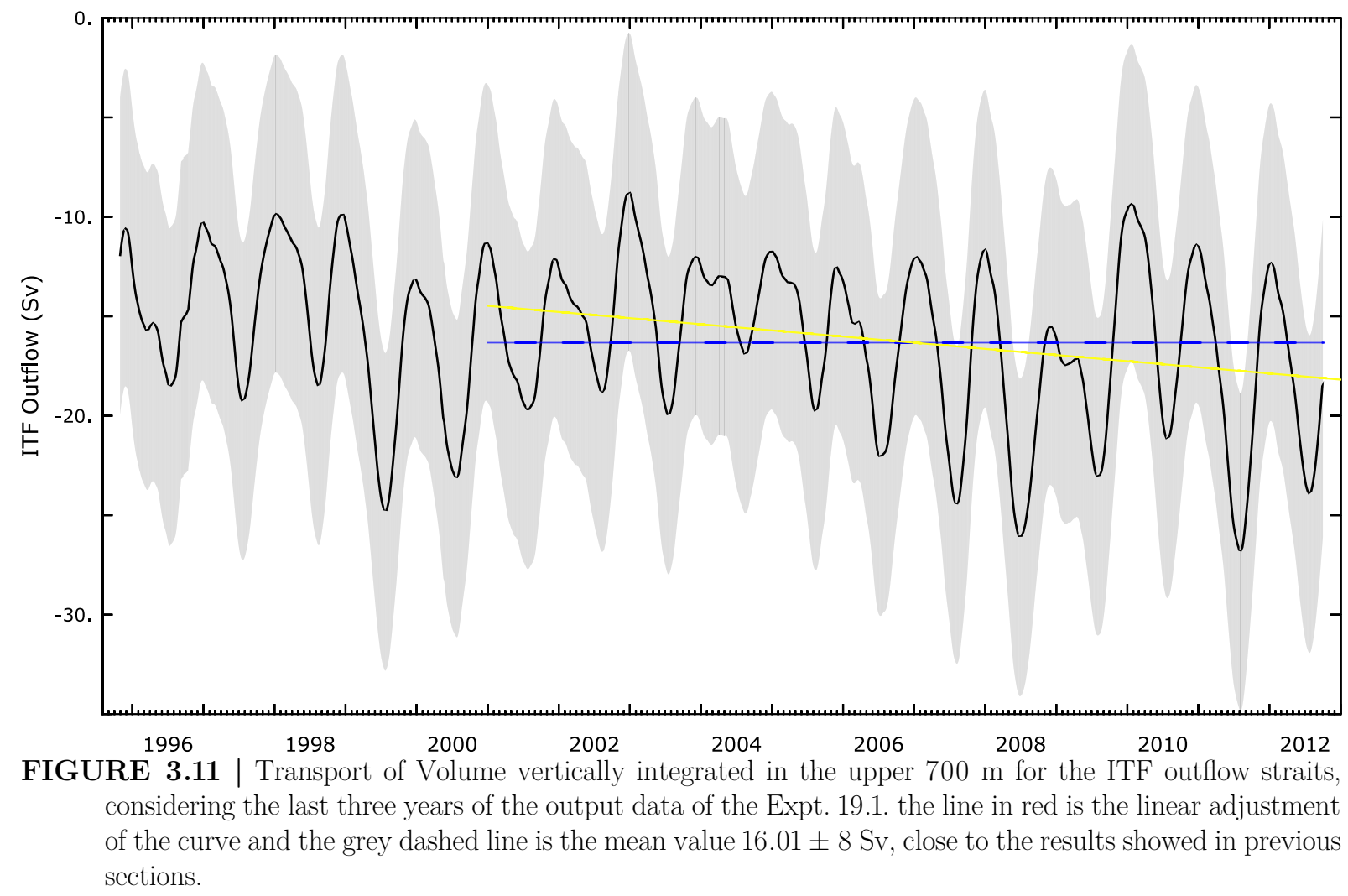

A linear trend for the entire timeseries was of increasing $0.008 \mathrm{~Sv} /$ year. But, considering only the hiatus period, from 2001 to 2012 , a trend of increasing $0.013 \mathrm{~Sv} /$ year is observed, revealing a response of ITF to the event. 


\subsection{HeAt TRANSPORT IN THE UPPER $700 \mathrm{M}$}

\subsubsection{Methodology}

The heat transported by a geophysical flow whose heat budget obeys to a closure relation can be given in terms of the transport of its Internal Energy (Vranes et al., 2002; England \& Huang, 2005; Tillinger \& Gordon, 2010):

$$
H_{T}=\iint_{A} \rho c_{p}\left(\Theta-\Theta_{R}\right) \mathbf{v} \cdot \hat{\mathbf{n}}_{S} \mathrm{~d} A
$$

where $\rho$ is the density of water; $c_{p}$ is the specific heat at constant pressure; $\Theta$ is the potential temperature and $\Theta_{R}$ is the referential potential temperature evaluated at an arbitrary section where the transport is zero for that flow.

Usually, $\Theta_{R} \sim 3{ }^{\circ} \mathrm{C}$ is used for ITF, when the referential section is considered from the southern Australia to Antarctica. But, once this work is concerned about relative values of transport between different years, for simplification, the referential temperature will be considered as

$$
\Theta_{R}=0.0{ }^{\circ} \mathrm{C}
$$

For the Indonesian Throughflow, the meridional (southward) transport of heat for the upper $700 \mathrm{~m}$ across a vertical section of latitude $\theta_{s}=\theta_{s}\left(y_{s}\right)$ will be (see Appendix A):

$$
H_{T m}\left(x, y_{s}, z\right)=-c_{p} \int_{z=0}^{z=700} \int_{x=x_{W}}^{x=x_{E}} \rho\left(x, y_{s}, z\right) \Theta\left(x, y_{s}, z\right) v\left(x, y_{s}, z\right) \mathrm{d} x \mathrm{~d} z
$$

where the minus (-) signal on the left is to denotate a positive Heat Transport southward. The specific heat of water is considered constant, equal to:

$$
c_{p}=3993.0 \frac{\mathrm{J}}{\mathrm{kg} \cdot{ }^{\circ} \mathrm{C}}
$$

For a vertical section at longitude $\lambda_{s}=\lambda_{s}\left(x_{s}\right)$, the upper $700 \mathrm{~m}$ depth integrated heat transport from ITF westward is:

$$
H_{T z}\left(x_{s}, y, z\right)=-c_{p} \int_{z=0}^{z=700} \int_{y=y_{S}}^{y=y_{N}} \rho\left(x_{s}, y, z\right) \Theta\left(x_{s}, y, z\right) u\left(x_{s}, y, z\right) \mathrm{d} y \mathrm{~d} z
$$




\subsubsection{Expt. 18.3 - Interannual Forcing Run}

Once the ITF is a relevant part of the global MOC, the amount of energy that it transports into the Indian Ocean is particularly important in the maintenance of the global climate and heat distribution around the planet. Fig. 3.11 shows the time series for the heat transport estimated as the sum of the heat transport across each outflow strait. The mean value was estimated in $1.20 \mathrm{PW}\left(1 \mathrm{PW}=10^{15} \mathrm{~W}\right)$, and a linear longterm trend of increasing $0.005 \mathrm{PW} /$ year. Interannual variabilities on the heat transport are also related to ENSO and IOD.

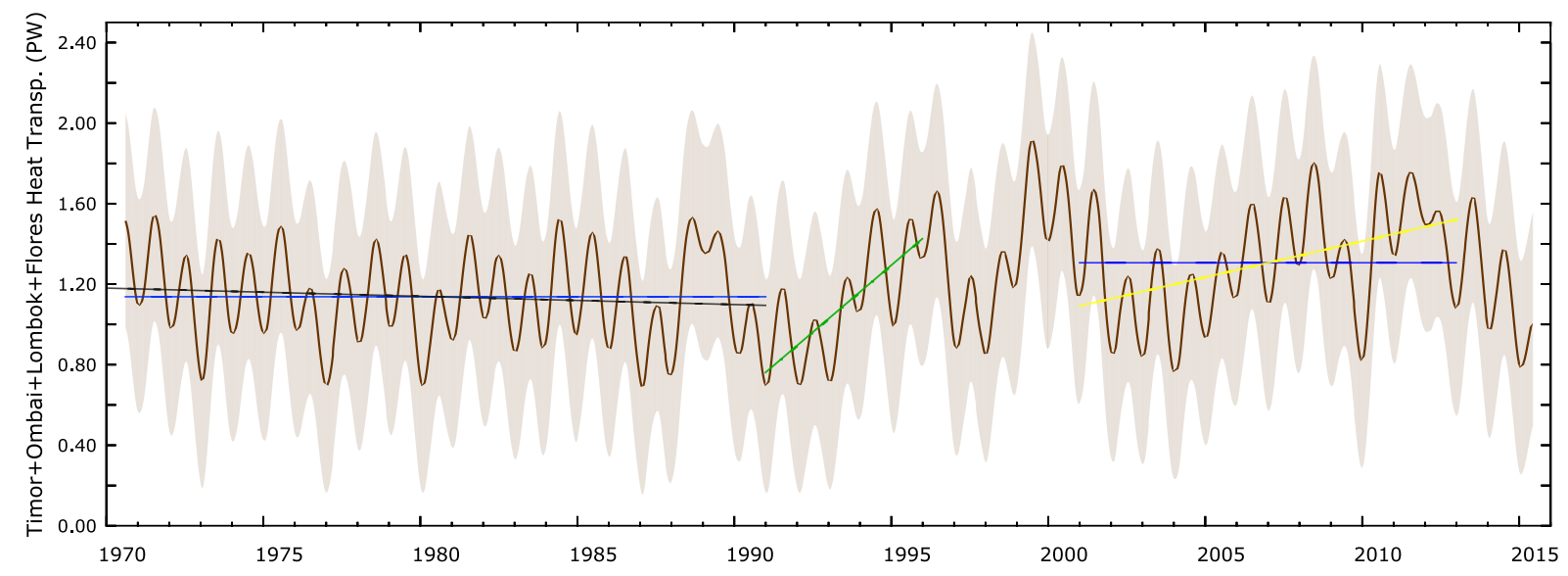

FIGURE 3.12 | ITF heat transport in the upper $700 \mathrm{~m}$ estimated across the outflow straits from 1970 to 2015, smoothed every four months. The envelopes denote the standard error. Blue dash line is the mean value and the red line is the linear fit of the curve. As for the volume transport, the ITF's heat transport also presents a strong interannual and seasonal variability. MEAN total $=-1.20 \mathrm{PW} \mid$ mean1 $=-1.14 \mathrm{PW}$ $\mid$ trend1 $=+0.004 \mathrm{PW} /$ year $\mid$ mean2 $=-1.32 \pm 0.5 \mathrm{PW} \mid$ trend $2=-0.01 \mathrm{PW} /$ year $\mid$ trend_green $=-0.10$ $\mathrm{PW} /$ year

Lee et al. (2015) showed that the abrupt increase in Indian Ocean heat content in recent years has an origin in anomalies within the Pacific Ocean. These anomalies could be transported into the Indian Ocean via the ITF. For the same period considered by authors, which also has been observed the global warming hiatus phenomenon, we also analyzed the ITF heat transport with HYCOM data. Considering the mean value of -1.2 PW, acquired in the whole time series, the anomaly on heat transport for the years between 2002 and 2012 were studied. Fig. 3.12 presents this curve. In this particular period, the increase in the heat transported from Pacific to Indian Ocean was much larger than the small trend in the entire series. From 2002 to 2012, around 0.05 PW was added annually to the ITF heat transport in the upper $700 \mathrm{~m}$. This result emphasizes that the 
abrupt increase of the heat content within Indian Ocean has originated in Pacific Ocean and has been transported from a basin to other via the Indonesian Throughflow, since it also shows an abrupt increase for the period on the outflow heat transport.

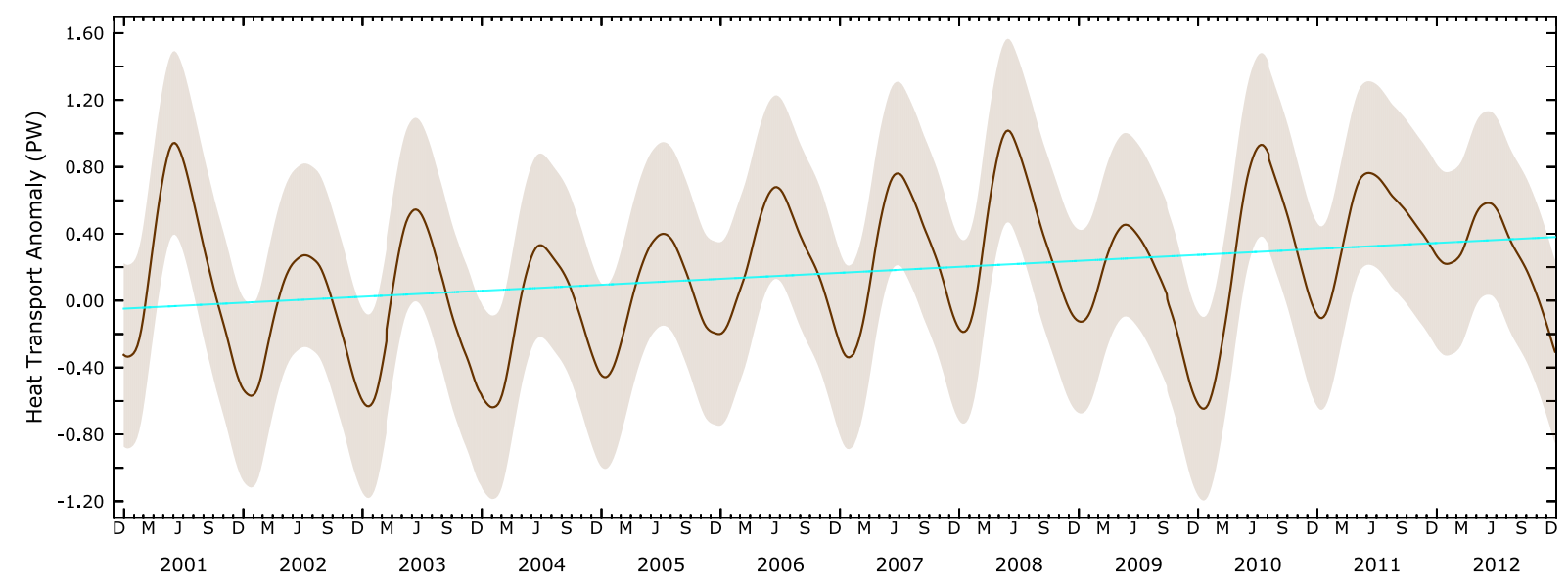

FIGURE 3.13 | ITF's heat transport anomaly from 2002 to 2012, bi-monthly smoothed. The anomaly was calculated considering the mean value for the entire time series, and the transports are estimated across the outflow straits. Envelopes are the standard errors. Red line is the fit linear of the points plotted. A large linear increasing trend of the ITF's heat transport was observed at this period.

However, this behavior is not verified for the last years of the time series of the model run. In fact, 2014/2015 were years related to a very strong El Niño event, and in such situation, a smaller value for the transport across the ITF should be expected. Fig. 3.13 shows the ITF heat transport anomaly from June/2013 to December/2015, and in the same graph is also plotted the Nino3.4 Index anomaly, as provided from the NOAA dataset (Rayner, 2003). Both curves variate in a similar way for these years: as the Nino3.4 increase, the ITF heat transport decrease (negative values). This represents a strong response of the ITF to the 2014/15 and 2015/16 El Niño events, and suggests possible relations with current anomalies on the heat content within the Indo-Pacific Ocean and possibly with climate change.

Table 3-2 shows the mean values of the heat transport by ITF over 4 different periods and their respective linear trends. Revealing, as the graph of Fig. 3.13, that ITF is becoming stronger since the beginning of the 1990's decade. During the hiatus, however, this increase of the ITF also happened but with a slower trend. 


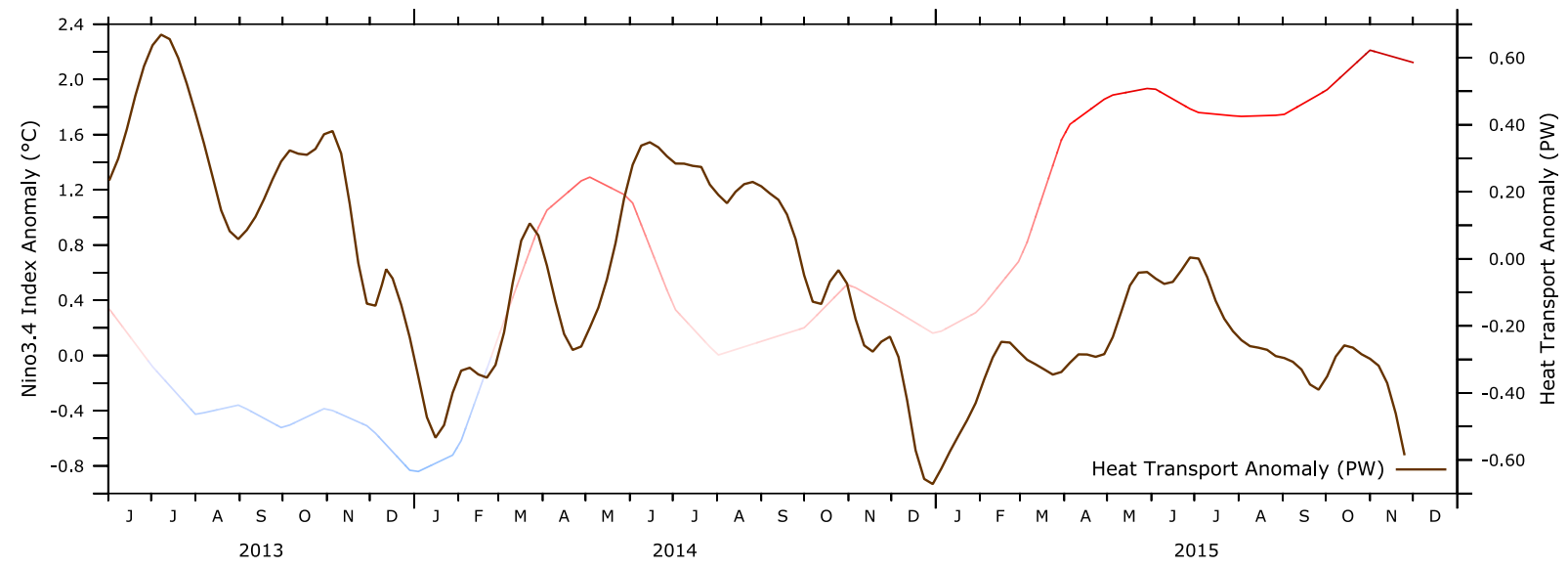

FIGURE 3.14 | ITF's heat transport anomaly from 2013 to 2015 (brown line) and Nino3.4 Index anomaly (colored blue-red line). Unlike the previous period, the last two years of time series show a strong decrease in the heat transport, following the increase of Nino3.4 index, in accordance to what is expected from the ITF along ENSO event years.

TABLE 3-2 Lean values and linear trends of heat transport for different periods.

\begin{tabular}{|c|c|c|}
\hline years & $\begin{array}{c}\text { Period mean } \\
\text { (PW) }\end{array}$ & $\begin{array}{c}\text { Linear trend } \\
\text { (PW/year) }\end{array}$ \\
\hline $1971-1990$ & $1.14 \pm 0.5$ & 0.00 \\
\hline $1991-1995$ & $1.09 \pm 0.5$ & 0.13 \\
\hline $2001-2012$ & $1.31 \pm 0.5$ & 0.04 \\
\hline $2013-2015$ & $1.27 \pm 0.5$ & -0.16 \\
\hline
\end{tabular}

That suggests ITF changes can also be related to other factors, as a longer effect of the volcanic activity of Pinatubo, in 1991, and the new Modoki kind of ENSO events that have driven the variability mode since this time (Shinoda et al., 2012). 


\section{4 | LAGRANGIAN ANALYSIS}

The present work is part of the research project Impact of the Southern Atlantic on the global overturning circulation (MOC) and climate (SAMOC), the Brazilian contribution for The South Atlantic Meridional Overturning Circulation (SAMOC) Initiative (find out more at: https://bv.fapesp.br/en/auxilios/46145/impact-of-thesouthern-atlantic-on-the-global-overturning-circulation-moc-and-climate-samoc/ and http://www.aoml.noaa.gov/phod/SAMOC_international/index.php), whose objectives is to study and promote observations and numerical modelling experiments to monitor the South Atlantic Circulation.

A particular meridional line has been used for that purpose: the $34.5^{\circ} \mathrm{S}$, known as SAMOC Basin-wide Array (SAMBA), that connects the South American continent to the further south point of the African continent and reveals lots of information about the circulation. From the surface to the sea floor of this line, there is the transit of many water masses of great importance to the global circulation (including cores of the North Atlantic Deep Water and of the Antarctic Bottom Water). Also, important currents cross that line: in the upper layers, for example, the Agulhas leakage can be found on the east portion of the line and the Brazil Current on the west, part of the South Atlantic Subtropical Gyre.

Output data from the Expt. 18.3 (Interannual Forcing Run - HYCOM GLBa0.08 by LABMON) and the Expt. 19.1 (HYCOM GLBu0.08 by NRL) were used for a set of Lagrangian Analyses employing PARCELS and CMS algorithms, and were labeled as: PAR_18.3mix; CMS_18.3 and CMS_19.1.

The Lagrangian description of the geophysical fluids is based on tracking every 
macroscopic particle of the fluid and follow their trajectories (see Appendix B). The study of the movement of particles in complex flows, the case for the Earth's ocean and atmosphere, should consider chaotic motion, that is found even for the simplest fields of velocity for the geophysical fluids. The result of a Lagrangian analysis based on data from Eulerian fields for a discrete treatment, i.e., not considering every single particle of the fluid, will be a probabilistic distribution that represents the chance of some variable, particle, or property of the fluid being observed at that instant and position.

\subsection{Methodology}

To study correlations between the South Atlantic Circulation and the Indonesian Throughflow, virtual Lagrangian particles have been tracked from the present days to the past, i.e.: an initial ensemble of particles is virtually released at the SAMBA line at every time interval. The Eulerian velocity fields are inverted and the particles are advected using the $4^{\text {th }}$ order Runge-Kutta numerical integrator for a timestep of 6 hours, computing the trajectories in a backward recovered motion. This approach aims to answer the question "where did those particles come from?", i.e., the main objective is to evaluate the sources of the composition of the waters in the South Atlantic for the present days. Output data of the simulations is given every 24 hours.

Trying to represent chaotic transports, effects of molecular and turbulent diffusion and physical processes weakly or not represented in models' outputs, both Lagrangian algorithms descripted in Chapter 2 (CMS and PARCELS) bring, as usually is done, numerical modules of stochastic parametrizations that mix stochastic components to the deterministic advection terms. However, depending on the spatial and time resolutions available for the Eulerian fields provided by the OGCM, and on the processes supposedly not solved by the model and that one wishes to represent, adding stochastic terms can be unnecessary or not efficient at all, besides bringing an additional computing effort. That can be especially true in the case there is sufficient resolution and 
proper representation of the mesoscale processes (Koszalka et al., 2013; Sebille et al., 2018).

Having in mind such aspects related to the HYCOM runs whose this work has utilized, no stochastic noise were added to the advection for the Lagrangian experiments that will be studied in this Chapter, for both CMS and PARCELS, once the GLBa0.08 implementation of HYCOM was based on resolving mesoscale eddies. Additional considerations about the chaotic behavior of the interoceanic exchange are beyond the purposes of this work.

\subsection{PAR_18.3mIX}

This experiment utilizes the PARCELS algorithm as the numerical tool for Lagrangian Analysis. However, as yet not fully operational, PARCELS holds some limitations, as not dealing with particles too close to the coast, and only works at 1 processor at each time.

Output data of Expt. 18.3 were used to input the Eulerian fields of the barotropic velocity and the temperature of the mixed layer, from 2015 backward to 1990. Particles were released on the surface at $34.5^{\circ} \mathrm{S}$ ( $0 \mathrm{~m}$ depth) every month from 2015 to 2010 and horizontally advected, simulating surface drifters. The temperature is interpolated by the code along the computed trajectory. If the particle travels beyond the spatial limit of interest, it is then excluded from that time instant of simulation. The map with all trajectories for the entire simulation time is given in Fig. 4.1. Blue colors denote lower water temperature, and the red ones warmer waters. Some patterns of the surface circulation can be inferred from Fig. 4.1: Subtropical gyres of the South Atlantic and Indian Ocean; the ITF (very weak though) coming from the east; the temperature difference between the Benguela Current (pink color to the southwest of Africa) matching a cold water current - and the Brazil Current - represented by the warmer trajectories as a western boundary current; the region of Brazil-Malvinas Confluence 


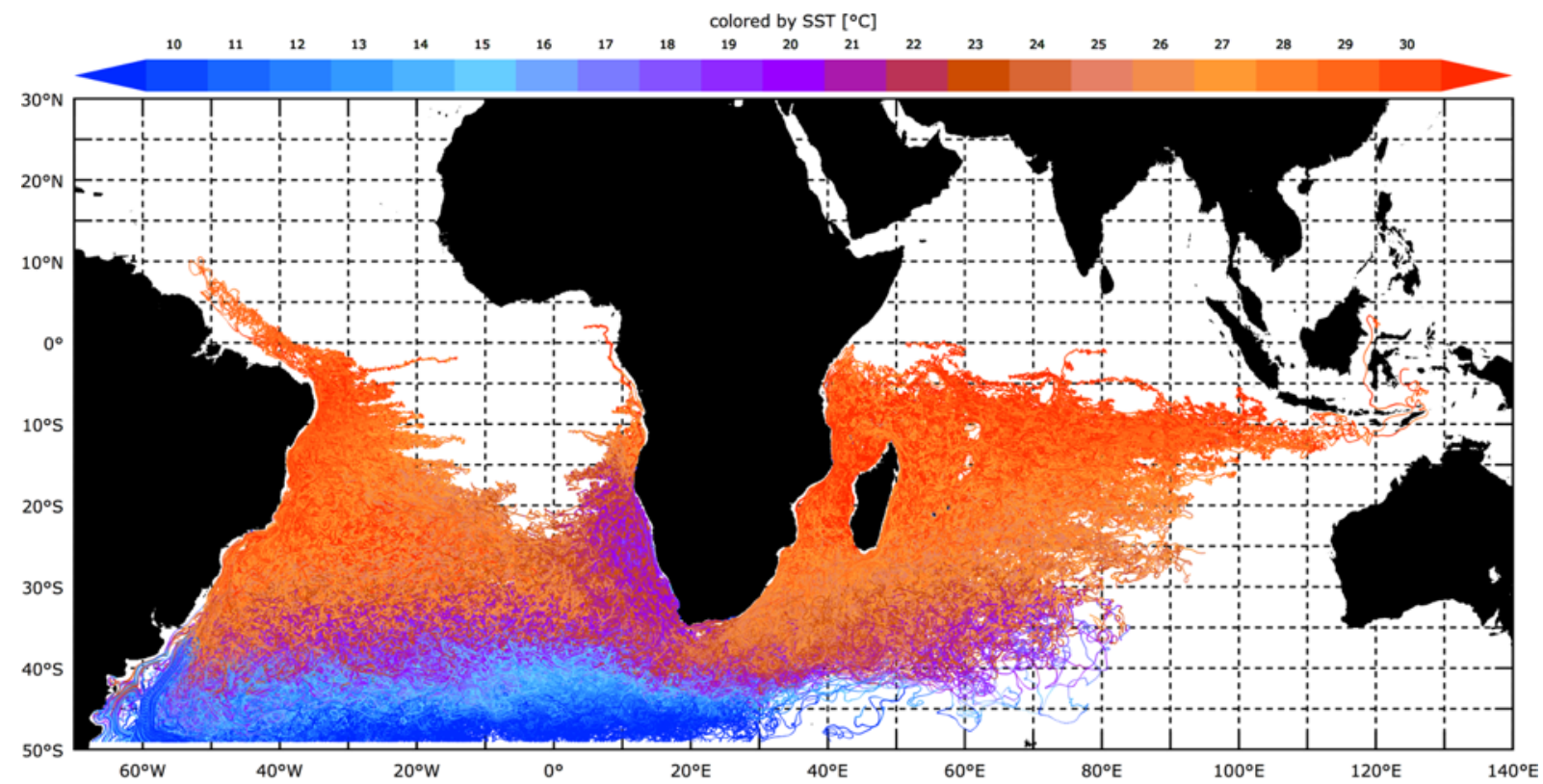

FIGURE 4.1 | Conjunct of all trajectories of simulation PAR 18.3mix, between 1990 and 2015. Colors indicate the temperature at each trajectory position, in ${ }^{\circ} \mathrm{C}$.

between $35^{\circ} \mathrm{C}$ and $50^{\circ} \mathrm{S}$, with some portion of the Malvinas Current flowing northward into the Brazilian coast; and the South Atlantic Current, carrying cooler waters to the east.

For a probabilistic approach, it is common to analyze the set of trajectories through the frequency of visits in binned grid. A grid of reasonable size must be scaled in terms of the time resolution with which the trajectories' data are written and must be large enough so that all the trajectory points that pass through a grid cell in the simulation time are computed.

The result is a probability distribution map as seen in Fig. 4.2. For that map, the colors represent the probability to find any particle at an arbitrary time of the entire simulation time considered for the PAR_18.3mix, within a $1^{\circ} \times 1^{\circ}$ horizontally spaced cell. This map is, above all, a correlation profile: since all the initial conditions starts along the line $34.5^{\circ} \mathrm{S}$ (shown as the white dashed line in Fig. 4.2), it is expected that the grid cells close to that region are more likely to host some particle for the observation time of all trajectories.

However, one needs to be in mind that all the Lagrangian analyses that is shown in this chapter were computed with a negative timestep, that is, from the present to the 


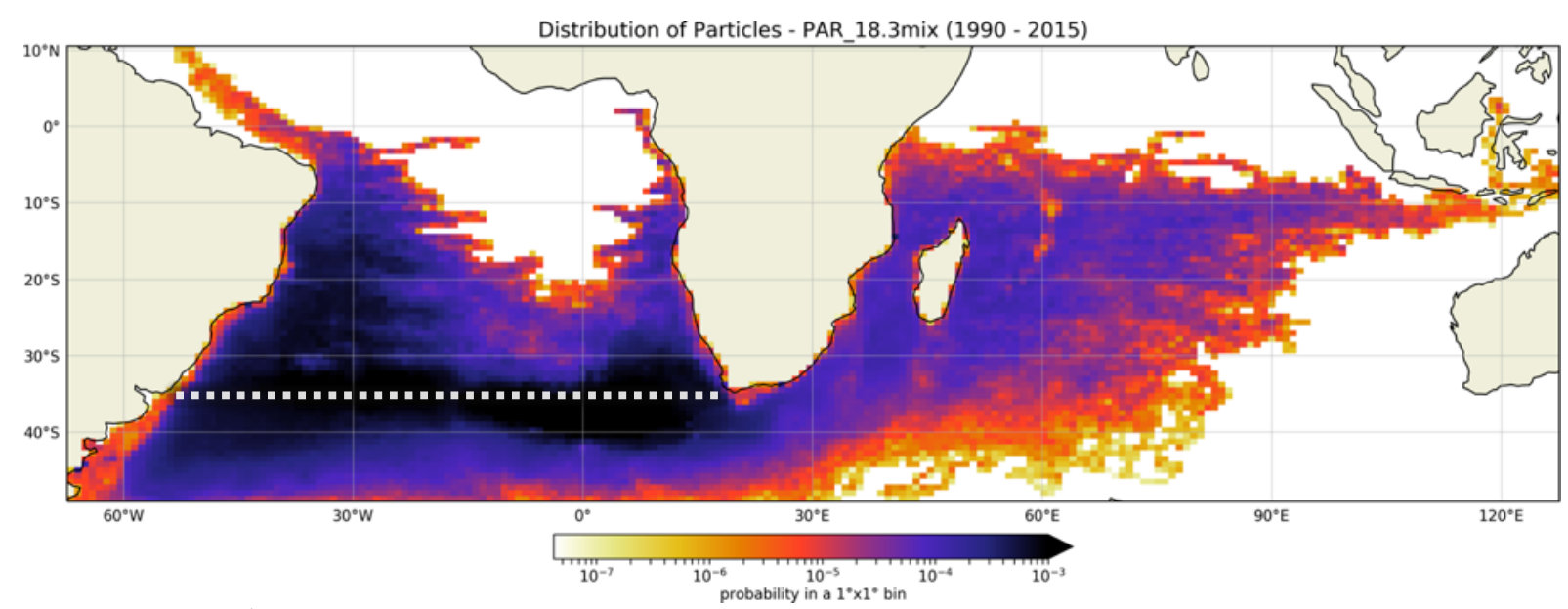

FIGURE $4.2 \mid$ Probability to observe a particle in a $1^{\circ} \times 1^{\circ}$ horizontal binned grid at the sea surface, considering the simulation time for all trajectories, according to the analysis PAR_18.3mix. The white line shows the SAMBA line, the initial position on which particles were released.

past, which investigates the origin of the water parcels present in the initial condition region at the initial time. Therefore, the correlation that must be done is that the colors also represent a greater or lesser probability of each binned cell being responsible for a different source of water bodies present in the vicinity of the surface of the SAMBA line from 2010 to 2015 of initial conditions).

Another point to note is that darker colors, which denote higher probability of observation by grid cell, do not necessarily denote a more intense circulation pattern. Instead, the high frequency of observations may mean recirculation of particles. This phenomenon is highlighted in black and lilac in the South Atlantic, which, although distant from the region of initial condition to the northwest and southwest, coincide with the contour of the subtropical gyration, where, especially for the South Atlantic is a region of accumulation of (eg McAdam \& Sebille, 2018), which in the oceans are floats that spread on the surface in a manner similar to the dynamics considered in the PAR_18.3mix simulation.

Among the central objectives of the present work is the correlation study between the ITF and the LA, and the developed Lagrangian analyses were designed and conceived for this purpose. However, as shown in Fig. 4.3, the PAR_18.3mix simulation did not provide enough data for such analysis: of all computed trajectories, only three were those that connected the two systems for the analyzed period. This result, however, 


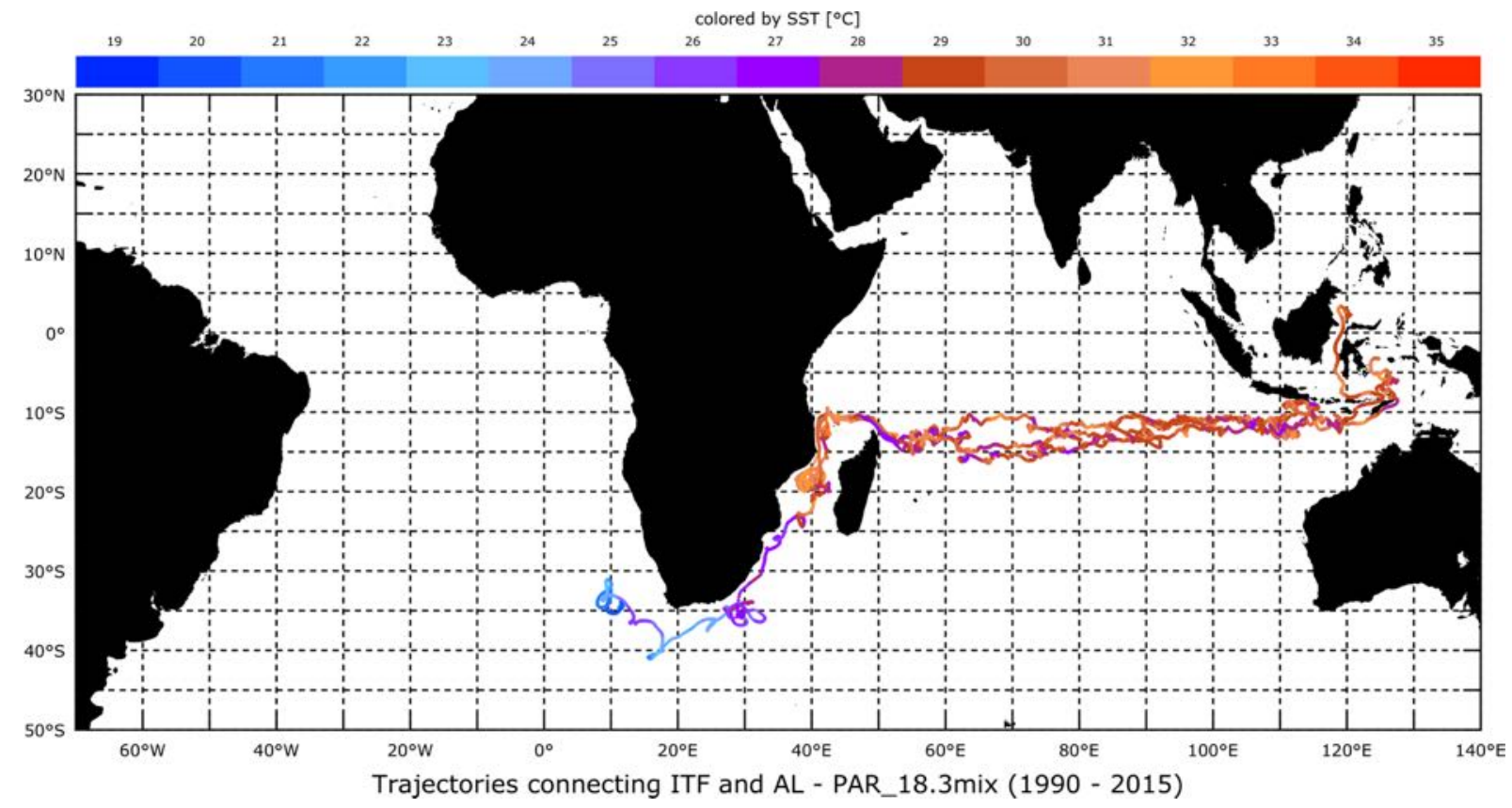

FIGURE 4.3 | Conjunct of trajectories connecting ITF and AL, according to simulation PAR_18.3mix, corresponding to only 3 trajectories (or $0.05 \%$ ) of the whole 5912 initial conditions computed.

is not an abnormal not expected result, because surface floats are subject to dynamic processes that rather depend on the superficial pressure oscillation and atmospheric events, causing the particles to be confined for long periods in the subtropical turns, necessitating longer displacement so that connections between ocean basins can be verified. Also, the purely horizontal surface movement may not be enough to represent the movement in the open ocean (predominantly baroclinic), when it is desired to study processes that depend, among other factors, on vertical flows, as in the case of ITF.

\subsection{CMS_18.3}

This experiment considers the CMS as a numerical model for trajectory simulation. Virtual particles were released once monthly during the year 2015, along the SAMBA line and between 0 and $1000 \mathrm{~m}$ depth. As the CMS does not interpolate the initial values of the particles, the values for the depth are the same made available in the HYCOM output files, where some of the 33 vertical levels in meters were considered: $\{0,5,10,25,50,75,100,125,150,200,250,300,400,500,600,700,800,900,1000\}$.

As the systems under study (ITF and AL) occur essentially on the surface and 
subsurface of the oceans, depths up to $1000 \mathrm{~m}$ are sufficient for this study. In addition, as we have shown in previous reports, results with Expt. 18.3 in the ITF does not seem to represent with fidelity the deeper regions. As a cause of this, in other factors, there may be the "warm up" time of the model: the deep ocean requires hundreds of years to adjust; but for the upper ocean that is just about 50 years (Kantha \& Clayson, 2000).

We consider as input values for the velocity fields in the CMS the results of Expt 18.3 with HYCOM. Outputs are provided with mean values computed every 6 days, comprising the zonal, meridional and vertical components of the total velocity, that is, as HYCOM associates for data output purposes the vertical coordinate with density levels, grid to which the CMS does not support, the speed computed in the orthogonal grid linearly interpolated and smoothed, and later interpolated once more by the CMS, considers not only the baroclinic component of the velocity in the original grid point of the model, but the total component taking possible rotations of adjust to the orthogonal grid at z-levels.

The simulation is for the period between 1994 and 2015. The particles are also advected using Runge-Kutta of 4th order, in the 3 spatial dimensions and in the time with negative integration step also of $6 \mathrm{~h}$. Results are written every 1 day.

This simulation brings relevant data regarding the vertical dynamics of the movement, considering three-dimensional velocity fields, available from the surface to the ocean floor, for the entire analyzed region. Fig. 4.4 shows the complete set of trajectories obtained, indicating in red the initial condition points on the line $34.5^{\circ} \mathrm{S}$, and, in blue tones, the different depths at which the particles were observed. Although the largest depth provided as the initial condition was $1000 \mathrm{~m}$, the input data contained values for the entire water column, including values for the vertical velocity component, which allowed the particles to move to shallower or deeper regions.

As discussed in the previous section, Fig. 4.5 shows the probability distribution by grid cell, in this case also $1^{\circ} \times 1^{\circ}$ horizontally spaced and vertically extended from 


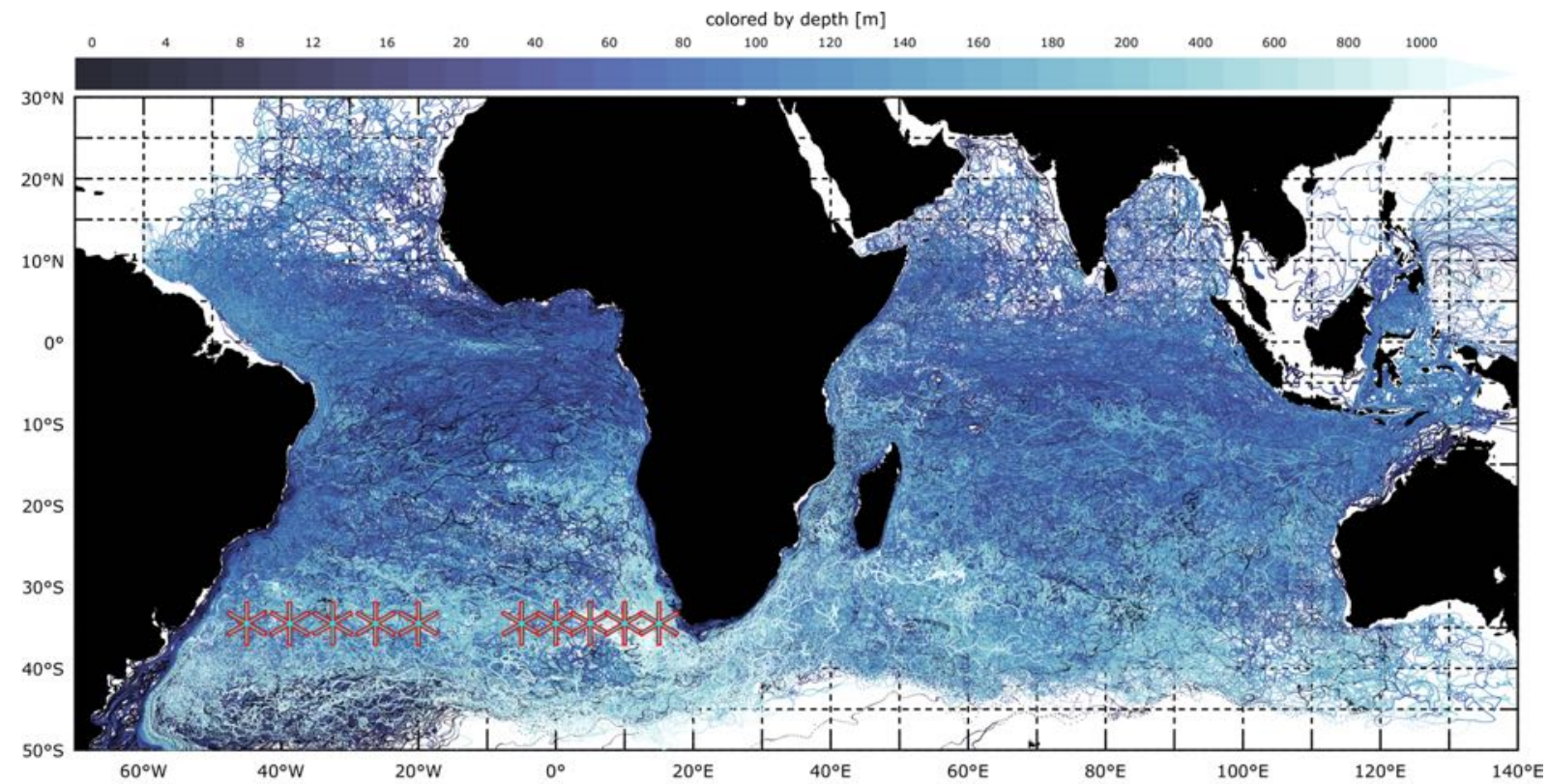

FIGURE 4.4 | Conjuct of all trajectories computed by simulation CMS_18.3 (1994 - 2015). Blue colors represent different depths (in meters). The red dots show the region of initial condition on the SAMBA line.

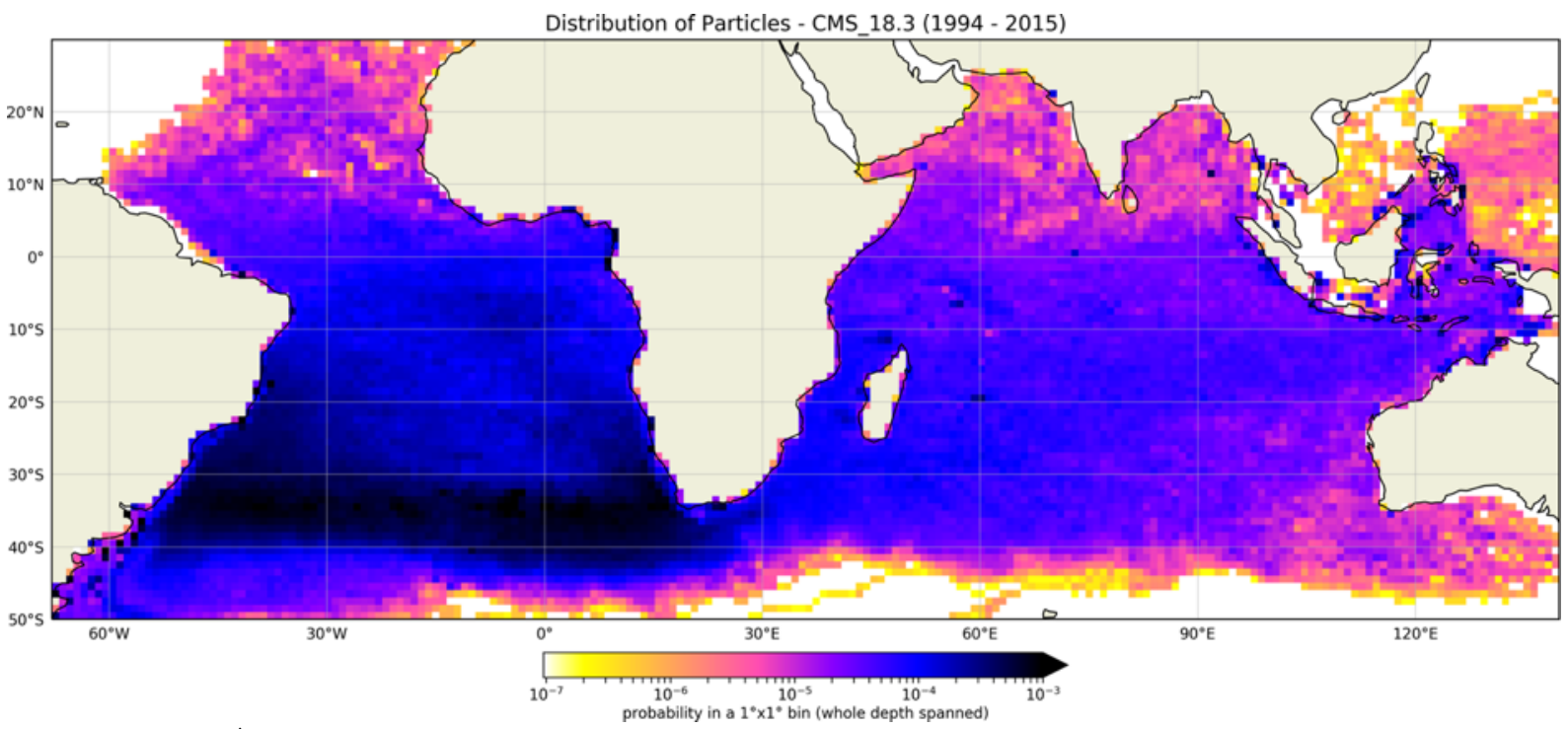

FIGURE 4.5 | Probability to observe a particle in a $1^{\circ} \times 1^{\circ}$ horizontally spaced grid expanded from the surface to the bottom, considering the analysis CMS_18.3, for the complete time of simulation and all trajectories.

the surface to the bottom, of observing a particle at some instant of time for the simulation period. The same correlation analysis can be done: the color scale denotes a stronger or weaker probability that each grid cell was a location from which the waters that were present between the surface and $1000 \mathrm{~m}$ depth along the SAMBA line in the year of 2015: the year in which the particles were "collected" monthly, that is, strictly, considering the integration of the present into the past, the particles are not "released", but collected in the position and instant of initial condition (which is in the final condition 
of the movement).

In addition to the circulation patterns quoted for the simulation with the surface floats of the previous section, the maps of Figs. 4.4 and 4.5 show flow through the Indonesian straits more intense, with depths varying in $\sim 10 \mathrm{~m}$ below the surface. It can also be seen a flow through the south of Australia, bringing waters of the South Pacific that mix with the subtropical turn of the Indian Ocean: that is the Tasmania Leak (Speich et al., 2002), less intense than ITF, and with less contribution to the formation of waters in the South Atlantic (given the color scale - represented in pink -, compared to the ITF blue in the Indian Ocean).

Again, in order to study connections with the ITF and Circulation in the South Atlantic, the map in Fig. 4.6 shows the overlap of all trajectories connecting the ITF to the Agulhas Leak region, that is: once the initial conditions are given in the South Atlantic, on the SAMBA line, any trajectory observed in the North Pacific region (north of Australia on the map) must connect the two systems. It is possible to note aspects of the pathway descripted by the trajectories, which are maintained in the subtropical gyres, merging with the circulation of the Indian basin before finally being distributed in the South Atlantic, with variable depths.

Fig. 4.7 shows the same map in terms of probabilities in a horizontal grid. When one considers only the trajectories that certainly connect the South Atlantic to the Pacific, the probability of finding a particle in the Atlantic is smaller when compared to the set of particles. Considering the integration of position of the particles being performed from the present to the past, then the particles must, for these trajectories, return to the Pacific. Likewise, the probabilities in the Indian Ocean are higher when compared to the total set of particles, since for the trajectories that connect the ITF to the LA, they must pass through the Indian Ocean. Darker points from the region southeast of Africa to the coast of Indonesia trace the most likely places to find a particle.

Also, one can see the decrease of the Tasmania Leak, which has little correlation 


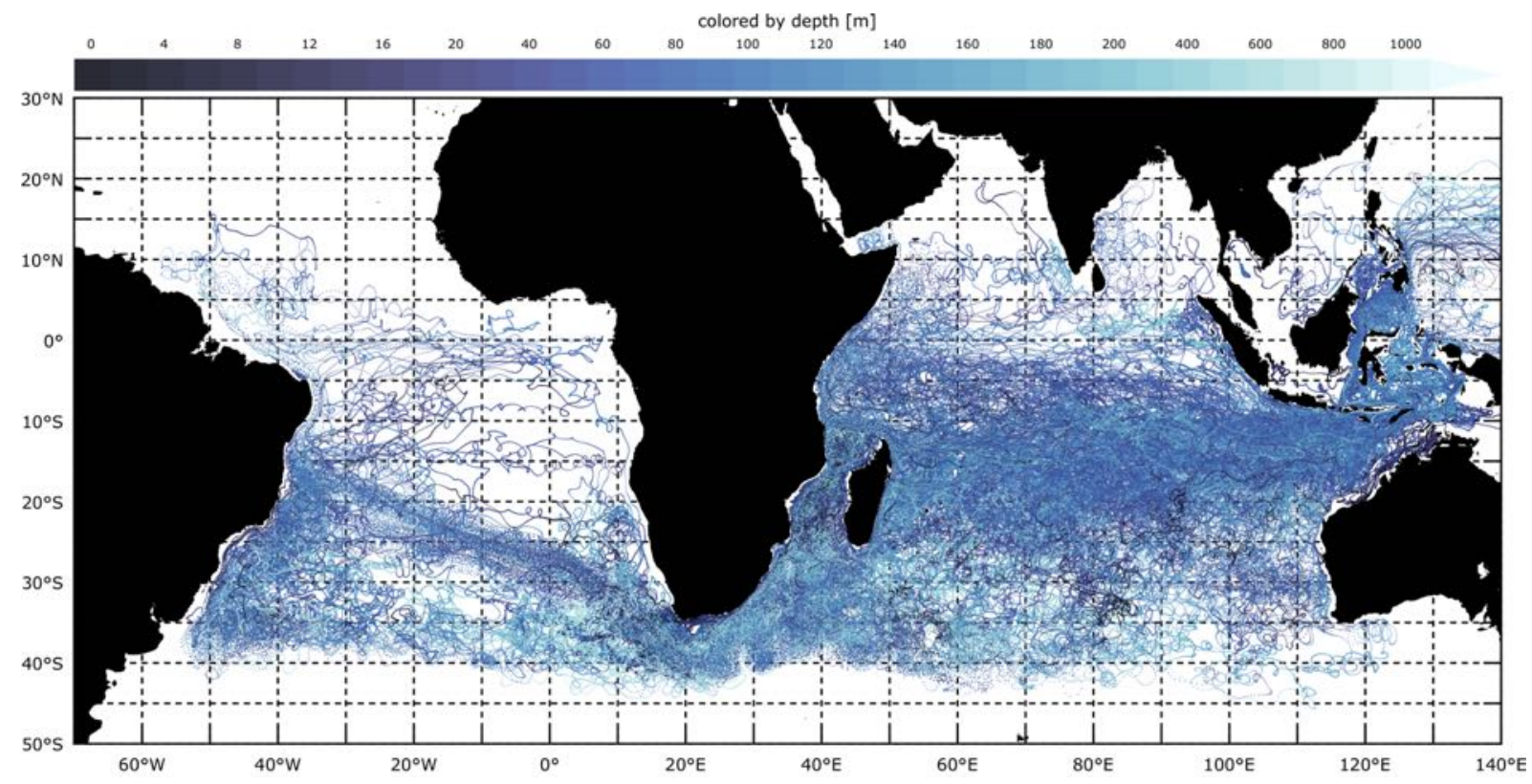

FIGURE 4.6 | Conjunct of trajectories connecting ITF and AL (6.45\% of the whole ensemble), considering the simulation CMS_18.3 (1994-2015)

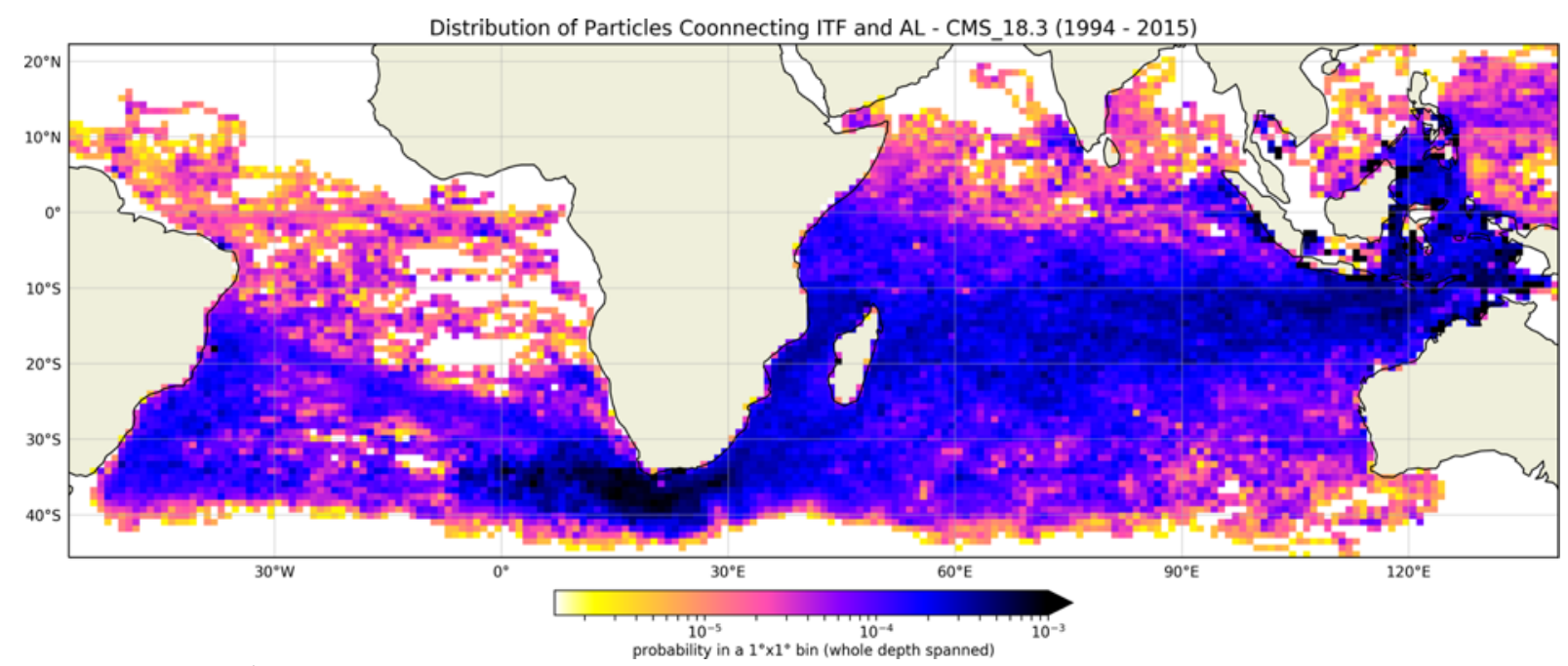

FIGURE $4.7 \mid$ Probability to observe a particle in a $1^{\circ} \times 1^{\circ}$ horizontally spaced grid expanded from the surface to the bottom, considering only the trajectories the connect the Pacific and Atlantic Oceans, for the complete time of simulation of the analysis CMS_18.3

with these specific trajectories.

An area of high probability density is revealed in Fig. 4.7 for the Agulhas Leak region, since all the particles (once sown in the South Atlantic) must pass through, to have come from the North Pacific Ocean. In addition, the recirculation of these particles around this region, traveling with the anticyclonic vortices, the so-called "rings" of the Agulhas, make it a likely region of observation.

An aspect that must be studied for the simulation CMS_18.3 is the vertical 
structure of the trajectories, since it is the only experiment that considers the vertical movement of the particles. If there were no vertical movement, the mean value of the depth of the set of trajectories should remain constant and equal to the initial condition. But it is not what runs him. Figure 4.8 illustrates this behavior, showing a variation of $100 \mathrm{~m}$ in the mean depth over time, if only the trajectories linking the three ocean basins are considered.

For the open ocean, far from the boundaries and the surface, one can expect a baroclinic behavior, and three-dimensional flows traveling on surfaces of constant density (isopicnals), which usually are not parallel to the surface, leading to changes in the depth of each particle, and changing the ensemble's average pattern over the time.

Moreover, the histogram of Fig. 4.9 shows that there are among the trajectories that connect the Needle and ITF Systems a predilection for greater depths when compared to the set with all trajectories: it is more likely to observe the entire set of trajectories between 0 and $150 \mathrm{~m}$ depth, between the trajectories that connect the two systems, the probability is greater between 50 and $200 \mathrm{~m}$ depth.

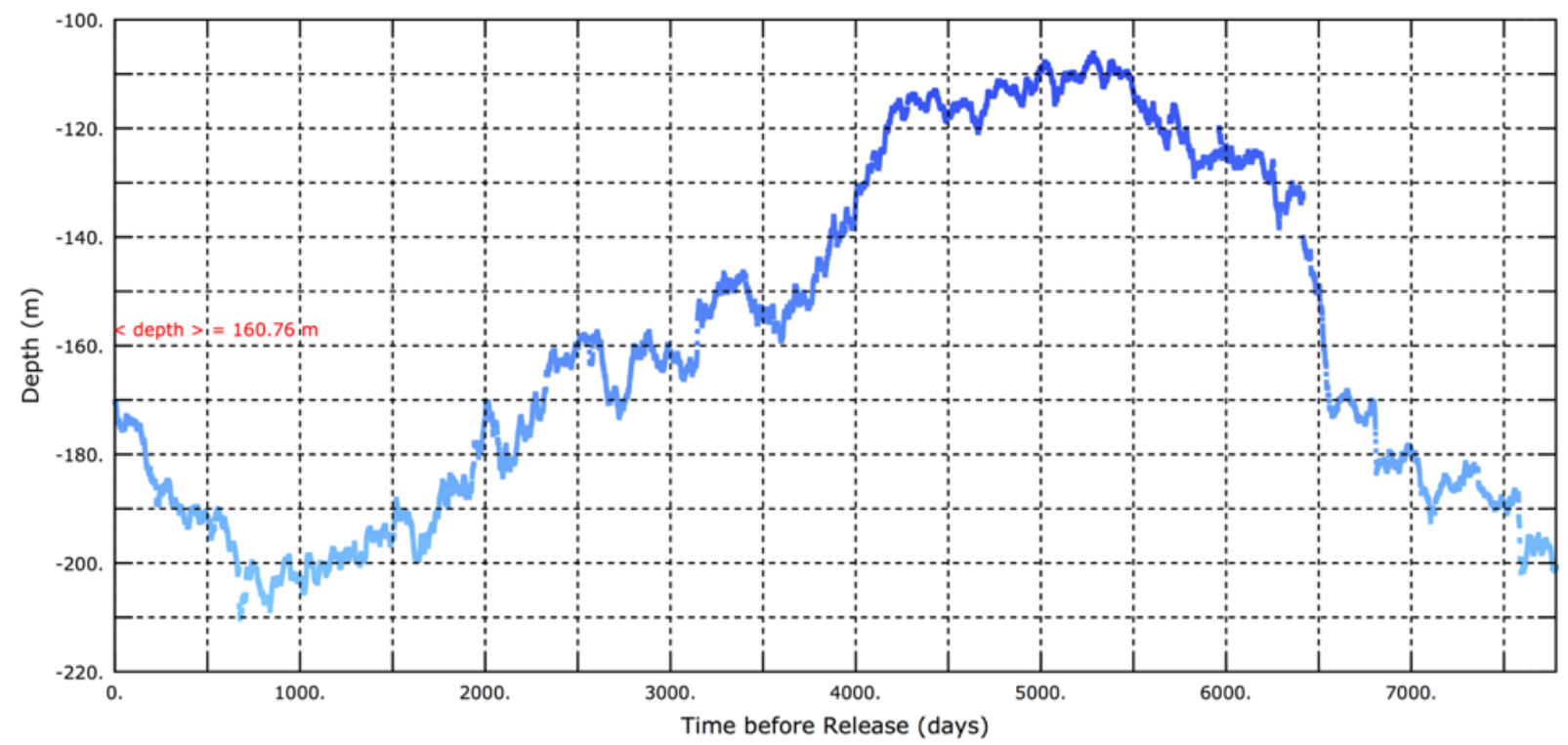

FIGURE 4.8 | Evolution of the mean depth of the conjunct of trajectories connecting ITF and AL, over the time of simulation of CMS_18.3

Furthermore, Fig. 4.10 shows that when we consider only trajectories in which the depth remained above $100 \mathrm{~m}$ for the entire period, only two of these trajectories are those that cross the Indian Ocean and link the ITF to the South Atlantic. 


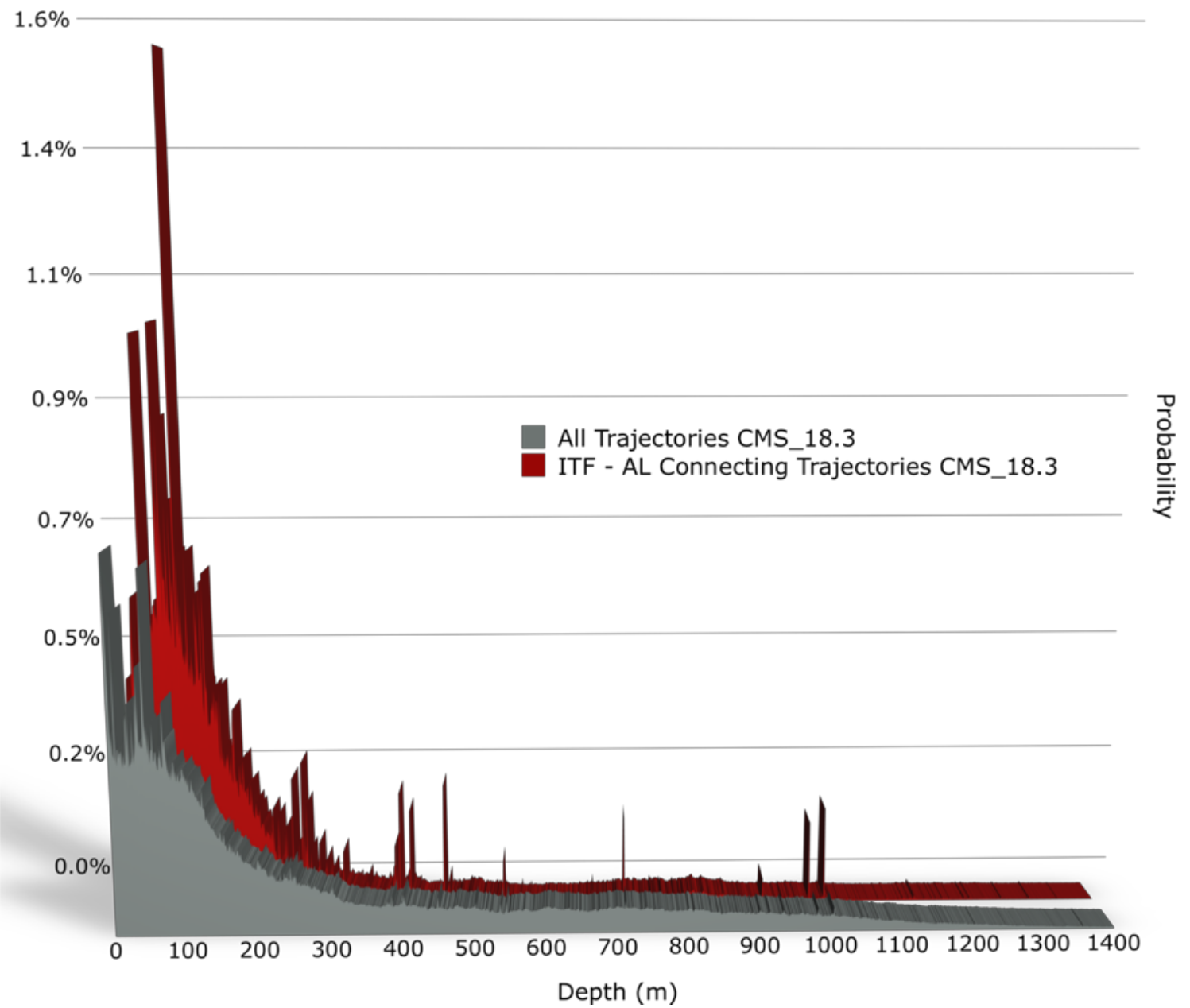

FIGURE 4.9 | Probability to observe a particle at different depths, over the simulation time of CMS_18.3, considering the complete conjunct of trajectories (grey) and the conjunct of trajectories connecting ITF and AL (red).

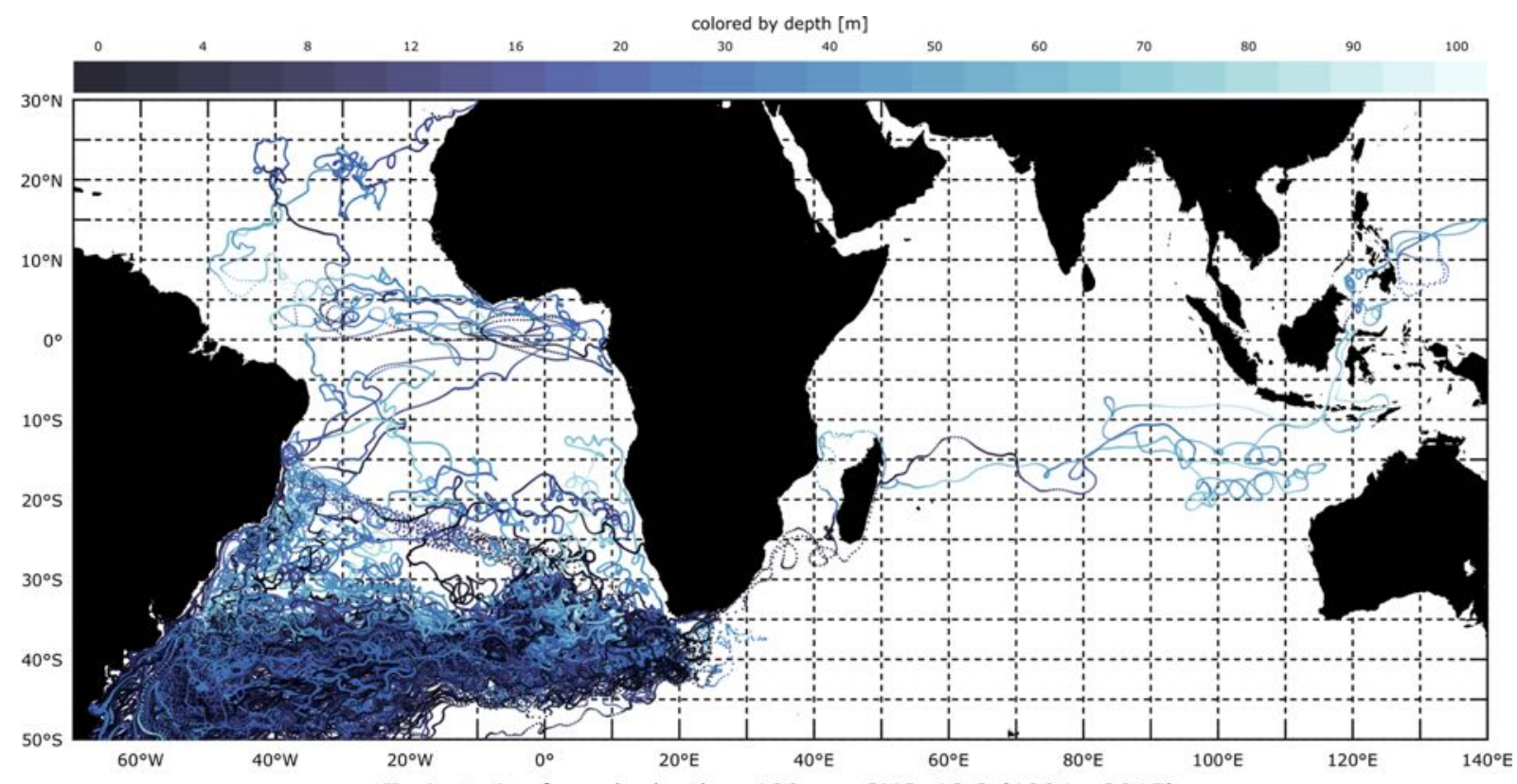

Trajectories for only depth $<100 \mathrm{~m}$ - CMS_18.3 (1994 - 2015)

FIGURE 4.10 | Conjunct of trajectories that have kept themselves in the upper $100 \mathrm{~m}$ of depth during the entire time of simulation 


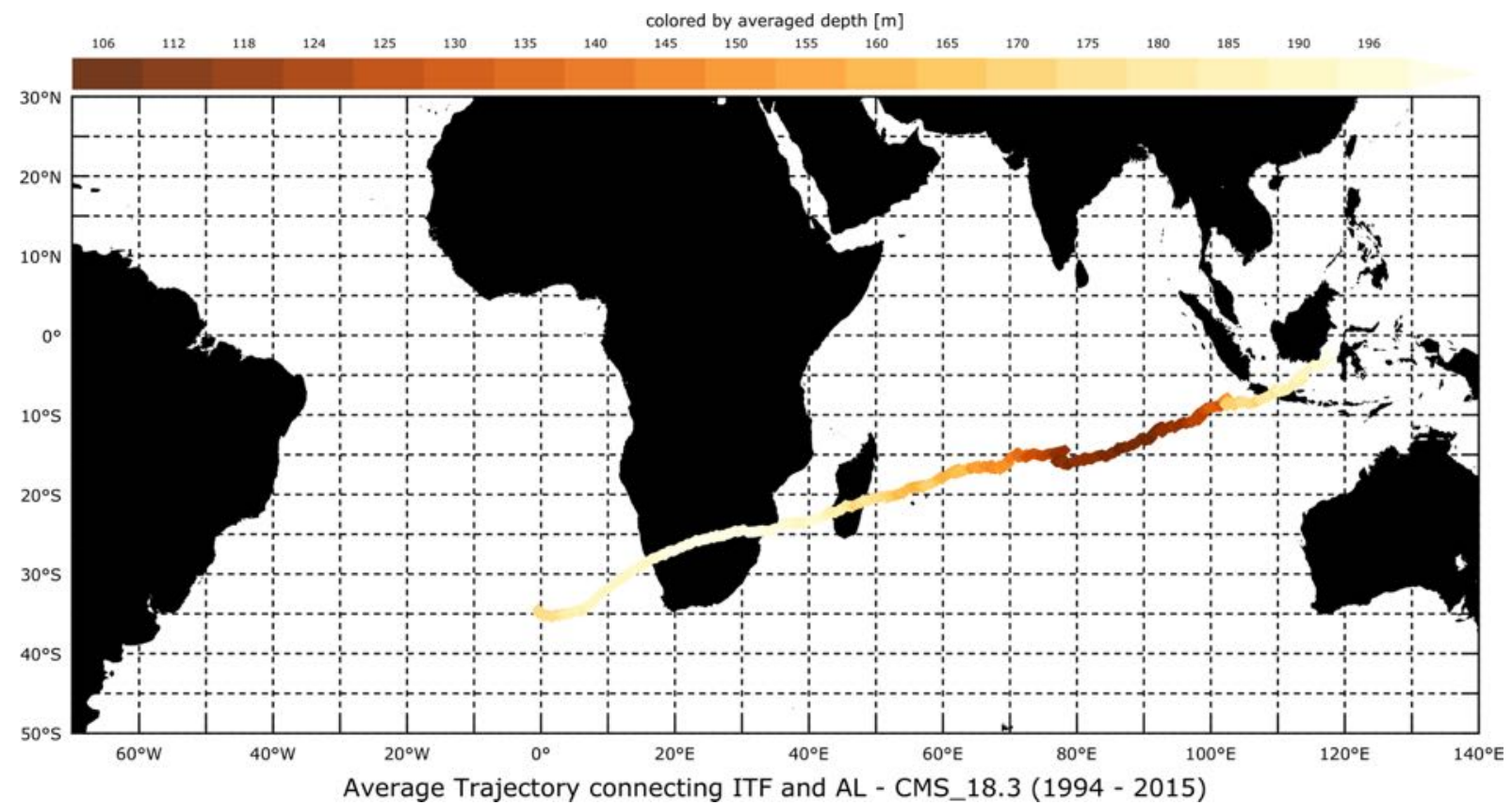

FIGURE 4.11 | Average behavior of the conjunct of trajectories connecting ITF and AL: colors represent the mean depth of the whole ensemble, being closer to the surface when traveling over in the Indian Ocean basin, considering the simulation CMS_18.3.

And if we consider a mean fictitious trajectory, considering the average of the horizontal and vertical positions of the trajectories that connect ITF and AL, we see the behavior which is shown in Fig. 4.11, where mean shallower depths of $100 \mathrm{~m}$ are revealed during the average trajectory trajectory within the Indian Ocean basin when compared to the mean depths in the horizontal positions corresponding to the South Atlantic and North Pacific Oceans.

An analysis of the simulation time, counted as days before the initial conditions (given in the course of the year 2015), that each trajectory takes to actually be observed in the Pacific, passing through the ITF, shows in Fig. 4.12 that the highest probability is that the trajectories are only observed in the ITF region at the end of the simulation time series between 5500 and 7800 days (15-20 years). This means that the trajectories remain most of the simulation time confined, first, to the subtropical South Atlantic swirl and then to the Indian basin before finally being found in the Indonesian region. A time of 10 to 30 years was also found by Durgadoo et al. (2017) so that ITF waters left the Indian Ocean basin through the Agulhas Leakage in a similar Lagrangian analysis. This result and those of Figs. 4.10 and 4.11 are in accordance with the graph of Fig. 4.8, which 
shows: greater depths for short simulation times, what means they are closer to the initial conditions - (Atlantic basin); smaller depths for average times - Indian Ocean; and, then again, larger depths for the final simulation times: ITF region and North Pacific Ocean.

This means that although the flow through the ITF is primarily superficial, dynamic processes in subsurface directly influence the system and model the characteristics of the masses of water that will be transported from one basin to another. A more precise analysis for this hypothesis would be to consider the interpolation of parameters such as density, temperature and salinity of the particles along the trajectory. Although CMS was designed to perform this activity, none of the temperature data we provided in all experiments with the CMS were correctly interpolated, returning values close to zero for the entire geographic distribution.

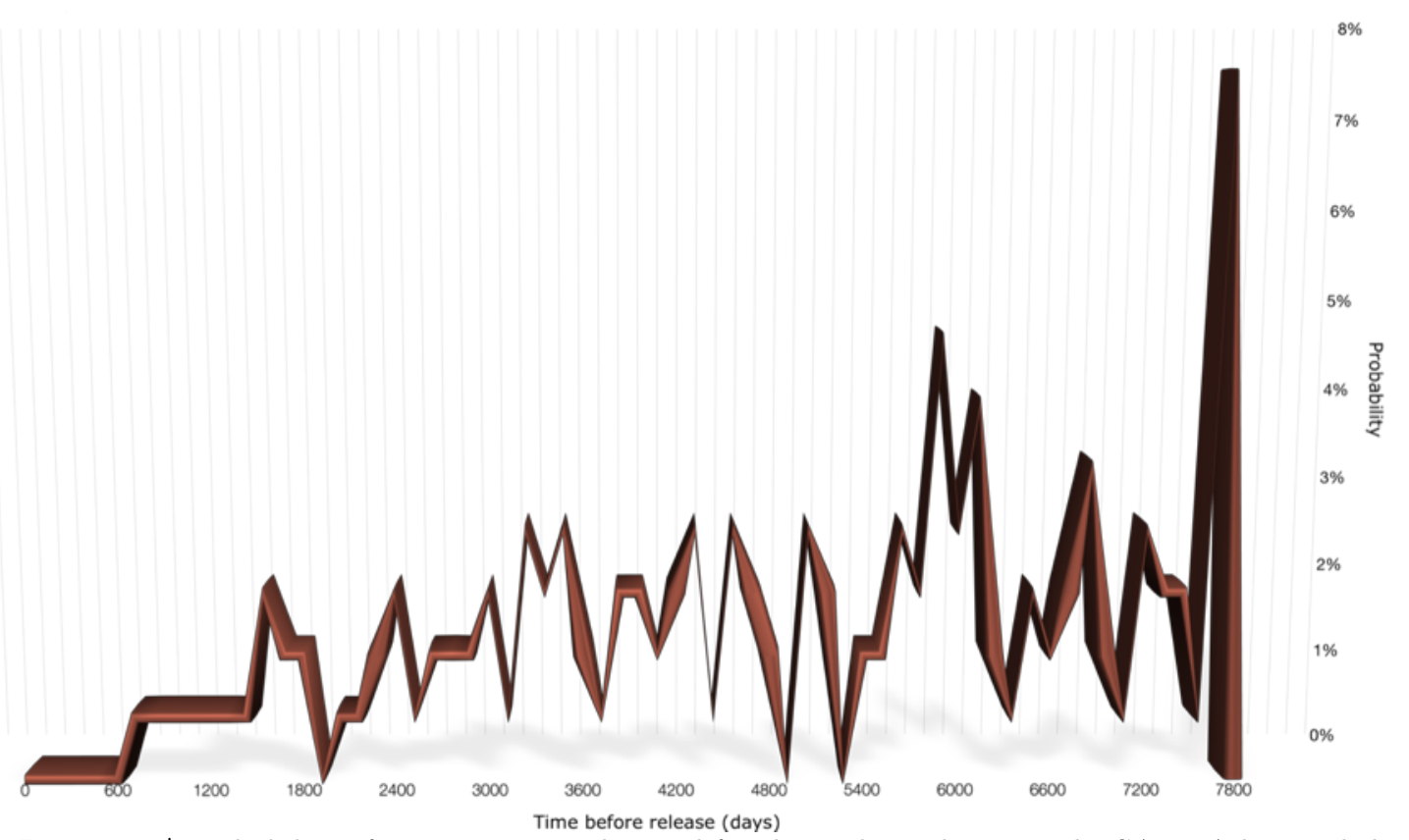

FIGURE 4.12 | Probability of transient time observed for the pathway between the SAMBA line and the ITF System, considering the conjunct of trajectories that connect both regions in the simulation CMS_18.3

\subsection{CMS_19.1}

The initial conditions of this simulation are as close as possible to the simulation CMS_18.3. But, in this case, particles were released every month in the course of the year 2012 , on the line $34.5^{\circ} \mathrm{S}$, with some difference in the initial depths, as described in 
Eq. (7): $\{0,4,0,25,25,50,70,100,125,150,200,250,300,400,500,600,700,800$, $900,1000\}$.

Although the temporal resolution of data availability for velocity fields is greater, we maintained the integration step in $6 \mathrm{~h}$ and results written in 1-day frequencies for comparison purposes. The Expt. 19.1 does not provide prediction for the vertical component $w$ of the velocity. So, even if we consider initial conditions at different depths, the CMS integrates a purely horizontal displacement keeping the depth constant. In the open ocean, predominantly baroclinic, such an analysis may not be adequate.

This simulation evaluated the movement of particles between the surface and $1000 \mathrm{~m}$ depth, considering the largest time series continuously available for Expt. 19.1 with HYCOM GLBu0.08, which goes from November 28, 1996 to December 31, 2012. Data prior to November 1996 are not complete and have not been used.

As the data in Expt. 19.1 do not bring values for the vertical component of the velocity field, and we did not consider stochastic terms of vertical diffusivity, the particles are advected horizontally and remain at the same depth for the entire simulation period. Fig. 4.13 shows the overlap of all trajectories obtained.

Although it has a total of 5 years less than the time considered in the CMS_18.3 experiment, the maps of Figs. 4.4 and 4.13 can be compared. Like those in Figs. 4.5 and 4.14. In the Atlantic basin of the map it is possible to note a meridional transport of particles, where is shown the northern portion of the Atlantic Ocean present on the map much less dense in the CMS_19.1 simulation than in the CMS_18.3. In the Indian, the same can be observed, with the trajectories concentrated below the equatorial line, making in general the trajectories for the simulation CMS_19.1 are mostly confined to the subtropical region. In the small portion of the North Pacific that is presented in the extreme northeast of the maps, Figs. 4.13 and 4.14 show a flow of particles moving in the South China Sea and Gulf of Thailand (marked in red in Figures 4.13 and 4.14) which are not verified in the maps of Figs. 4.4 and 4.5. These flows converge to the ITF 


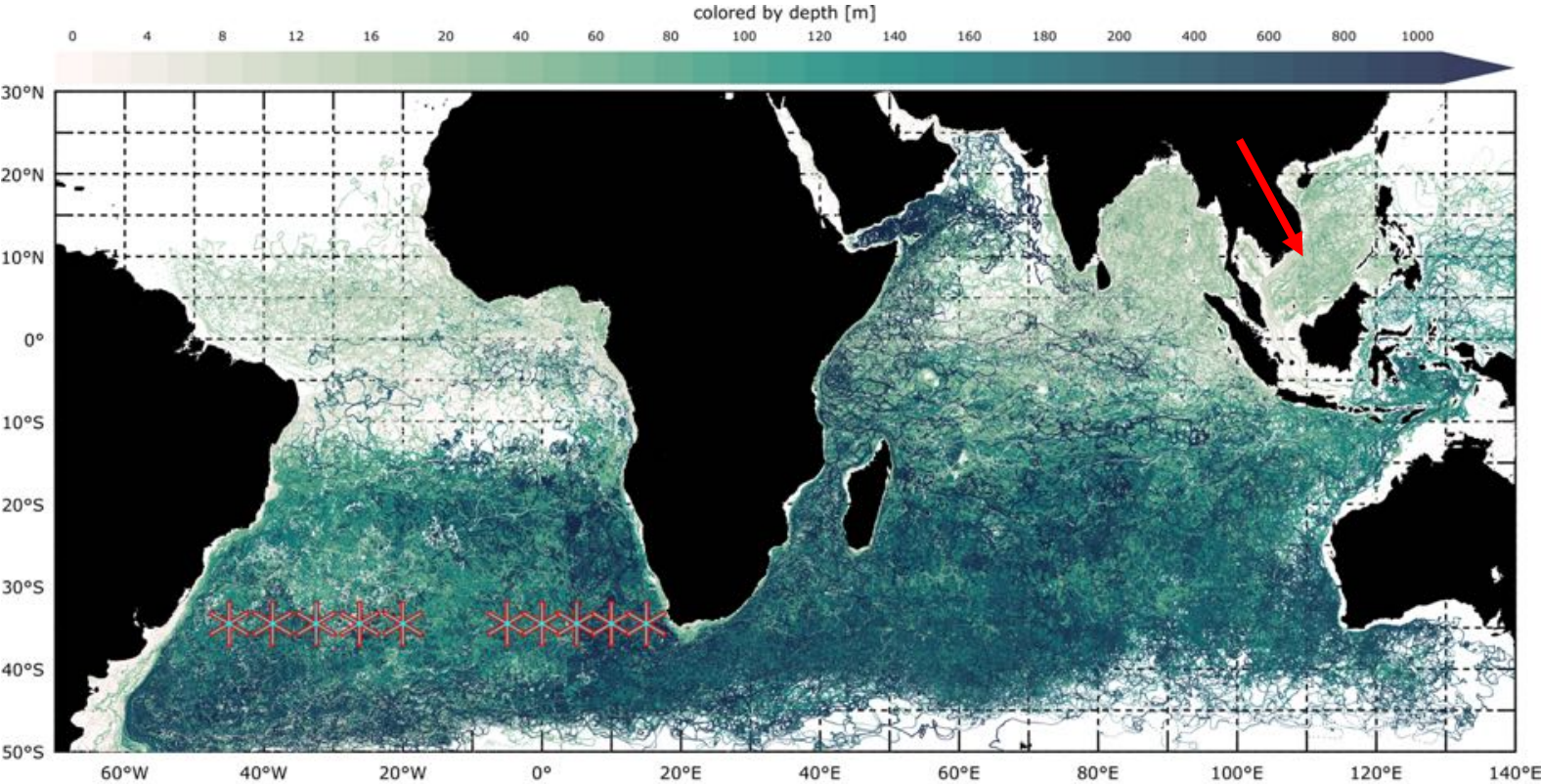

FIGURE 4.13 | Conjunct of all trajectories computed by simulation CMS 19.1 (1997 - 2012). Green colors represent different depths (in meters). Red dots in red show the region of initial condition on the SAMBA line.

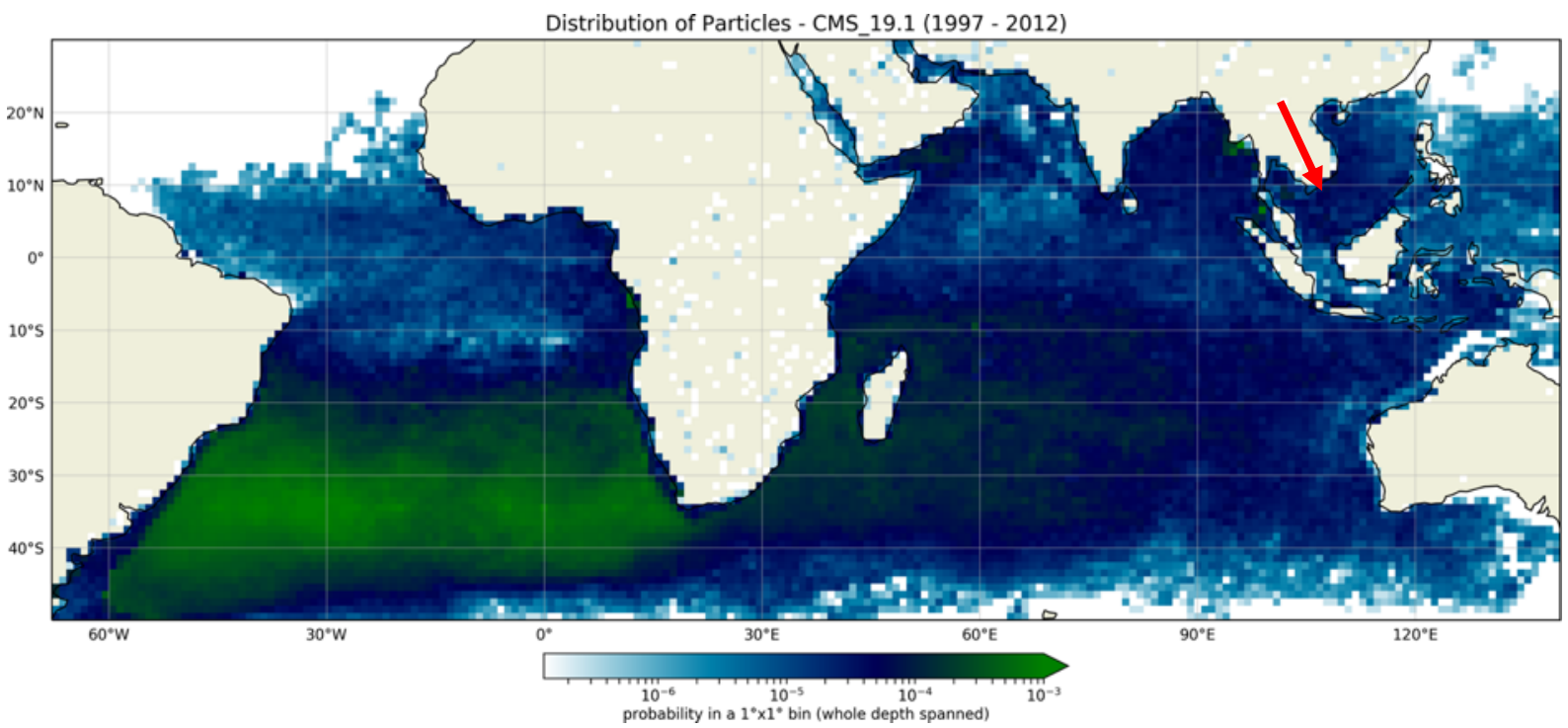

FIGURE 4.14 $\mid$ Probability to find a particle in a $1^{\circ} \times 1^{\circ}$ spaced horizontal grid cell, expanded from surface to $1000 \mathrm{~m}$ of depth, considering the analysis CMS 19.1, for the whole time of simulation and all trajectories.

region in the Java and Flores seas, flowing into the Indian Ocean, representing an unlikely path, according to the literature (eg Gordon \& Fine, 1996; Lee et al., 2010) and the preliminary ITF studies that we have shown in past reports with the Eulerian Expt. 18.3.

One of the properties of ITF is to modify the characteristics of incoming water masses from the Pacific Ocean via, among other means, different vertical flows that alter the density, temperature, and salinity of these waters before they could be exported to 
the Indian Ocean basin. An analysis like the CMS_19.1, for which the OGCM velocity fields do not allow such vertical flows, and where we did not impose stochastic terms on the Lagrangian code that could simulate vertical displacements (via diapycnal diffusion, for example), it is probable that the trajectories are not conveniently representing the prediction that the outputs of the HYCOM GLBu0.08 model from Expt 19.1 are in fact providing.

Still qualitatively, Figs. 4.6 and 4.7 can be compared to the maps of Figs. 4.15 and 4.16 and show, respectively, the overlap of the set of all the trajectories that connect the ITF to the South Atlantic and the probability distribution per grid cell to observe a particle belonging to this set at any time in the simulation period. With noticeable difference from the results of the CMS_18.3 simulation, Figs. 4.15 and 4.16 show trajectories connecting the three ocean basins through flows that, as already mentioned, pass to the northwest of the island of Brunei, coming from the South China Sea with great recirculation and probabilities of observations (marked in red in Fig. in contrast to the flows across the Makassar Strait that should be most likely (marked on the yellow arrow). The waters leave the ITF by straits that are not representative for the flow, such as the Singapore Strait, and a small shallow passage to the west of Jakarta. In the Indian Ocean, trajectories weakly join the subtropical gyre, but rather, similar to a meandering zonal flow, propagate westward to the east coast of the African continent, and rapidly join the Agulhas System, which transmits all trajectories to the South Atlantic, without representing the retroflexion of the Agulhas Current, which could take the particles back to the Indian Ocean circulation, merging the particles back to the subtropical gyre of this basin.

Fig. 4.17 shows a plot of the probability distribution of the average depth of the trajectories, considering the complete set of Lagrangian particles and only the set of trajectories that connect ITF and AL. The distributions of the histogram occur in peaks of values, since the depth of each particle remains constant throughout the movement. 


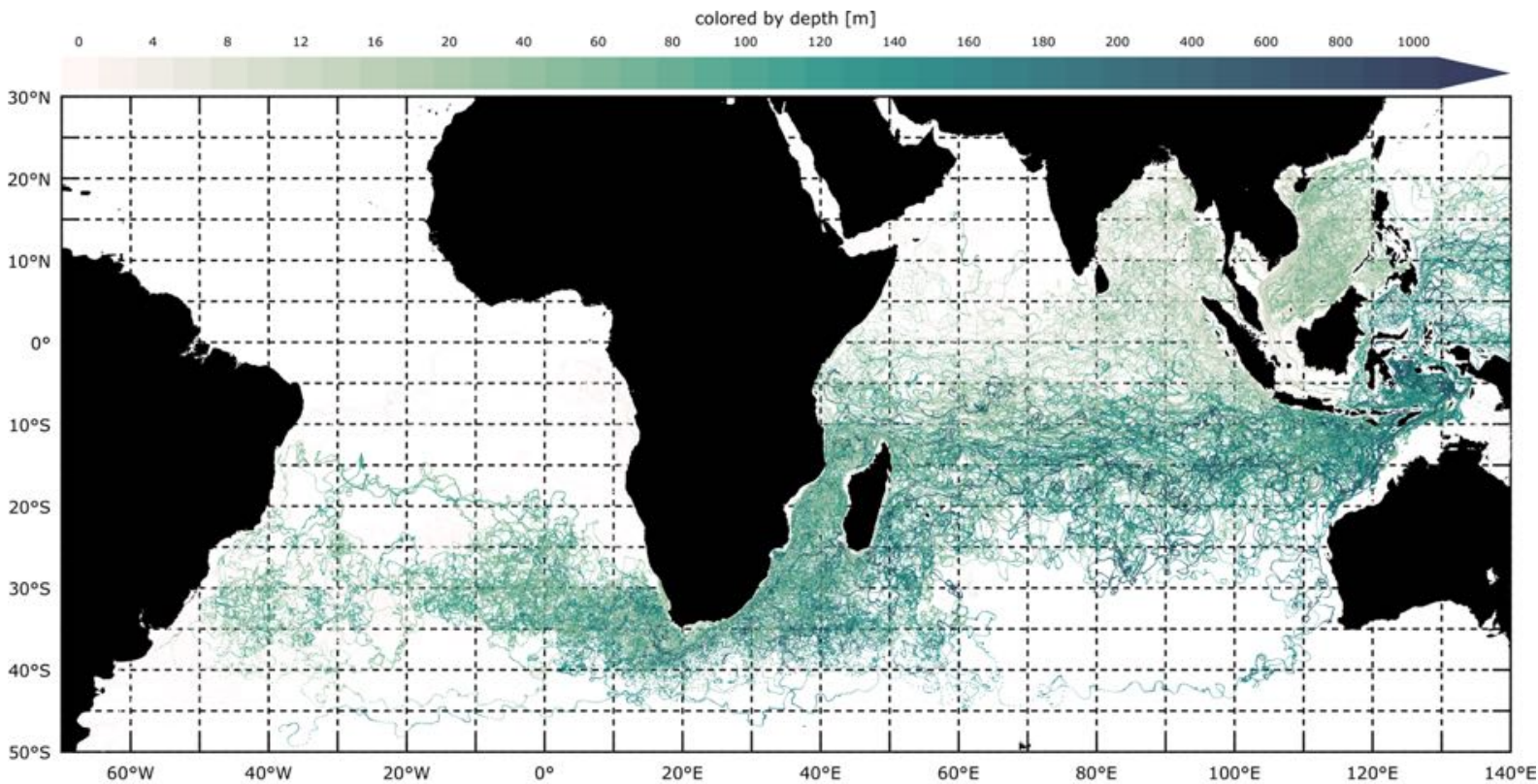

FIGURE 4.15 | Conjunct of trajectories connecting ITF and AL (5.22\% of the whole ensemble), considering the simulation CMS_19.1 (1997-2012)

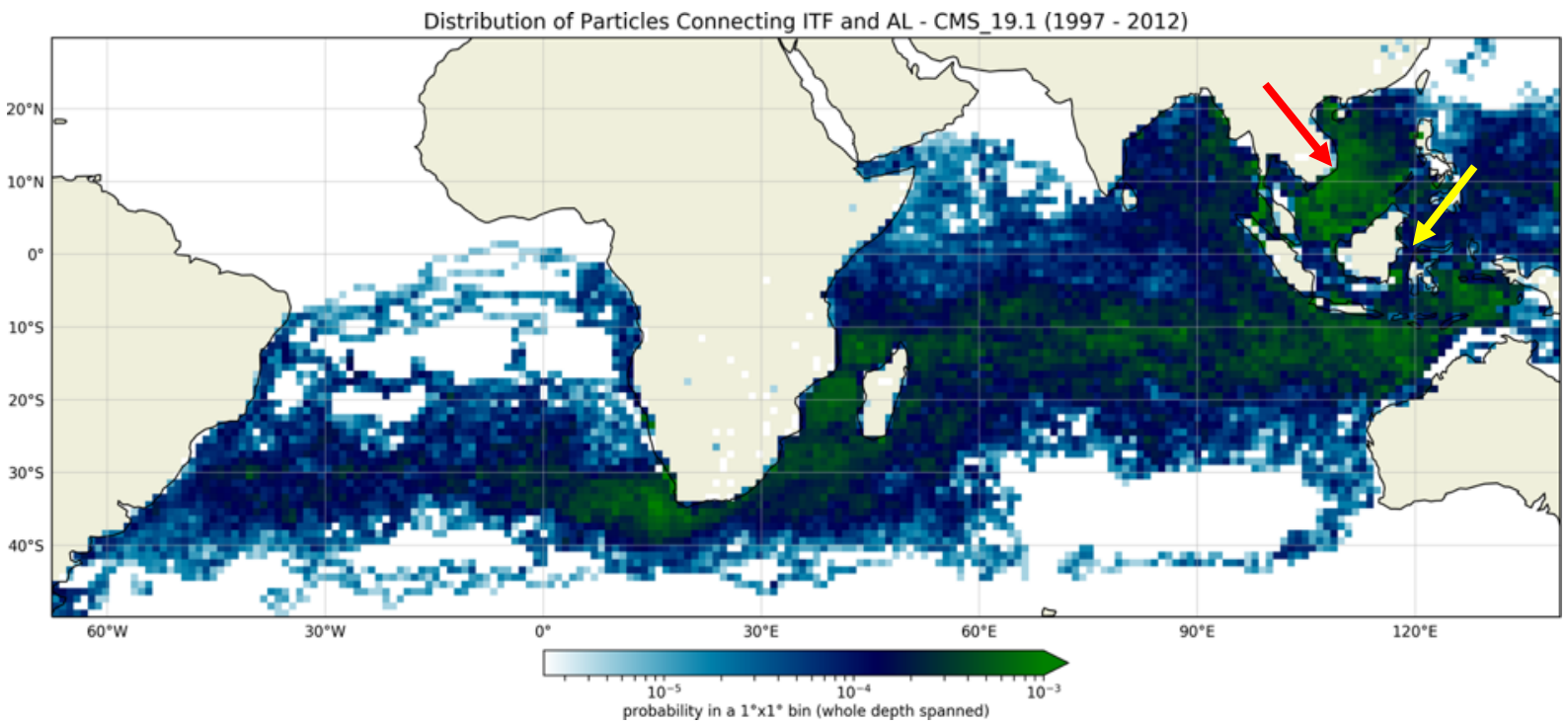

FIGURE 4.16 | Probability to find a particle in a $1^{\circ} \times 1^{\circ}$ spaced horizontal grid cell, expanded from surface to $1000 \mathrm{~m}$ of depth, considering the analysis CMS_19.1, for the trajectories connecting the Pacific Ocean and the South Atlantic Ocean for the whole time of the simulation CMS_19.1.

Unlike the graph shown in Fig. 4.9, where there was a preference for regions of greater depth for the connection trajectories in relation to the whole ensemble, in this simulation CMS_19.1 the particles collected in the South Atlantic and that certainly came from the ITF moved preferentially in more superficial regions when compared to the set of all the trajectories considered.

This is another indication of the inadequate representation of three-dimensional flows without considering the vertical displacements that are part of the dynamics of 


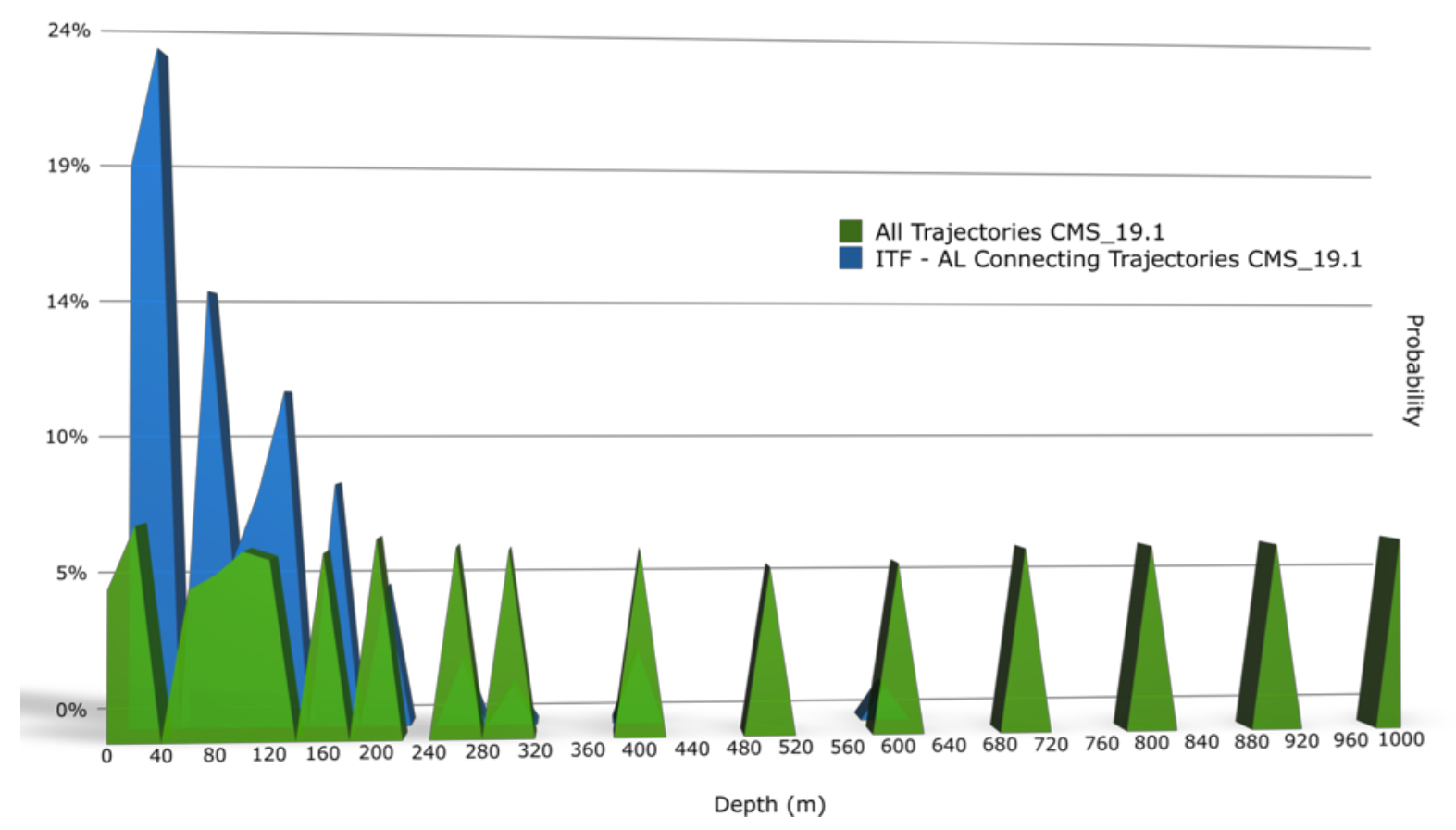

FIGURE 4.17 | Probability to observe a particle at different depths, over the time of simulation for the experiment CMS_19.1, considering all trajectories (green) and the trajectories connecting ITF and AL (blue)

water mass transformations that are known to be part of the circulation systems and patterns studied here. 


\section{5 | CONCLUSION}

An implementation of HYCOM in a global, eddy-resolving resolution experiment was used to study the Indonesian Throughflow. Output data of the run forced with climatology of atmospheric data have been utilized to study the ITF structure, mean paths for horizontal flow and seasonal variability. The fluxes on surface and the mean path of inflow and outflow are represented satisfactorily. However, the deep flow in Lifamatola passage is not in accordance to the INSTANT data.

The ITF volume transport has been estimated for surface flows, in the upper $700 \mathrm{~m}$ depth. Results have shown the seasonal ITF variability is mostly driven by the monsoon winds system that acts on the region. A maximum flow is observed when winds blow in the same direction of the ITF superficial outflow path, between June to September. The values of volume transport estimated for the surface are in accordance with INSTANT data and other works.

Using the output data of the run forced with atmospheric fields varying on years, it was possible to study the interannual variability of the ITF. A response to ENSO events is being well represented by the model. El Niño and La Niña events cause the ITF transport decrease and increase, respectively. Analyzing each ITF's strait individually, was also possible to verify the response of each region.

The ITF heat transport has been estimated in the upper $700 \mathrm{~m}$ depth. Both volume and heat transports present a small trend of increase, in the whole time series, but it seems not to be related to real changes in the system.

Anomalies in the heat transport for three different periods of the time series have been studied in order to understand the representation of HYCOM concerning the abrupt 
increase of heat content within the Indian Ocean during the global surface warming slowdown. Between 2001 and 2012 the simulation with HYCOM shows a strong change in the surface heat transport of the ITF, increasing the amount of energy carried from the Pacific to the Indian Ocean in the same period. This could help explaining changes in the heat content within the Indian Ocean and also corroborate the hypothesis that correlates the phenomenon with the global warming hiatus.

However, another period, between 1991 and 1995 revealed that the ITF is getting stronger one decade earlier than the beginning of the hiatus, and other events could be correlated for that, like the Pinatubo volcanic eruption that happened in 1991. The fact is that the Indian Ocean is being more active than in the past and its connection with the Pacific Ocean is becoming weaker.

In addition, the analysis of the ITF heat transport in the last three years of the experiment shows a strong correlation to Nino3.4 Index and an evident response to El Niño event, where the increase before observed in the ITF heat transport now is converted in a hard decrease. Further analysis should be considered concerning the state of Indian Ocean's heat content after 2012, and the ITF for beyond the year 2015.

The experiments with HYCOM demonstrate good representation concerning the ITF structure and its variability. Once it has been used a global implementation, other systems can be studied in order to find further correlations. A global eddy-resolving resolution can permit, for example, to analyze the coherence of the ITF with Agulhas leakage and a better understood of the global MOC and its importance in the global climate system and in the recent climate changes.

Numerical experiments of Lagrangian analyses for the flow represented by different runs of the OGCM. The goal of this additional effort was to establish a numerical tool that could be used in future studies that consider output of forced ocean models and of coupled ocean-atmosphere models, looking for contributions concerning the ITF and the AL circulation patterns, net transports, and their variability in different 
timescales.

The outputs of 2 different runs were used to carry out the main investigation of the ITF variabilities and to force different test-experiments simulating the backward motion of virtual Lagrangian particles from the South Atlantic Ocean. Then, the computed pathways can be used to describe qualitative and quantitatively the flow parcels connecting ITF to the South Atlantic Ocean, carried by the Agulhas rings and the Indian Ocean circulation.

\subsection{SUgGESTIONS FOR FUtURE WORK}

Until now, the experiments performed using CMS and PARCELS allowed us to a fully understanding the methodology once proposed.

That allows to evaluate volume and heat transport through the ITF and the Agulhas Leakage using the Lagrangian data that will be compared with transports evaluated in the Eulerian frame.

As a natural continuation of the present work, it is suggested that an evaluation of changes and variability of the ocean heat budget in the Indian Ocean and in the South Atlantic Ocean be performed in the global warming hiatus period, considering possible correlations with the ITF and the Agulhas Leakage.

Changes and variability of water masses exchange can be computed. Eulerian fields from a coupled ocean-atmosphere climate model could help to establish correlations with these changes by tracking the flow, the forcing winds and climate events associated. 


\section{APPENDIX A}

\section{GEOGRAPHIC COORDINATE SYSTEMS}

In this work, two coordinate systems have been referred and used, for example, in the estimates of transports. This appendix proposes to explain the notation and definitions adopted.

Any fixed point in an approximately spherical Earth can be described by a position vector $\boldsymbol{\chi}$, represented in terms of angular components of a geodetic coordinate system:

$$
\chi=\lambda \hat{\boldsymbol{\lambda}}+\theta \hat{\boldsymbol{\theta}}-z \hat{\boldsymbol{n}}
$$

where:

$\rightarrow \lambda$ is the longitude, for $180^{\circ} \mathrm{W}=-180^{\circ} \leq \lambda \leq+180^{\circ}=180^{\circ} \mathrm{E}$ and $180^{\circ} \mathrm{W} \equiv 180^{\circ} \mathrm{E}$, defined as the azimuthal angle in the east-west direction measured from the prime meridian $(\lambda=0)$, typically, the Greenwich Meridian;

$\rightarrow \theta$ is the latitude, $90^{\circ} \mathrm{S}=-90^{\circ} \leq \theta \leq+90^{\circ}=90^{\circ} \mathrm{N}$, defined as the polar angle measured in the south-north direction from the equator $(\theta=0)$;

$\rightarrow z$ is the vertical downward distance from the Earth's surface $(z=0),[z]=\mathrm{m}$;

$\rightarrow \hat{\lambda}$ is the eastward pointing unit vector;

$\rightarrow \hat{\boldsymbol{\theta}}$ is the northward pointing unit vector;

$\rightarrow \hat{\boldsymbol{n}}$ is the upward pointing unit normal vector to the Earth's surface.

Once the angular components $\lambda$ and $\theta$ are usually given in degrees, they can be efficient for locating points in space, but do not work friendly with other physical properties given in conventional units. Thus, a metric coordinate system may be defined.

If the position vector written in these new coordinates is

$$
\mathbf{r}=x \hat{\boldsymbol{x}}+y \hat{\boldsymbol{y}}+z \hat{\boldsymbol{z}}
$$

defined by the transformation: 


$$
(\lambda, \theta, z) \Longleftrightarrow\left\{\begin{array}{l}
x(\lambda, \theta)=R_{E}\left(\frac{\pi}{180^{\circ}}\right) \lambda \cos \theta \\
y(\theta)=R_{E}\left(\frac{\pi}{180^{\circ}}\right) \theta \\
z=z
\end{array}\right.
$$

where:

$$
\rightarrow \quad R_{E}=6.371 \times 10^{6} \mathrm{~m}
$$

is the mean radius of the Earth considered approximately spherical;

$\rightarrow x$ is the eastward arc length related to the angle $\lambda$ measured from latitude $\theta,[x]=\mathrm{m}$

$\rightarrow y$ is the northward arc length related to the angle $\theta,[y]=\mathrm{m}$;

$\rightarrow z$ is the depth, measured vertically downward from the Earth's surface; $[z]=\mathrm{m}$.

The unit vectors are related to each other system as:

$$
\hat{\boldsymbol{x}}=\hat{\boldsymbol{\lambda}} ; \hat{\boldsymbol{y}}=\hat{\boldsymbol{\theta}} ; \hat{\boldsymbol{z}}=-\hat{\boldsymbol{n}}
$$

The system of coordinates $(x, y, z)$ is usually called quasi-Cartesian, and an element of volume in space can be simply described for these coordinates as:

$$
\delta \mathrm{V}=\delta x \delta y \delta z \equiv\left[m^{3}\right]
$$

If $\delta \rightarrow 0$, then:

$$
\mathrm{dV}=\mathrm{d} x \mathrm{~d} y \mathrm{~d} z \Leftrightarrow\left\{\begin{array}{l}
\mathrm{d} x=R_{E} \frac{\pi}{180^{\circ}} \cos \theta \mathrm{d} \lambda \\
\mathrm{d} y=R_{E} \frac{\pi}{180^{\circ}} \mathrm{d} \theta \\
\mathrm{d} z=\mathrm{d} z
\end{array}\right.
$$

where $\mathrm{d} x$ and $\mathrm{d} y$ are infinitesimal line elements of the arc lengths in the eastward and the northward directions, respectively, while $\mathrm{d} z$ is an infinitesimal downward distance.

If instead of continuous, the geographical space was discretized into $i \times j \times k$ fixed-points located at

$$
\chi_{i j k}=\left(\lambda_{i j}, \theta_{i j},-z_{k}\right)
$$

where $i, j$ are indices of a horizontal grid and $k$ of a vertical grid in which those points were placed, then

$$
\mathbf{r}_{i j k}=x_{i j} \hat{\boldsymbol{x}}+y_{i j} \hat{\boldsymbol{y}}+z_{k} \hat{\boldsymbol{z}}
$$

is the position vector in the quasi-Cartesian coordinates, where: 


$$
\left(\lambda_{i j}, \theta_{i j}, z_{k}\right) \Longleftrightarrow\left\{\begin{array}{l}
x_{i j}\left(\lambda_{i j}, \theta_{i j}\right)=R_{E}\left(\frac{\pi}{180^{\circ}}\right) \lambda_{i j} \cos \theta_{i j} \\
y_{i j}\left(\theta_{i j}\right)=R_{E}\left(\frac{\pi}{180^{\circ}}\right) \theta_{i j} \\
z_{k}=z_{k}
\end{array}\right.
$$

An independent field evaluated in the spherical-geodetic coordinates must be the same for the corresponding position in the quasi-Cartesian coordinates, i.e., if $\mathbf{r}=\boldsymbol{\chi}(\mathbf{r})$ and $\boldsymbol{\chi}=\mathbf{r}(\boldsymbol{\chi})$, then the scalar field $\psi$ that represents a property of the fluid must be:

$$
\psi(\mathbf{r}, t)=\psi(\mathbf{x}, t)
$$

The analog is valid for a vector field, considering the point unit vectors:

$$
\begin{aligned}
& \boldsymbol{\Psi}(\mathbf{r}, t)=\Psi_{A}(\mathbf{r}, t) \hat{\boldsymbol{x}}+\Psi_{B}(\mathbf{r}, t) \hat{\boldsymbol{y}}+\Psi_{C}(\mathbf{r}, t) \hat{\boldsymbol{z}}= \\
= & \boldsymbol{\Psi}(\boldsymbol{\chi}, t)=\Psi_{A}(\boldsymbol{\chi}, t) \hat{\boldsymbol{\lambda}}+\Psi_{B}(\boldsymbol{\chi}, t) \hat{\boldsymbol{\theta}}-\Psi_{C}(\boldsymbol{\chi}, t) \hat{\boldsymbol{n}}
\end{aligned}
$$




\section{APPENDIX B}

\section{EULERIAN AND LAGRANGIAN REPRESENTATIONS OF THE GEOPHYSICAL FLUID FLOWS}

The Newton's Second Law of motion stablishes that the net force acting over a moving particle is the responsible for the time variation of the particle's linear momentum, in other words:

$$
\sum_{n} \mathbf{F}^{n}=\frac{\mathrm{d}}{\mathrm{d} t}(m \mathbf{v})=m \frac{\mathrm{d}^{2} \mathbf{r}}{\mathrm{d} t^{2}}+\frac{\mathrm{d} \mathbf{r}}{\mathrm{d} t} \frac{\mathrm{d} m}{\mathrm{~d} t}
$$

where:

$\rightarrow \sum_{n} \mathbf{F}^{n}$ is the net force;

$\rightarrow \mathbf{v}=\frac{\mathrm{d} \mathbf{r}}{\mathrm{d} t}$ is the velocity vector;

$\rightarrow \frac{\mathrm{d}^{2} \mathbf{r}}{\mathrm{d} t^{2}}=\mathbf{a}$ is the acceleration vector;

$\rightarrow m$ is the mass of the particle;

$\rightarrow t$ is the instant of time.

However, this statement is only valid for an inertial referential, a physical concept defined by the Newton's First Law. To describe a movement in terms of the Newton's Second Law in a non-inertial referential, the case of an observer placed in a rotating system, for example, inertial forces must be added to the dynamics. Physically, those forces do not exist, but they are felt by whatever is moving following a non-inertial frame. Thus, if $\mathbf{v}$ is measured at position $\mathbf{r}$ by a fixed observer placed somewhere in a rotating system, the Eq. (B-1) can be given, for $m$ constant on time, as:

$$
\begin{aligned}
\frac{1}{m} \sum_{n} \mathbf{F}^{\boldsymbol{n}} & =\left[\frac{\mathrm{d}}{\mathrm{d} t}+\boldsymbol{\Omega} \times\right]\left[\left(\frac{\mathrm{d}}{\mathrm{d} t}+\boldsymbol{\Omega} \times\right) \mathbf{r}\right]=\left[\frac{\mathrm{d}}{\mathrm{d} t}+\boldsymbol{\Omega} \times\right](\mathbf{v}+\boldsymbol{\Omega} \times \mathbf{r})= \\
& =\frac{\mathrm{d} \mathbf{v}}{\mathrm{d} t}+2 \boldsymbol{\Omega} \times \mathbf{v}+\boldsymbol{\Omega} \times(\boldsymbol{\Omega} \times \mathbf{r})+\frac{\mathrm{d} \boldsymbol{\Omega}}{\mathrm{d} t} \times \mathbf{r}
\end{aligned}
$$

where: 
$\rightarrow \mathbf{r}$ is the position vector with coordinates system fixed in the rotating frame;

$\rightarrow \mathbf{v}=\frac{\mathrm{d} \mathbf{r}}{\mathrm{d} t}$ is the velocity measured in the rotating frame;

$\rightarrow \Omega$ is the angular velocity of the frame;

$\rightarrow \Omega \times \mathbf{r}$ is the linear velocity of the rotating frame itself at position $\mathbf{r}$;

$\rightarrow \frac{\mathrm{d} \mathbf{v}}{\mathrm{d} t}$ is the variation in time of the velocity measured in the rotating frame;

$\rightarrow 2 \boldsymbol{\Omega} \times \frac{\mathrm{d} \mathbf{v}}{\mathrm{d} t}$ is the acceleration due to the Coriolis inertial force;

$\rightarrow \boldsymbol{\Omega} \times(\boldsymbol{\Omega} \times \mathbf{r})$ is the acceleration due to the centrifugal inertial force;

$\rightarrow \frac{\mathrm{d} \boldsymbol{\Omega}}{\mathrm{d} t} \times \mathbf{r}$ is the acceleration due to the Euler inertial force, that is zero if $\boldsymbol{\Omega}$ does not vary on time.

For each single constant mass parcel of water that moves in the ocean with velocity $\mathbf{v}$ measured at some point on the Earth, rotating with constant angular velocity $\boldsymbol{\Omega}$, there will be accelerations due to the sum of forces that can drive the Eq. (B-2) to set up the form of the Navier-Stokes Equation:

$$
\frac{\mathrm{D} \mathbf{v}}{\mathrm{D} t}+2 \boldsymbol{\Omega} \times \mathbf{v}=-\frac{1}{\rho} \boldsymbol{\nabla} p+\mathbf{g}+\frac{\mu}{\rho} \nabla^{2} \mathbf{v}
$$

where:

$\rightarrow \mathbf{v}=\mathbf{v}(\mathbf{r}, t)$ is the Eulerian velocity field, at position $\mathbf{r}$ in the instant $t$

$\rightarrow p=p(\mathbf{r}, t)$ is the pressure field;

$\rightarrow \rho=\rho(\mathbf{r}, t)$ is the particle's density field;

$\rightarrow \mu=\mu(\mathbf{r}, t)$ is the dynamic viscosity;

$\rightarrow \Phi=\Phi(\mathbf{r})$ is the gravitational potential;

$\rightarrow-\frac{\boldsymbol{\nabla} p}{\rho}$ is the Pressure Gradient Force per unit of mass;

$\rightarrow \mathbf{g}=-\nabla \Phi-\boldsymbol{\Omega} \times(\boldsymbol{\Omega} \times \mathbf{r})$ is the Gravity Force per unit of mass;

$\rightarrow \frac{\mu}{\rho} \nabla^{2} \mathbf{v}$ describes frictional forces per unit of mass;

$\rightarrow$ and the material derivative, is defined as:

$$
\frac{\mathrm{D}}{\mathrm{D} t} \stackrel{\text { def }}{=} \frac{\partial}{\partial \mathrm{t}}+\mathbf{v} \cdot \nabla
$$

The Eq. (B-3) describes the fluid in terms of fields, and each property is evaluated at a desired fixed point $\mathbf{r}$ in space by an also fixed observer placed somewhere 
in the Earth. This approach for characterizing the geophysical fluids is known as the Eulerian description, and assumes a continuous or discrete space.

On the other hand, instead of analyzing the motion at arbitrary positions, the Lagrangian description considers the referential frame following the flow by representing the entire fluid as a sufficiently large number of indivisible particles (but not molecules), and evaluating the system state along the pathway, or, the trajectory, of those parcels of fluid. A complete Lagrangian formulation for the Earth's Ocean, therefore, provides a continuum description by tracking every single parcel of sea water in the world.

For a simpler discrete Lagrangian representation of the flow, consider a finite $P$ set of $N$ different particles with constant mass $m_{(P)}$, for $P=1,2,3, \ldots, N$. If each particle represents only one fluid parcel, the motion described by Eq. (B-2) can be written for each particle as:

$$
\begin{aligned}
\frac{1}{m_{(P)}} \sum_{n} \mathbf{F}_{(P)}^{n} & =\left[\frac{\mathrm{d}}{\mathrm{d} t}+\boldsymbol{\Omega} \times\right]\left[\left(\frac{\mathrm{d}}{\mathrm{d} t}+\boldsymbol{\Omega} \times\right) \mathbf{R}^{(P)}\right] \\
& =\left(\frac{\mathrm{d}}{\mathrm{d} t}+\boldsymbol{\Omega} \times\right)\left(\mathbf{V}_{\mathbf{L}}^{(P)}+\boldsymbol{\Omega} \times \mathbf{R}^{(P)}\right)
\end{aligned}
$$

where:

$$
\mathbf{R}^{(P)}=\mathbf{R}^{(P)}(t) \stackrel{\text { def }}{=} \mathbf{r}\left(\boldsymbol{R}_{0}^{(P)}, t\right)
$$

is the vector function that describes the trajectory of the single particle $P$ along time $t$, that depends on its initial position $\boldsymbol{R}_{0}^{(P)}=\mathbf{R}^{(P)}\left(t_{0}\right)=\mathbf{r}\left(\boldsymbol{R}_{0}^{(P)}, t_{0}\right)$;

and

$$
\mathbf{V}_{\mathbf{L}}^{(P)}(t) \stackrel{\text { def }}{=} \frac{\mathrm{d}}{\mathrm{d} t} \mathbf{R}^{(P)}(t)=\frac{\mathrm{D}^{*}}{\mathrm{D} t} \mathbf{R}^{(P)}(t)=\frac{\partial}{\partial t} \mathbf{R}^{(P)}
$$

is defined as the Lagrangian velocity of the particle $P$ at the instant of time $t$, and it represents the velocity that is felt by that particle, and by an observer that is moving with the particle, at the instant $t$.

If $\mathbf{v}(\mathbf{r}, t)$ describes the velocity of the fluid at the position $\mathbf{r}=\mathbf{r}^{(P)}(t)$ in space with respect to a fixed referential frame, for an arbitrary instant $t$, from Eq. (B-3), (B4) and (B-7), it can be seen that: 


$$
\left.\mathbf{v}(\mathbf{r}, t)\right|_{\mathbf{r}=\mathbf{r}^{(P)}}=\left.\frac{\mathrm{d}}{\mathrm{d} t} \mathbf{r}\right|_{\mathbf{r}=\mathbf{R}^{(P)}}=\frac{\mathrm{d}}{\mathrm{d} t} \mathbf{r}\left(\boldsymbol{R}_{0}^{(P)}, t\right)=\frac{\mathrm{d}}{\mathrm{d} t} \mathbf{R}^{(P)}(t) \stackrel{\text { def }}{=} \mathbf{V}_{\mathbf{L}}^{(P)}(t)
$$

Eq. (B-8) states that the Eulerian velocity $\mathbf{v}$ of the fluid evaluated at a fixed-point $\mathbf{r}$ in space is equal to the Lagrangian velocity $\mathbf{V}_{\mathbf{L}}$, that is the velocity actually felt by the referential frame of the fluid parcel $P$ that occupies that position in space at that instant of time.

If the Eulerian velocity field $\mathbf{v}=\mathbf{v}(\mathbf{r}, t)$ is known, the pathways $\mathbf{R}^{(P)}=\mathbf{R}^{(P)}(t)$ for each particle $P$, representing a discrete set for the Lagrangian frame, can be computed from Eq. (B-3), (B-6) and (B-8):

$$
\mathbf{R}^{(P)}(t) \stackrel{\text { def }}{=} \mathbf{r}\left(\boldsymbol{R}_{0}^{(P)}, t\right)=\int_{t_{0}}^{t} \mathbf{v}\left(\mathbf{r}, t^{\prime}\right) \mathrm{d} t^{\prime}+\boldsymbol{R}_{0}^{(P)}
$$

In Eq. (B-7), the operator:

$$
\frac{\mathrm{D}^{*}}{\mathrm{D} t} \stackrel{\text { def }}{=} \frac{\partial}{\partial \mathrm{t}}
$$

is called the Eulerian derivative, that added up to the Lagrangian derivative (or also material derivative: the one that tracks the "moving material") given by Eq. (B-4) constitute the transitioning connection between both descriptions. That enacts Eulerian and Lagrangian descriptions to be equivalent, but, in a practical way, they are also complimentary, once the choice for which one to employ should support the practical methodology or fits to the objectives, that could be focused on studying motions of the fluid that happens at (fixed) desired positions or limited space or on tracking specific flows from some initial position. 


\section{REFERENCES}

ALLAN, R.P. Elusive origin of warming slowdown. Nature Climate Change, 7, p. 316$317,2017$.

ARAKAWA, A. Design of the UCLA General Circulation Model. Numerical Simulation of weather and climate: Technical report, 7, 116 p, 1972.

ARAKAWA, A., LAMB, V.R. Computational Design of the Basic Dynamical Processes of the UCLA General Circulation Model. Methods in Computational Physics: Advances in Research and Applications, 17, p. 173-265, doi.org/10.1016/B978-0-12460817-7.50009-4, 1977.

ARAKAWA, A., SUAREZ, M.J. Vertical Differencing of the Primitive Equations in Sigma Coordinates. Monthly Weather Review, 111, p. 34-45, 1983.

ASCHMAnN, J., BURROWS, J.P., GEBHARDT, C., ROZANOV, A., HOMMEL, R., WEBER, M., THOMPSON, A.M. On the hiatus in the acceleration of tropical upwelling since the beginning of the 21st century. Atmos. Chem. Phys., 14, p. 1280312814, https://doi.org/10.5194/acp-14-12803-2014, 2014.

ASSIREU, A.T., STEVEnSON, M.R., STECH, J.L. Surface circulation and kinetic energy in the SW Atlantic obtained by drifters. Continental Shelf Research, 23, 2, p. $145-157,2003$.

BEAL, L. M., RUIJTER, W. P. M., BIASTOCH, A., ZAHN, R., SCOR/WCRP/IAPSO Working Group 136. On the role of the Agulhas system in ocean circulation and climate. Nature, 472, p. 429-436, doi:10.1038/nature09983, 2011.

BIASTOCH, A., BÖNING, C.W., LUTJEHARMS, J.R.E. Agulhas leakage dynamics affects decadal variability in Atlantic overturning circulation, Nature, 456, p. 489492, doi:10.1038/nature07426, 2008.

BIASTOCH, A., BÖNING, C.W., LUTJEHARMS, J.R.E., SCHWARZKOPF, F.U. Increase in Agulhas Leakage due to poleward shift of the Southern Hemisphere westerlies. Nature, 462, p. 495-498, 2009. 
BLECK, R., BENJAMIN, S. Regional weather prediction with a model combining terrain-following and isentropic coordinates. Part I: Model description. Mon. Wea. Rev., 121, p. 1770-1785, 1993.

BLECK, R. An oceanic general circulation model framed in hybrid isopycnic-Cartesian coordinates. Ocean Modeling, 4, p. 55-88, 2002.

BRYAN, K. Poleward Heat Transport by the Ocean: Observations and Models. Annual Review of Earth and Planetary Sciences, 10, p. 15-38, doi:10.1146/annurev.ea. 10.050182.000311, 1982.

CHANGNON, S.A.; BELL, G.D. El Niño, 1997-1998: the climate event of the century. Oxford University Press, 2000.

CHENG, L., ZHENG, F., ZHU, J. Distinctive ocean interior changes during the recent warming slowdown. Scientific Reports, 5, 14346, 2015.

COWTAN, K., WAY, R.G. Coverage bias in the HadCRUT4 temperature series and its impact on recent temperature trends. Q. J. R. Meteorol. Soc., 140, p. 1935-1944 2014 .

CUMMINGS, J.A. Operational multivariate ocean data assimilation. Quart. J. Royal Met. Soc., Part C, 131(613), p. 3583-3604, 2005.

CUMMINGS, J.A., SMEDSTAD, O.M. Variational Data Assimilation for the Global Ocean. Data Assimilation for Atmospheric, Oceanic and Hydrologic Applications, v. 2, p. 303-343, 2013.

DAI, A., FYFE, J.C., XIE, S-P., DAI, X. Decadal modulation of global surface temperature by internal climate variability. Nature Climate Change, 5, p. 555-559, 2015 .

DE RUIJTER, W.P.M. Asymptotic Analysis of the Agulhas and Brazil Current Systems. J. Phys. Oceanogr., 12, p. 361-373, 1982.

DE RUIJTER, W.P.M., BIASTOCH, A., DRIJFHOUT, S.S., LUTJEHARMS, J.R.E., MATANO, R.P., PICHEVIN, T., VAN LEEUWEN, P.J., WEIJER, W. IndianAtlantic interocean exchange: Dynamics, estimation and impact. J. Geophys. Res., 104, (C9), p. 20885-20910, doi:10.1029/1998JC900099, 1999.

DELWORTH, T.L., ZENG, F. Simulated impact of altered Southern Hemisphere winds on the Atlantic Meridional Overturning Circulation. Geophysical Research Letters, 35, L20708, doi:10.1029/2008GL035166, 2008. 
DRIJFHOUT, S.S., BLAKER, A.T., JOSEY, S.A., NURSER, A.J.G., SINHA, B., BALMASEDA, M.A. Surface warming hiatus caused by increased heat uptake across multiple ocean basins. Geophysical Research Letters, 41, p. 7868-7874, doi:10.1002/2014GL061456, 2014.

DURGADOO, J.V., RUHS, S., BIASTOCH, A., BONING, C.W.B. Indian Ocean sources of Agulhas leakage. J. Geophys. Res. Oceans, 122, doi:10.1002/2016JC012676, 2017.

EASTERLING, D.R., WEHNER, M.F. Is the climate warming or cooling? Geophys. Res. Lett., 36, L08706, doi: 10.1029/2009GL037810, 2009.

ENGLAND, M.H., HUANG, F. On the Interannual Variability of the Indonesian Throughflow and Its Linkage with ENSO. J. Climate, 18, p. 1435-1444, https://doi.org/10.1175/JCLI3322.1, 2005.

ENGLAND, M.H., McGREGOR, S., SPENCE, P., MEEHL, G.A., TIMMERMANN, A., CAI, W., GUPTA, A.S., McPHADEN, M.J., PURICH, A., SANTOSO, A. Recent intensification of wind-driven circulation in the Pacific and the ongoing warming hiatus. Nature Climate Change, 4, p. 222-227, 2014.

FRIOCCOURT, Y., DRIJFHOUT, S., BLANKE, B., SPEICH, S. Water Mass Export from Drake Passage to the Atlantic, Indian, and Pacific Oceans: A Lagrangian Model Analysis. Journal of Physical Oceanography, 35, p. 1206-1222, 2005.

FYFE, J.C., von SALZEN, K., GILlETT, N.P., ARORA, V.K., FLATO, G.M., McCONNELL, J.R. One hundred years of Arctic surface temperature variation due to anthropogenic influence. Scientific Reports, 3, 2013.

FYFE, J.C., MEEHL, G.A. ENGLAND, M.H., MANN, M.E., SANTER, B.D., FLATO, G.M., HAWKINS, E., GILlETT, N.P., XIE, S.P., KOSAKA, Y., SWART, N.C. Making sense of the early-2000s warming slowdown. Nature Climate Change, 6, p. 224-228, 2016.

FOLlAND, CK., BOUCHER, O., COLMAN, A., PARKER, D.E. Causes of irregularities in trends of global mean surface temperature since the late 19th century. Science Advances, 4(6), doi:10.1126/sciadv.aao5297, 2018.

GODFREY, J.S. The effects of the Indonesian throughflow on ocean circulation and heat exchange with the atmosphere: a review. J. Geophys. Res., 101, 14217-14237, 1996.

GORDON, A.L. When is Appearance Reality? A comment on Why Does the Indonesian Throughflow Appear to Originate from the North Pacific. Journal of Physical Oceanography, 25, 1560-1567, 1995. 
GORDON, A.L., FINE, R.A. Pathways of water between the Pacific and Indian Oceans in the Indonesian seas. Nature, 379, 146-149, 1996.

GORDON, A.L., SUSANTO, R. D., FFIELD, A.L. Throughflow within Makassar Strait, Geophys. Res. Lett., 26, 3325-3328, 1999.

GORDON, A.L. Oceanography of the Indonesian seas and their throughflow. Oceanography, 18, p. 14-27, doi:10.5670/oceanog.2005.01, 2005.

GORDON, A.L., SPRINTALL, J., VAN AKEN, H.M., SUSANTO, D., WIJFFELS, S., MOLCARDE, R., FFIELDF, A., PRANOWO, W., WIRASANTOSA, S. The Indonesian throughflow during 2004-2006 as observed by the INSTANT program. Dynamics of Atmospheres and Oceans, 50, p. 115-128, 2010.

HAARSMA, R.J., CAMPOS, E.J.D., DRIJFHOUT, S., HAZELEGER, W., \& SEVERIJNS, C. Impacts of Interruption of the Agulhas Leakage on the tropical Atlantic in coupled ocean-atmosphere simulations. Climate Dynamics, 36, p. 9891003, doi:10.1007/s00382-009-0692-7, 2009.

HALLIWELL, G. R., Jr. Simulation of North Atlantic decadal/multi-decadal winter SST anomalies driven by basin-scale atmospheric circulation anomalies. J. Phys. Oceanogr., 28, p. 5-21, 1998.

HALLIWELL, G.R, BLECK, R., CHASSIGNET, E.P., SMITH, L.T. Mixed layer model validation in Atlantic Ocean simulations using the Hybrid Coordinate Ocean Model (HYCOM). EOS, 80, OS304, 2000.

HAWKINS, E., EDWARDS, T.L., McNEALL, D. Pause for thought. Nature Climate Change, 4, p. 154-156, doi:10.1038/nclimate2150, 2014.

HAYWOOD, J.M., JONES, A., JONES, G.S. The impact of volcanic eruptions in the period 2000-2013 on global mean temperature trends evaluated in the HadGEM2ES climate model. Atmos. Sci. Lett., 15, p. 92-96, doi:10.1002/asl2.471, 2014.

HEDEmanN, C., MAURITSEn, T., JUnGClAUS, J., MAROTZKE, J. The subtle origins of surface-warming hiatuses. Nature Climate Change, 7, p. 336-339, 2017.

HIRST, A.C., GODFREY, J.S. The role of Indonesian throughflow in a global ocean GCM. Journal of Physical Oceanography, 23, 1057-1086, https://doi.org/10.1175/ 1520-0485(1993)023<1057:TROITI>2.0.CO;2, 1993.

HU, A., OTTO-BLIESNER, B.L., MEEHL, G.A., HAN, W., MORRILL, C., BRADY, E.C., BRIEGLEB, B. Response of Thermohaline Circulation to Freshwater Forcing under Present-Day and LGM Conditions. J. Climate, 21, p. 2239-2258, 
https://doi.org/10.1175/2007JCLI1985.1, 2008.

HU, S., FEDOROV, A.V. The extreme El Niño of 2015-2016 and the end of global warming hiatus. Geophys. Res. Lett., 44, p. 3816-3824, doi:10.1002/2017 GL072908, 2017.

HUANG, J., ZHANG, X., ZHANG, Q., LIN, Y., HAO, M., LUO, Y., ZHAO, Z., YAO, Y., CHEN, X., WANG, L., NIE, S., YIN, Y., XU, Y., ZHANG, J. Recently amplified arctic warming has contributed to a continual global warming trend. Nat. Clim. Chang., 7, p. 875-879, 2017.

ILAHUDE, A.G., GORDON, A.L. Thermocline stratification within the Indonesian Seas. Journal of Geophysical Research, 101, p. 12401- 12409, 1996.

KAlnAY, E., KANAMitSU, M., KISTleR, R., COllins, W., DEAVEN, D., GANDIN, L., IREDELL, M., SAHA, S., WHITE, G., WOOLLEN, J., ZHU, Y., CHELliAH, M., EBISUZAKI, W., HIGGINS, W., JANOWIAK, J., MO, K.C., ROPELEWSKI, J. WANG, A. LEETMAA, R. REYNOLDS, R. JENNE, AND D. JOSEPH, C. The NCEP/NCAR 40-year reanalysis project. Bull. Amer. Meteor. Soc., $\quad 77, \quad$ p. 437-472, https://doi.org/10.1175/1520-0477(1996)077<0437: TNYRP $>2.0$. CO;2, 1996 .

KANTHA, L., CLAYSON, C. Numerical Models of Oceans and Oceanic Processes. Academic Press, v. 66, 1 ed, 2000.

KARL, T.R., ARGUEZ, A., HUANG, B., LAWRIMORE, J.H., MCMAHON, J.R., MENnE, M.J., PETERSON, T.C., VOSE, R.S., ZHANG, H.-M. Possible artifacts of data biases in the recent global surface warming hiatus. Science, 348, p. 1469$1472,2015$.

KATSMAN, C.A., VAN OLDENBORGH, G.J. Tracing the upper ocean's "missing heat". Geophys. Res. Lett., 38, 2011.

KOSZALKA, I.M., HAINE, T.W.N., MAGALDI, M.G. Fates and travel times of Denmark Strait Overflow Water in the Irminger Basin. J. Phys. Oceanogr., 43 (12), p. 2611-2628. http://dx.doi.org/10.1175/JPO-D-13-023.1, 2013.

KUO, H., VERONIS, G. The use of oxygen as a test for an abyssal circulation model. Deep Sea Res., 20, p. 871-888, 1973.

LANGE, M., VAN SEBILLE, E.. Parcels v0.9: prototyping a Lagrangian Ocean Analysis framework for the petascale age. Geoscientific Model Development, 10, p. 4175-4186, https://doi.org/10.5194/gmd-10-4175-2017, 2017. 
LE BARS, D., DIJKSTRA, H.A., De RUIJTER, W.P.M. Impact of the Indonesian Throughflow on Agulhas leakage. Ocean Sci., 9, p. 773-785, doi:10.5194/os-9-7732013, 2013.

LEE, T., FUKUMORI, I., MENEMENLIS, D., XING, Z., FU, L-L. Effects of the Indonesian throughflow on the Pacific and Indian Oceans. Journal of Physical Oceanography, 32:1, p. 404-429, 2002.

LEE, T., AWAJI, T., BALMASEDA, M., FERRY, N., FUJII, Y., FUKUMORI, I., GIESE, B., HEIMBACH, P., KÖHL, A., MASINA, S., REMY, E., ROSATI, A., SCHODLOK, M., STAMMER, D., WEAVER, A. Consistency and fidelity of Indonesian-throughflow total volume transport estimated by 14 ocean data assimilation products. Dynamics of Atmospheres and Oceans, 50, 2, p. 201-223, 2010 .

LEE, S.-K., PARK, W., VAN SEBILlE, E., BARINGER, M.O., WANG, C., ENFIELD, D.B., YEAGER, S.G., KIRTMAN, B.P. What caused the significant increase in Atlantic Ocean heat content since the mid-20th century? Geophys. Res. Lett., 38, L17607, doi:10.1029/2011GL048856, 2011.

LEe, S.K., PARK, W., BARINGER, M.O., GORDON, A.L., HuBER, B., LIU, Y. Pacific origin of the abrupt increase in Indian Ocean heat content during the warming hiatus. Nature Geoscience, 8, p. 445-449, doi:10.1038/ngeo2438, 2015.

LEWANDOWSKY, S., RISBEY, J.S., ORESKES, N. On the definition and identifiability of the alleged "hiatus" in global warming. Scientific Reports, 5, 16784, 2015 .

LI, M.; GORDON, A.L.; WEI, J.; GRUENBURG, L.K.; JIANG, G. Multi-decadal timeseries of the Indonesian throughflow. Dynamics of Atmospheres and Oceans, 81, p. 84-95, doi:10.1016/j.dynatmoce.2018.02.001, 2018.

LIMPKIN, R., GARZOLI, S.L. Near-surface circulation in the tropical Atlantic Ocean, Deep-Sea Research Part I, 52, 3, p. 495-518, 2005.

LIU, W., XIE, S.-P., LU, J. Tracking ocean heat uptake during the surface-warming hiatus. Nature Comm., 7, doi:10.1038/ncomms10926, 2016.

LIU, W., XIE, S.-P., LIU, Z., ZHU, J. Overlooked possibility of a collapsed Atlantic Meridional Overturning Circulation in warming climate. Sci. Adv., 3 (1), doi: 10.1126/sciadv.1601666, 2017.

LOEB, N.G., LYMAN, J.M., JOHNSON, G.C., AllAN, R.P., DOELling, D.R., WONG, T., SODEN, B.J., STEPHENS, G.L. Observed changes in top-of-the- 
atmosphere radiation and upper-ocean heating consistent within uncertainty. Nature Geoscience, 5, p. 110-113, 2012.

LOVEJOY, S. Return periods of global climate fluctuations and the pause. Geophys. Res. Lett., 41, p. 4704-4710, doi:10.1002/2014GL060478, 2014.

LUICK, J.L., and CRESSWELL, G.R. Current measurements in the Maluku Sea, J. Geophys. Res., 106(C7), p. 13953-13958, doi:10.1029/2000JC000694, 2001.

LUTJEHARMS, J.R.E. The Agulhas Current. Springer, 2006.

MAHER, N., GUPTA, A.S., ENGLAND, M.H. Drivers of decadal hiatus periods in the 20th and 21st centuries. Geophys. Res. Lett., 41, p. 5978-5986, doi:10.1002/ 2014GL060527, 2014.

MAYER, B., DAMM, P.E.; POHLMANN, T., RIZAL, S. What is driving the ITF? An illumination of the Indonesian throughflow with a numerical nested model system. Dynamics of Atmospheres and Oceans, 50, 2, p. 301-312, 2010.

McADAM, R., VAN SEBILLE, E. Surface Connectivity and Interocean Exchanges From Drifter-Based Transition Matrices. Journal of Geophysical Research: Oceans, 123, p. 514-532, doi.org/10.1002/2017JC013363, 2018.

MEEHL, G.A., ARBlaster, J.M., FASUllo, J.T., HU, A., TREnBERTH, K.E. Model-based evidence of deep-ocean heat uptake during surface-temperature hiatus periods. Nature Clim. Change, 1, p. 360-364, 2011.

METZGER, E.J., HURLBURT, H.E., XU, X., SHRIVER, J. F., GORDON, A.L., SPRINTALL, J., SUSANTO, R.D., VAN AKEN, H.M. Simulated and observed circulation in the Indonesian Seas: $1 / 12^{\circ}$ global HYCOM and the INSTANT observations. Dynamics of Atmospheres and Oceans, 50, 2, p. 275-300, 2010.

MURRAY, R.J. Explicit generation of orthogonal grids for ocean models. J. Comput. Phys., 126, p. 251-273, 1996.

MURTUGUDDE, R., BUSALACCHI, A.J., BEAUCHAMP, J. Seasonal-to-interannual effects of the Indonesian throughflow on the tropical IndoPacific basin. Journal of Geophysical Research, 103:21, p. 425-21, 441, 1998.

PARIS, C.B., HELGERS, J, VAN SEBILlE, E., SRINIVASAN, A. Connectivity modeling system: A probabilistic modeling tool for the multiscale tracking of biotic and abiotic variability in the ocean. Environ. Modell. Software, 42(C), p. 47-54, doi:10.1016/j.envsoft.2012.12.006, 2013. 
PEETERS, F.J.C., ACHESON, R., BRUMMER, G.A., DE RUIJTER, W.P.M., SCHNEIDER, R.R., GANSSEN, G.M., UFKES, E., KROON, D. Vigorous exchange between the Indian and Atlantic oceans at the end of the past five glacial periods. Nature, 430, p. 661-665, 2004.

PUJIANA, K., GORDON, A.L., SPRINTALL, J. Intraseasonal Kelvin wave in Makassar Strait. Journal of Geophysical Research: Oceans, 118, p. 2023-2034, doi:10.1002/jgrc.20069, 2013.

QIN, X., GUPTA, A. S., VAN SEBILLE, E. Variability in the origins and pathways of Pacific Equatorial Undercurrent water. J. Geophys. Res. Oceans, 120, p. 3113-3128, 2015 .

RAYNER, N. A., PARKER, D.E., HORTON, E.B., FOllAnd, C.K., AlEXANDER, L.V., ROWELL, D.P., KENT, E.C., KAPLAN, A. Global analyses of sea surface temperature, sea ice, and night marine air temperature since the late nineteenth century. J. Geophys. Res., 108 (D14), p. 4407, doi:10.1029/2002JD002670, 2003.

RIDLEY, D.A., et al. Total volcanic stratospheric aerosol optical depths and implications for global climate change. Geophys. Res. Lett., 41, p. 7763-7769, doi: 10.1002/2014GL061541, 2014.

ROXY, M.K., RITIKA, K., TERRAY, P., MASSON, S. The Curious Case of Indian Ocean Warming. J. Climate, 27, p. 8501-8509, https://doi.org/10.1175/JCLI-D-14$00471.1,2014$.

SAHA, S., NADIGA, S., THIAW, C., WANG, J., WANG, W., ZHANG, Q., VAN DEN DOOL, H. M., PAN, H.-L., MOORTHI, S., BEHRINGER, D., STOKES, D., PENA, M., LORD, S., WHITE, G., EBISUZAKI, W., PENG, P., XIE, P. The NCEP Climate Forecast System. Journal of Climate, 19, 15, p. 3483.3517, 2006.

SANTER, B.D., BONFILS, C., PAINTER, J.F., ZELINKA, M.D., MEARS, C., SOLOMON, S., SCHMIDT, G.A., FYFE, J.C., COLE, J.N.S., NAZARENKO, L., TAYLOR, K.E., WENTZ, F.J. Volcanic contribution to decadal changes in tropospheric temperature. Nature Geoscience, 7, p. 185-189, doi: 10.1038/NGEO2098, 2014.

SCHILlER, A., WIJFFELS, S.E., SPRINTALL, J., MOLCARDC, R., OKE, P.R. Pathways of intraseasonal variability in the Indonesian Throughflow region. Dynamics of Atmospheres and Oceans, 50, p. 174-200, 2010.

SCHNEIDER, N. The Indonesian Throughflow and the global climate system. J. Clim., 11, p. 676-689, 1998. 
SENEVIRATnE, S.I., DONAT, M.G., MUELlER, B., ALEXANDER, L.V. No pause in the increase of hot temperature extremes. Nature Climate Change, 4, p. 161-163, https://doi.org/10.1038/nclimate2145, 2014.

SHINODA, T.; HURLBURT, H.E.; METZGER, E.J. Anomalous tropical ocean circulation associated with La Niña Modoki. Journal of Geophysical Research: Oceans, 115 (12), doi:10.1029/2011JC007304, 2011.

SLINGO, J.M., ANNAMALAI, H. 1997: The El Niño of the Century and the Response of the Indian Summer Monsoon. Monthly Weather Review, 128, p. 1778-1797, https://doi.org/10.1175/1520-0493(2000)128<1778:TENOOT>2.0.CO;2, 2000.

SOLOMON, S., ROSENLOF, K.H., PORTMANN, R.W., DANIEL, J.S., DAVIS, S.M., SANFORD, T.J., PLATTNER, G-K. Contributions of stratospheric water vapor to decadal changes in the rate of global warming. Science, 327, p. 1219-1223, 2010.

SONG, J., WANG, Y., TANG, J. A Hiatus of the Greenhouse Effect. Sci Rep., 6 (33315), doi:10.1038/srep33315, 2016.

SPEICH, S., et al. Tasman leakage: A new route in the global ocean conveyor belt. Geophysical Research Letters, 29, 10, p. 1416, doi.org/10.1029/2001GL014586, 2002.

SPEICH, S., LUTJEHARMS, J. R. E., PENVEN, P. \& BLANKE, B. Role of bathymetry in Agulhas Current configuration and behaviour. Geophys. Res. Lett., 33, L23611, 2006.

SPRINTALL, J., WIJFFELS, S., GORDON, A.L., FFIELD, A., MOLCARD, R., DWI Susanto, R., SOESILO, I., SOPAHELUWAKAN, J., SURACHMAN, Y., VAN AKEN, H. INSTANT: a new international array to measure the Indonesian throughflow. EOS, 85 (39), p. 369, 2004.

SPRINTALL, J., WIJFFELS, S. E., MOLCARDE, R., JAYA, I. Direct estimates of the Indonesian Throughflow entering the Indian Ocean: 2004-2006. J. Geophys. Res. Oceans, 114, doi:10.1029/2008JC005257, 2009.

SPRINTAlL, J., GORDON, A.L., KOCH-LARROUY, A., LEE, T., POTEMRA, J.T., PUJIANA, K., WIJFFELS, S.E. The Indonesian seas and their role in the coupled ocean-climate system. Nature Geoscience, 7, p. 487-492, doi:10.1038/ngeo2188, 2014.

STEINMAN, B.A., MANN, M.E., MILLER, S.K. Atlantic and Pacific multidecadal oscillations and Northern Hemisphere temperatures. Science, 347, 6225, p. 988-991 doi:10.1126/science.1257856, 2015. 
SUSANTO, R.D., GORDON, A.L. Velocity and transport of the Makassar Strait throughflow. J. Geophys. Res., 110, C01005, doi:10.1029/2004JC002425, 2005.

SUSANTO, R.D., FFIELD, A., GORDON, A.L., ADI, T.R. Variability of Indonesian Throughflow within Makassar Strait: 2004 - 2009. Journal of Geophysical Research Oceans, 117, doi:10.1029/2012JC008096, 2012.

SUSANTO, R.D., WEI, Z., ADI, R.T., FAN, B., LI, S., FANG, G. Observations of the Karimata Strait througflow from December 2007 to November 2008. Acta Oceanol. Sin., 32 (5), p. 1-6, doi:10.1007/s13131-013-0307-3, 2013.

TILLINGER, D., GORDON, A.L. Transport weighted temperature and internal energy transport of the Indonesian throughflow. Dynamics of Atmospheres and Oceans, 50, p. 224-232, 2010 .

TRENBERTH, K.E. Has there been a hiatus? Science, 349, 6249, p. 691-692, doi: 10.1126/science.aac9225, 2015.

VALSALA, V.K., and IKEDA, M. Pathways and effects of the Indonesian Throughflow water in the Indian Ocean using particle trajectory and tracers in an OGCM. $J$. Clim., 20(13), p. 2994-3017, doi:10.1175/JCLI4167.1, 2007.

VAN AKEN, H.M., PUNJANA, J., SAIMIMA, S. Physical aspects of the flushing of the East Indonesian basins. Neth. J. Sea Res., 22, p. 315-339, 1988.

VAN AKEN, H.M., BRODJONEGORO, I. S., JAYA, I. The deep-water motion through the Lifamatola Passage and its contribution to the Indonesian throughflow. DeepSea Research I, 56, p. 1203-1216, 2009.

VAN SEBILlE, E., SPRINTALL, J., SCHWARZKOPF, F.U., GUPTA, A.S., SANTOSO, A., ENGLAND, M.H., BIASTOCH, A., BÖNING, C.W. Pacific-toIndian Ocean connectivity: Tasman leakage, Indonesian Throughflow, and the role of ENSO. J. Geophys. Res. Oceans, 119, p. 1365-1382, 2014.

VAN SEBILLE, E. et al. Lagrangian ocean analysis: Fundamentals and practices. Ocean Modelling, 121, p. 49-75, doi.org/10.1016/j.ocemod.2017.11.008, 2018.

VRANES, K., GORDON, A.L., FFIELD, A. The heat transport of the Indonesian Throughflow and implications for the Indian Ocean heat budget. Deep-Sea Res. II, 49, p. 1391-1410, https://doi.org/10.1016/S0967-0645(01)00150-3, 2002.

WAJSOWICZ, R.C., SCHNEIDER, E.K. The Indonesian throughflow's effect on global climate determined from the COLA Coupled Climate System. Journal of Climate, 14, p. 3029-3042, 2001. 
WAJSOWICZ, R.C. Air-sea interaction over the Indian Ocean due to variations in the Indonesian throughflow. Climate Dynamics, 18, p. 437-453, 2002.

WANG, C., XIE, S., KOSAKA, Y., LIU, Q., ZHENG, X. Global Influence of Tropical Pacific Variability with Implications for Global Warming Slowdown. J. Climate, 30, p. 2679-2695, https://doi.org/10.1175/JCLI-D-15-0496.1, 2017.

WATANABE, M., SHIOGAMA, H., TATEBE, H., HAYASHI, M., ISHII, M., KIMOTO, M. Contribution of natural decadal variability to global warming acceleration and hiatus. Nature Climate Change, 4, p. 893-897, 2014.

WILSON, E., GORDON, A.L., KIM, D. Observations of the Madden Julian Oscillation during Indian Ocean Dipole Events. Journal of Geophysical Research - Atmospheres, 118, doi:10.1002/jgrd.50241, 2013.

WUNSCH, C. Variability of the Indo-Pacific Ocean exchanges. Dynamics of Atmospheres and Oceans, 50, p. 157-173, 2010.

XIE, S.-P., KOSAKA, Y., OKUMURA, Y.M. Distinct energy budgets for anthropogenic and natural changes during global warming hiatus. Nature Geosciences, 9, p. 29$33,2016$.

YAN, X.-H., BOYER, T., TRENBERTH, K., KARL, T.R., XIE, S.-P., NIEVES, V., TUNG, K.-K., ROEMMICH, D. The global warming hiatus: Slowdown or redistribution? Earth's Future, 4, doi:10.1002/2016EF000417, 2016.

ZHOU, Q., WANSOU, D., MU, M., FENG, R. Influence of positive and negative Indian Ocean Dipoles on ENSO via the Indonesian Throughflow: Results from sensitivity experiments. Advances in Atmospheric Sciences, 2, p. 783-793, 2015. 